Júlio César Gonçalves Trabanco

\title{
Efeitos da exposição a produtos químicos ou ao ruído
}

\section{sobre a audição}

Dissertação apresentada à Faculdade de Medicina da Universidade de São Paulo para obtenção do título de Mestre em Ciências

Programa de Ciências da Reabilitação

Orientadora: Prof $\stackrel{a}{\text {. }}$ Dr $\stackrel{a}{\text {. }}$ Alessandra Giannella Samelli

SÃO PAULO

2019 
Júlio César Gonçalves Trabanco

\title{
Efeitos da exposição a produtos químicos ou ao ruído
} sobre a audição

\author{
Dissertação apresentada à Faculdade de Medicina \\ da Universidade de São Paulo para obtenção do \\ título de Mestre em Ciências
}

Programa de Ciências da Reabilitação

Orientadora: Prof $\stackrel{a}{\text {. }}$ Dra . Alessandra Giannella Samelli

SÃO PAULO

2019 
Dados Internacionais de Catalogação na Publicação (CIP)

Preparada pela Biblioteca da

Faculdade de Medicina da Universidade de São Paulo

Creprodução autorizada pelo autor

Trabanco, Júlio César Gonçalves

Efeitos da exposição a produtos químicos ou ao

ruido sobre a audição / Júlio César Gonçalves

Trabanco. -- São Paulo, 2019.

Dissertação(mestrado)--Faculdade de Medicina da

Universidade de São Paulo.

Programa de Ciências da Reabilitação.

Orientadora: Alessandra Giannella Samelli.

Descritores: 1.Ruído 2.Substâncias tóxicas 3.Perda auditiva provocada por ruído 4.Audiometria

5.Emissões otoacústicas espontăneas 6.Vias auditivas

7. Exposiçăo ocupacional

$\mathrm{USP} / \mathrm{FM} / \mathrm{DBD}-260 / 19$

Responsável: Erinalva da Conceição Batista, CRB-8 6755 


\section{AGRADECIMENTOS}

À minha orientadora, $\operatorname{Prof}^{\underline{a}} \operatorname{Dr}^{\underline{a}}$ Alessandra Giannella Samelli, pelos ensinamentos, dedicação, paciência e atenção durante todo o processo.

Aos meus pais, por todo o suporte e incentivo, sempre constantes.

Ao meu irmão, por toda a ajuda e suporte oferecidos.

À Drª. Seisse Gabriela Gandolfi Sanches, por todas as orientações e ensinamentos.

À Dra . Renata Rodrigues Moreira, por todo o auxílio e suporte fornecidos.

Ao Laboratório de Investigação Fonoaudiológica em Audiologia: Atenção Primária.

Ao Laboratório de Investigação Fonoaudiológica em Audição Humana.

Ao Hospital Universitário, em especial, ao Ambulatório de Audiologia.

A todos que me auxiliaram nesse processo, muito obrigado! 


\section{NORMALIZAÇÃO ADOTADA}

Esta dissertação está de acordo com as seguintes normas, em vigor no momento desta publicação:

Referências: adaptado de International Committee of Medical Journals Editors (Vancouver).

Universidade de São Paulo. Faculdade de Medicina. Divisão de Biblioteca e Documentação. Guia de apresentação de dissertações, teses e monografias. Elaborado por Anneliese Carneiro da Cunha, Maria Julia de A. L. Freddi, Maria F. Crestana, Marinalva de Souza Aragão, Suely Campos Cardoso, Valéria Vilhena. 3a ed. São Paulo: Divisão de Biblioteca e Documentação; 2011.

Abreviaturas dos títulos dos periódicos de acordo com List of Journals Indexed in Index Medicus. 


\section{SUMÁRIO}

\section{LISTA DE ABREVIATURAS}

LISTA DE TABELAS

LISTA DE FIGURAS

RESUMO

\section{ABSTRACT}

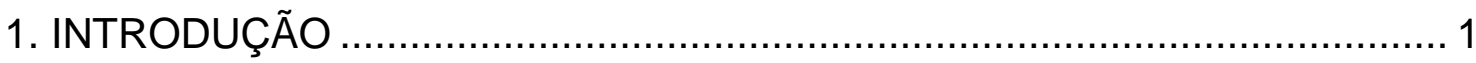

2. OBJETIVO.

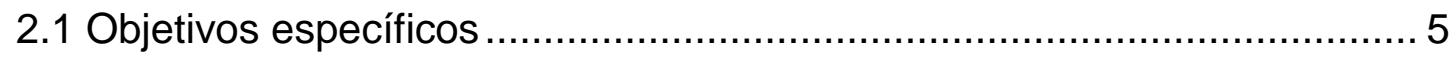

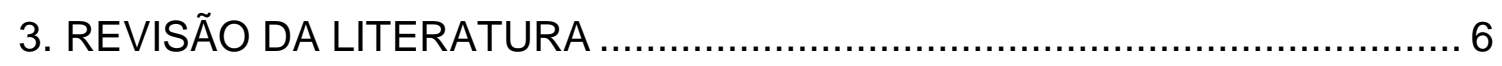

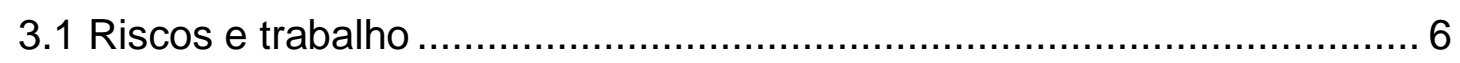

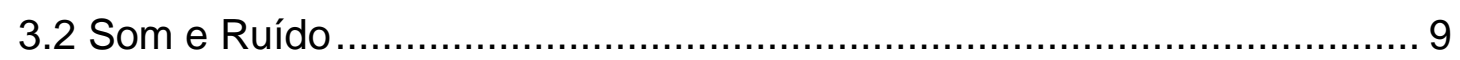

3.3 Efeitos do ruído sobre a saúde e medidas de proteção ........................... 13

3.4 Efeitos da ototoxicidade e medidas de proteção .................................... 20

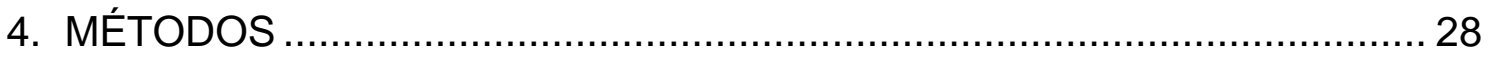

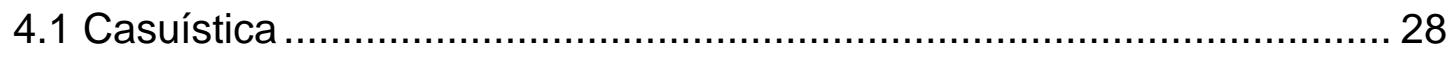

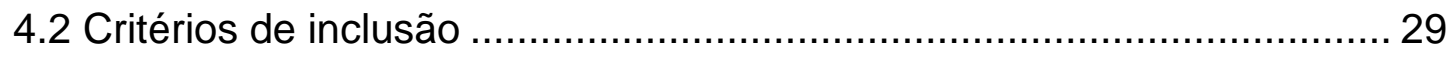

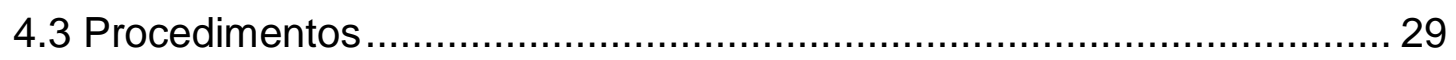

4.3.1 Dados de exposição a riscos ocupacionais..................................... 29

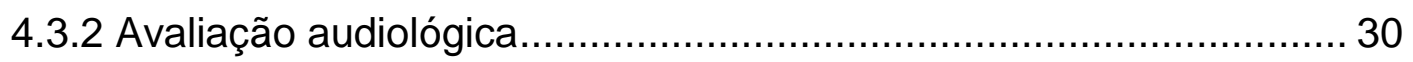

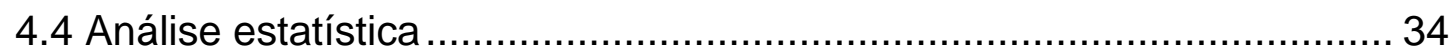

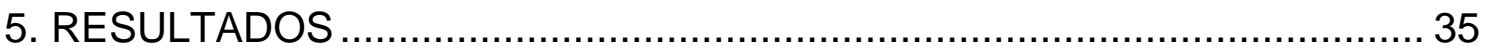

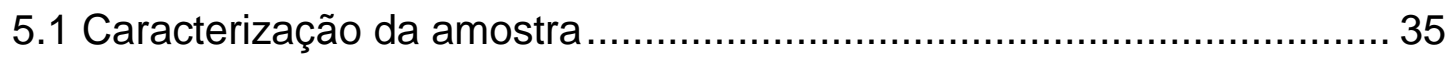

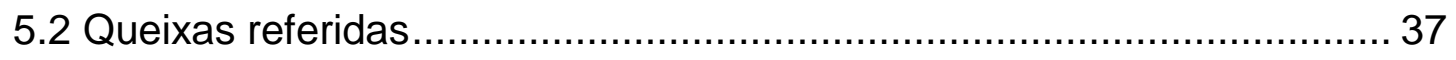

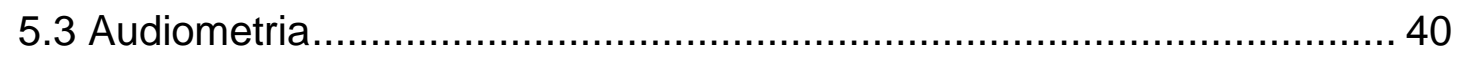

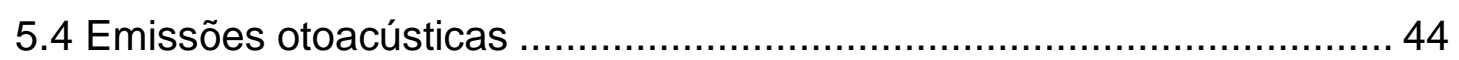

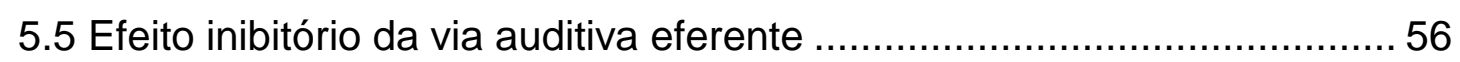

5.6 Habilidade auditiva de figura-fundo para sons verbais - SSW ............... 58

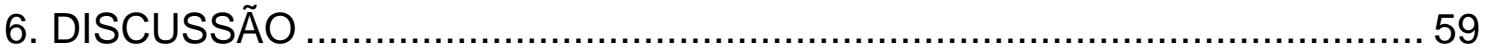

7. CONCLUSÃO

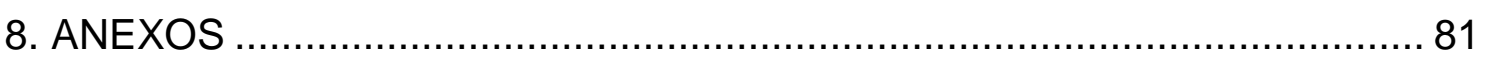

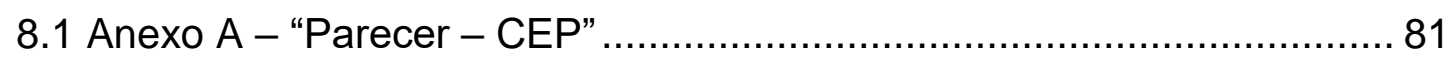

8.2 Anexo B - "Termo de consentimento livre e esclarecido" ........................ 84

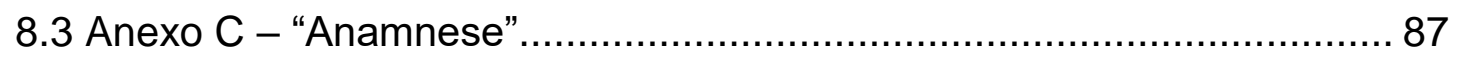

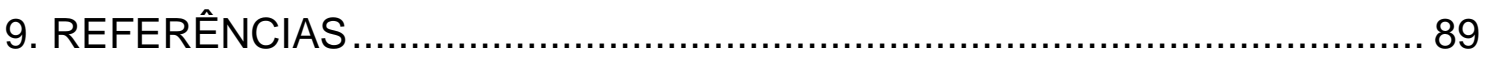




\section{LISTA DE ABREVIATURAS}

a.C.: Antes de Cristo

ABNT: Associação Brasileira de Normas Técnicas

AVE: Acidente Vascular Encefálico

B: Bel

BSI: British Standards Institution

CAAE: Certificado de Apresentação para Apreciação Ética

CD: Compact Disk

CEP: Código de Endereçamento Postal

CEP: Comitê de Ética em Pesquisa

COM: Complexo Olivococlear Medial

CRFa 2: Conselho Regional de Fonoaudiologia - $2^{\text {a }}$ Região

daPa: decaPascal

dB: Decibel

dBNA: Decibel nível de audição

dBNS: Decibel nível de sensação

dBNPS: Decibel nível de pressão sonora

DC: Direita Competitiva

DN: Data de Nascimento

DNC: Direita Não Competitiva

DP: Desvio padrão

$\operatorname{Dr}(\underline{a})$ : Doutor (a)

EC: Esquerda Competitiva

ENC: Esquerda Não Competitiva

EOAPD: Emissões otoacústicas evocadas por produto de distorção

EOAT: Emissões otoacústicas evocadas por transientes

EPI: Equipamento de proteção individual

EU: European Union

f: Frequência

FM USP: Faculdade de Medicina da Universidade de São Paulo

h: Horas 


\section{LISTA DE ABREVIATURAS (continuação)}

HU: Hospital Universitário (Universidade de São Paulo - USP)

$\mathrm{Hz}$ : Hertz

IPRF: Índice Percentual de Reconhecimento de Fala

ISO: International Organization for Standardization

kHz: kiloHertz

Log: Logarítmo

LRF: Limiar de Reconhecimento de Fala

$\mathrm{n}$ : Número

NBR: Norma Brasileira (aprovada pela ABNT)

NIOSH: National Institute for Occupational Safety and Health

NR: Norma Regulamentadora

OHSAS: Occupational Health and Safety Assessment Series

OMS: Organização Mundial da Saúde

OSHA: Occupational Safety and Health Administration

PA: Perda auditiva

PAINPSE: Perda Auditiva Induzida por Níveis de Pressão Sonora Elevados

PAIR: Perda Auditiva Induzida por Ruído

PCMSO: Programa de Controle Médico de Saúde Ocupacional

PPRA: Programa de Prevenção de Riscos Ambientais

Prof (a): Professor (a)

SESMT: Serviço Especializado em Engenharia de Segurança e em Medicina do Trabalho

SQM: Sensibilidade Química Múltipla

SSW: Staggered Spondaic Word

TCLE: Termo de Consentimento Livre e Esclarecido

USP: Universidade de São Paulo

$\mu \mathrm{Pa}$ : microPascal 


\section{LISTA DE TABELAS}

Tabela 1 - Distribuição da amostra em valores absolutos e percentuais em relação à variável "Sexo" por grupo (porcentagens calculadas por grupo) e valor-p

Tabela 2 - Distribuição da amostra em números absolutos, média, desvio padrão, valores mínimos, máximos e mediana em relação à variável "Idade" por grupo e valor-p 36

Tabela 3 - Distribuição da amostra em números absolutos, média, desvio padrão, valores mínimo, máximos e mediana em relação à variável "Tempo na função" (em meses) por grupo e valor-p 36

Tabela 4 - Distribuição da amostra em números absolutos e percentuais em relação à variável "Utilização de Equipamento de Proteção" e valorp para os grupos Químicos e Ruído.

Tabela 5 - Distribuição da amostra em números absolutos e percentuais em relação à variável "Classe de produtos químicos utilizados" 38

Tabela 6 - Distribuição da amostra em números absolutos e percentuais em relação à variável "Zumbido" por grupo (porcentagens calculadas por grupo) e valor-p.

Tabela 7 - Distribuição da amostra em números absolutos e percentuais em relação à variável "Lado referido do zumbido".

Tabela 8 - Distribuição da amostra em números absolutos e percentuais em relação à variável "Ocorrência de tonturas" por grupo (porcentagens calculadas por grupo) e valor-p

Tabela 9 - Distribuição da amostra em números absolutos e percentuais em relação à variável "Tipo de tontura" por grupo (porcentagens calculadas por grupo)

Tabela 10 - Média, desvio padrão, valores mínimos, máximos e medianas em relação à variável "Limiares auditivos (dBNA)" e análise comparativa entre os grupos, valor-p

Tabela 11 - Média, desvio padrão, valores mínimos, máximos e medianas em relação à variável "Limiares auditivos (dBNA) (altas frequências)" e análise comparativa entre os grupos, valor-p 
Tabela 12 - Média, desvio padrão, valores mínimo, máximo e mediana e análise comparativa entre os grupos em relação à variável "Intensidade das emissões otoacústicas evocadas por produto de distorção (dBNPS)", por frequência e orelha para as frequências de 1001, 1257, 1587, 2002 e $2015 \mathrm{~Hz}$, valor-p.

Tabela 13 - Média, desvio padrão, valores mínimo, máximo e mediana e análise comparativa entre os grupos em relação à variável "Intensidade das emissões otoacústicas evocadas por produto de distorção (dBNPS)", por frequência e orelha para as frequências de 3174, 4004, 5042, 6348, valor-P.

Tabela 14 - Valores-p associados aos testes de diferenças de medianas da Intensidade das emissões otoacústicas evocadas por produto de distorção (dBNPS), entre dois grupos, para as frequências $4004 \mathrm{e}$ $5042 \mathrm{~Hz}$, por orelha

Tabela 15 - Distribuição de frequências da Classificação das emissões otoacústicas evocadas por produto de distorção, para a frequência $1001 \mathrm{~Hz}$, por orelha e grupo (as porcentagens foram calculadas por grupo) e valores-p do teste qui-quadrado de homogeneidade...... 48

Tabela 16 - Distribuição de frequências da Classificação das emissões otoacústicas evocadas por produto de distorção, para a frequência $1257 \mathrm{~Hz}$, por orelha e grupo (as porcentagens foram calculadas por grupo) e valores-p do teste qui-quadrado de homogeneidade.

Tabela 17 - Distribuição de frequências da Classificação das emissões otoacústicas evocadas por produto de distorção, para a frequência $1587 \mathrm{~Hz}$, por orelha e grupo (as porcentagens foram calculadas por grupo) e valores-p do teste qui-quadrado de homogeneidade...... 49

Tabela 18 - Distribuição de frequências da Classificação das emissões otoacústicas evocadas por produto de distorção, para a frequência $2002 \mathrm{~Hz}$, por orelha e grupo (as porcentagens foram calculadas por grupo) e valores-p do teste qui-quadrado de homogeneidade.

Tabela 19 - Distribuição de frequências da Classificação das emissões otoacústicas evocadas por produto de distorção, para a frequência 
$2515 \mathrm{~Hz}$, por orelha e grupo (as porcentagens foram calculadas por grupo) e valores-p do teste qui-quadrado de homogeneidade...... 50

Tabela 20 - Distribuição de frequências da Classificação das emissões otoacústicas evocadas por produto de distorção, para a frequência $3174 \mathrm{~Hz}$, por orelha e grupo (as porcentagens foram calculadas por grupo) e valores-p do teste qui-quadrado de homogeneidade...... 50

Tabela 21 - Distribuição de frequências da Classificação das emissões otoacústicas evocadas por produto de distorção, para a frequência $4004 \mathrm{~Hz}$, por orelha e grupo (as porcentagens foram calculadas por grupo) e valores-p do teste qui-quadrado de homogeneidade...... 51

Tabela 22 - Distribuição de frequências da Classificação das emissões otoacústicas evocadas por produto de distorção, para a frequência $5042 \mathrm{~Hz}$, por orelha e grupo (as porcentagens foram calculadas por grupo) e valores-p do teste qui-quadrado de homogeneidade...... 51

Tabela 23 - Distribuição de frequências da Classificação das emissões otoacústicas evocadas por produto de distorção, para a frequência $6348 \mathrm{~Hz}$, por orelha e grupo (as porcentagens foram calculadas por grupo) e valores-p do teste qui-quadrado de homogeneidade...... 52

Tabela 24 - Média, desvio padrão, valores mínimo, máximo e mediana e análise comparativa entre os grupos em relação à variável "Intensidade global das emissões otoacústicas evocadas por transiente (dBNPS)", por orelha e grupo. 53

Tabela 25 - Valores-p associados aos testes de diferenças de medianas da Intensidade global das emissões otoacústicas evocadas por transiente (dBNPS) entre dois grupos, por orelha

Tabela 26 - Distribuição da amostra em números absolutos e percentuais em relação à variável "Presença/ausência das emissões otoacústicas evocadas por transiente" e análise comparativa entre os grupos, valor-p. 54

Tabela 27 - Média, desvio padrão, valores mínimo, máximo e mediana e análise comparativa entre os grupos em relação à variável Intensidade das emissões otoacústicas evocadas por transiente 
(dBNPS), por frequência $(1000,1400,2000,2800,4000$, em Hz),

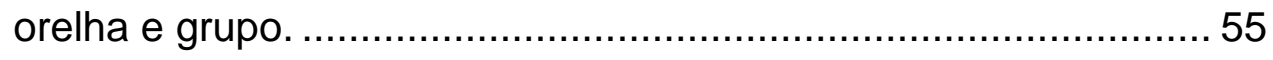

Tabela 28 - Valores-p associados aos testes de diferenças de medianas da Intensidade das emissões otoacústicas evocadas por transiente (dB) entre dois grupos, para a frequência $2800 \mathrm{~Hz}$, por orelha..... 56

Tabela 29 - Média, desvio padrão, valores mínimo, máximo, mediana e análise comparativa entre os grupos em relação à variável "Intensidade do efeito inibitório da via auditiva eferente $(\mu \mathrm{Pa})$ " na orelha direita, por grupo. 57

Tabela 30 - Média, desvio padrão, valores mínimo, máximo, mediana e análise comparativa entre os grupos em relação à variável "Intensidade do efeito inibitório da via auditiva eferente (\%)" na orelha direita, por grupo. 57

Tabela 31 - Distribuição de frequências da Classificação da supressão das emissões otoacústicas evocadas por transiente, por orelha e grupo (as porcentagens foram calculadas por grupo) e valores-p do teste qui-quadrado de homogeneidade.............................................. 58

Tabela 32 - Estatísticas descritivas para o Escore SSW (\%), por orelha competitiva e grupo. 58 


\section{LISTA DE FIGURAS}

Figura 1 - Gráfico de distribuição da amostra em relação ao valor das médias dos limiares auditivos (dBNA) para audiometria convencional e audiometria de altas frequências $(250-16.000 \mathrm{~Hz})$...................... 41 


\section{RESUMO}

Trabanco JCG. Efeitos da exposição a produtos químicos ou ao ruído sobre a audição [dissertação]. Faculdade de Medicina da Universidade de São Paulo; 2019.

INTRODUÇÃO: A exposição ao ruído em intensidade elevada pode causar danos ao sistema auditivo periférico e central. Da mesma forma, a utilização de diversos produtos químicos, com potencial ototóxico, pode causar prejuízos auditivos ou deflagrar efeitos neurotóxicos. Desta forma, é importante que os efeitos destes otoagressores sejam avaliados, uma vez que a prática clínica ocupacional somente inclui a audiometria convencional. OBJETIVOS: Avaliar os efeitos da exposição ao ruído ou a químicos sobre a audição periférica, habilidade do processamento auditivo e efeito inibitório da via auditiva eferente de trabalhadores expostos a produtos químicos ou a ruído intenso, comparando os grupos entre si e com trabalhadores que não possuem exposição a nenhum destes agentes. MÉTODOS: Participaram da pesquisa, 54 trabalhadores normo-ouvintes, sendo 28 mulheres e 26 homens, com idades entre 30 e 54 anos, divididos igualmente em três grupos: Grupo Químicos (expostos a químicos), Grupo Ruído (expostos a ruído) e Grupo Controle (sem exposição a químicos ou a ruído). Foram realizados os seguintes procedimentos: meatoscopia, imitanciometria, audiometria tonal por via aérea convencional e de altas frequências, logoaudiometria, pesquisa das emissões otoacústicas evocadas por estímulo transiente e por produto de distorção, bem como, do efeito inibitório da via auditiva eferente e Teste SSW para avaliação da habilidade auditiva de figura-fundo para sons verbais. Foram realizadas análises descritivas dos dados, bem como testes de hipótese (testes qui-quadrado, ANOVA e Kruskal-Wallis). RESULTADOS: Não houve diferença estatisticamente significante entre os grupos quanto ao sexo ou idade. Para a audiometria convencional e de altas frequências, não houve diferenças estatisticamente significantes entre os grupos quanto aos limiares auditivos. Quanto às emissões otoacústicas por produto de distorção, nas frequências de 4004 e $5042 \mathrm{~Hz}$, foi observado efeito de grupo com significância estatística, com amplitudes menores para o grupo Ruído. Na análise de presença e ausência das emissões produto de distorção, (5042 Hz), o grupo Ruído mostrou maior ocorrência de resultados ausentes. Para a análise da amplitude global das emissões otoacústicas transientes, para ambas as orelhas, o grupo Ruído apresentou amplitudes mais baixas, com diferença estatisticamente significante para a orelha esquerda. Analisando a presença ou ausência das emissões otoacústicas transientes, verificou-se que o grupo Ruído apresentou um número mais elevado de emissões ausentes, seguido pelo grupo Químicos, com diferença estatisticamente significante para a orelha esquerda e tendência à significância estatística para a orelha direita. Em relação ao efeito inibitório do sistema eferente, não houve diferença estatisticamente significante entre os grupos em relação à intensidade ou à porcentagem deste efeito. $\mathrm{Na}$ análise qualitativa, observou-se que $100 \%$ dos indivíduos do grupo Controle apresentaram presença deste efeito, enquanto $80 \%$ do grupo Químicos, e, $84,6 \%$ do grupo Ruído, apresentaram este efeito. Para o SSW, não houve diferenças entre os grupos. CONCLUSÃO: Com base nos resultados obtidos 
no presente estudo, pode-se sugerir que a exposição ao ruído ou a químicos produziu efeitos deletérios sobre a audição periférica, bem como, para a via auditiva eferente de trabalhadores expostos a produtos químicos ou a ruído intenso, apesar dos limiares auditivos dentro da normalidade para a audiometria convencional.

Descritores: Ruído; Substâncias tóxicas; Perda Auditiva Provocada por Ruído; Audiometria; Emissões Otoacústicas Espontâneas; Vias Auditivas; Exposição ocupacional 


\begin{abstract}
Trabanco JCG. Effects of exposure to chemicals or noise on hearing [dissertation]. Faculdade de Medicina da Universidade de São Paulo; 2019.
\end{abstract}

INTRODUCTION: Exposure to high-intensity noise can damage the peripheral and central auditory system. Likewise, the use of several chemicals with ototoxic potential may cause hearing loss or trigger neurotoxic effects. Thus, it is important that the effects of noise and ototoxic agents be evaluated, since occupational clinical practice only includes conventional audiometry. OBJECTIVES: To evaluate the effects of exposure to noise or chemicals on peripheral hearing, auditory processing ability and inhibitory effect of the efferent auditory pathway of workers exposed to chemicals or noise, comparing the groups with each other and with workers who do not have exposure to any of these agents. METHODS: Fifty-four normal-hearing workers, 28 women and 26 men, aged between 30 and 54 years old, were equally divided into three groups: Chemical Group (exposed to chemicals), Noise Group (exposed to noise) and Control Group (without exposure to chemicals or noise). The following procedures were performed: meatoscopy, immitanciometry, conventional audiometry, high-frequency audiometry, speech audiometry, transient and distortion product evoked otoacoustic emissions as well as the inhibitory effect of the efferent auditory pathway and the SSW Test for assessment of the auditory figure-ground ability for speech sounds. Descriptive analyses of the data were performed, as well as hypothesis tests (chi-square, ANOVA and Kruskal-Wallis tests). RESULTS: There was no statistically significant difference between the groups regarding sex or age. For conventional and high-frequency audiometry, there were no statistically significant differences between the groups regarding hearing thresholds. Concerning distortion product otoacoustic emissions, in the frequencies of 4004 and $5042 \mathrm{~Hz}$, a group effect with statistical significance was observed, with lower amplitudes for the Noise group. In the analysis of presence and absence of distortion product emissions $(5042 \mathrm{~Hz})$, the Noise group showed a higher occurrence of absent results. For the analysis of the global amplitude of transient otoacoustic emissions for both ears, the Noise group had lower amplitudes, with a statistically significant difference for the left ear. Analyzing the presence or absence of transient otoacoustic emissions, it was verified that the Noise group had a higher number of absent responses, followed by the Chemical group, with statistically significant difference for the left ear and tendency to statistical significance for the right ear. Regarding the inhibitory effect of the efferent system, there was no statistically significant difference between the groups in relation to the intensity or percentage of this effect. In the qualitative analysis, it was observed that $100 \%$ of the individuals in the Control group had presence of this effect, while $80 \%$ of the Chemical group and $84.6 \%$ of the Noise group had this effect. For SSW, there were no differences between groups. CONCLUSION: Based on the results obtained in the present study, it could be suggested that exposure to noise or chemicals produced deleterious effects on peripheral hearing, as well as the efferent auditory pathway of workers exposed to chemicals or intense noise, despite normal hearing thresholds to conventional audiometry. 
Descriptors: Noise; Chemical compounds; Hearing Loss, Noise-Induced; Otoacoustic Emissions, Spontaneous; Audiometry; Auditory pathways, Occupational exposure 


\section{INTRODUÇÃO}

A exposição ao ruído em intensidade elevada pode causar danos à cóclea, especialmente, às células ciliadas externas, que são vulneráveis a diversos estímulos deletérios (Hamernik et al., 1989; Campo et al., 2014), podendo ocasionar mudanças permanentes nos limiares auditivos, piora na inteligibilidade de fala, zumbido e alterações na função auditiva central (Sliwinska-Kowalska e Davis, 2012).

Diversos estudos retratam os efeitos do ruído em ambientes ocupacionais, permanecendo como o risco predominante para a audição (Kovalova et al., 2016; Irgens-Hansen et al., 2016; Broyles et al., 2017); porém, diversas evidências vêm sendo estabelecidas sobre a utilização de diversos produtos químicos com potencial para afetar a audição, agravar os efeitos nocivos do ruído, ou, até mesmo, deflagrar efeitos neurotóxicos (Campo et al., 2014; Unlu et al., 2014).

Qualquer droga ou substância química que provoque prejuízo funcional na orelha interna pode ser definida como agente ototóxico. O mecanismo de ação dessas substâncias pode apresentar especificidades de acordo com a região, células específicas e vias bioquímicas afetadas, podendo causar danos nos sistemas auditivos periférico e central, prejudicando as células sensoriais e os nervos auditivos na sua porção periférica, bem como, as vias auditivas centrais (Fuente et al., 2006; Johnson e Morata, 2010).

A prática clínica para avaliações audiológicas ocupacionais prevê a realização de audiometria tonal para determinação dos limiares auditivos de um 
indivíduo. Esse exame é adequado para a avaliação subjetiva dos limiares auditivos, porém, restringe-se a uma determinada faixa de frequências, de 250 a $8000 \mathrm{~Hz}$. Afecções na audição decorrentes da ototoxicidade ou da exposição ao ruído podem provocar redução da acuidade auditiva em frequências não captadas inicialmente no exame audiométrico convencional. Assim, estudos apontam para a importância da utilização de outros mecanismos de avaliação auditiva em indivíduos expostos a produtos químicos ou a ruído, como a audiometria de altas frequências e avaliação das emissões otoacústicas (Frota e lorio, 2002; Lopes et al., 2009), podendo detectar alterações com maior antecedência em relação à audiometria convencional.

Conforme mencionado, os agentes otoagressores podem afetar a função auditiva por meio de diferentes mecanismos. Contudo, algumas características comuns podem ser observadas para os agentes físicos (ruído) e alguns químicos (ototóxicos). O achado mais comum costuma ser a perda auditiva neurossensorial decorrente da degeneração das células ciliadas da cóclea. Em estudos com animais, ambos os agentes têm demonstrado causar perda das células ciliadas, que pode estar relacionada à formação de radicais livres ou espécies reativas de oxigênio (Johnson e Morata, 2010; Oishi e Schacht, 2011; Choi e Choi, 2015).

No que se refere aos danos para o sistema auditivo, tanto estudos em animais quanto em seres humanos já demonstraram os efeitos deletérios de agentes otoagressores. O ruído, por ser um risco físico, causa principalmente danos mecânicos e metabólicos ao receptor auditivo periférico (a cóclea) e, mais raramente, às vias auditivas centrais. Por outro lado, os químicos que 
atingem a corrente sanguínea podem acessar não só a cóclea, mas também, o sistema nervoso central, de maneira mais fácil (Campo et al., 2014).

Apesar das características inerentes a cada elemento, alguns estudos apontam que a exposição prolongada ao ruído também pode ser propiciadora de alterações no processamento auditivo (Kujala et al., 2004; Brattico et al., 2005; Massa et al., 2012).

Em estudos recentes, foram observados animais com atividade cortical alterada tanto pelo ruído como pela interação entre ruído e químicos. Os autores ressaltaram a importância do desenvolvimento deste tipo de pesquisa com humanos, para determinar a relevância dessas disfunções verificadas em modelos animais (Guthrie et al., 2016). Alguns outros estudos verificaram alteração no processamento auditivo central de indivíduos expostos a produtos químicos, utilizando diversos testes comportamentais para avaliação do processamento auditivo central (Fuente et al., 2006; Fuente e McPherson, 2007; Dutra et al., 2010) e enfatizaram a necessidade de incorporar ferramentas que avaliem a função auditiva central, já que os recentes achados demonstram que tanto a porção periférica quanto a central podem ser afetadas por esses agentes (Fuente e McPherson, 2007; Juaréz-Perez et al., 2014).

Dada a importância do tema e as diversas lacunas que existem sobre o assunto, um estudo comparando indivíduos expostos e não expostos a produtos químicos, comparando-os a indivíduos expostos ao ruído, pode auxiliar na compreensão dos agravos decorrentes da exposição a essas substâncias, e também, apontar avaliações que proporcionem diagnósticos mais precoces que os comumente utilizados na prática clínica. 
Ressalta-se que a maioria dos estudos da literatura, realizados para avaliar os efeitos do ruído e/ou dos químicos, avalia somente a porção periférica do sistema auditivo. Não foi encontrado na literatura nenhum estudo que avalie simultaneamente a via auditiva periférica e o início da via auditiva central de indivíduos expostos a ruído ou a químicos, como proposto, no presente estudo.

Desta forma, embora muito se saiba sobre os efeitos destes agentes otoagressores sobre a cóclea, muitas questões sobre o tema ainda existem, principalmente, no que se refere ao sistema nervoso auditivo central (aferente e eferente) de indivíduos expostos a ruído ou a químicos.

Nossa hipótese é que indivíduos, em situação de exposição contínua a produtos químicos ou a ruído, apresentem alterações mais evidentes nos exames de emissões otoacústicas e audiometria de altas frequências, mesmo na presença de limiares auditivos normais nas frequências convencionais, quando comparados a indivíduos sem esta exposição, indicando comprometimento no sistema auditivo periférico. Além disso, espera-se que o efeito inibitório da via auditiva eferente, bem como algumas habilidades auditivas do processamento auditivo, nos indivíduos expostos a estes agentes otoagressores, difiram dos resultados de indivíduos sem esta exposição, sugerindo alteração no sistema auditivo central. 


\section{OBJETIVO}

Avaliar os efeitos da exposição ao ruído ou a químicos sobre a audição periférica, habilidade do processamento auditivo e efeito inibitório da via auditiva eferente de trabalhadores expostos a produtos químicos ou a ruído intenso, comparando os grupos entre si e com trabalhadores que não possuem exposição a nenhum destes agentes.

\subsection{Objetivos específicos}

- Comparar os limiares auditivos da audiometria convencional e de altas frequências entre os grupos;

- Comparar a amplitude das emissões otoacústicas evocadas por produto de distorção (EOAPD) e das emissões otoacústicas evocadas por estímulo transiente (EOAT) entre os grupos, bem como, o efeito inibitório da via auditiva eferente;

- Comparar a relação entre presença e ausência das emissões otoacústicas evocadas por produto de distorção e por estímulo transiente entre os grupos;

- Comparar a habilidade do processamento auditivo (figura-fundo para sons verbais) entre os grupos. 


\section{REVISÃO DA LITERATURA}

Esta revisão da literatura abordou alguns aspectos a respeito dos riscos ocupacionais em geral, trabalho, ruído e ototóxicos.

Para melhor clareza de apresentação, este capítulo foi dividido em subitens, nos quais foi priorizado o encadeamento de ideias e, quando possível, buscou-se manter a ordem cronológica dos estudos.

\subsection{Riscos e trabalho}

Segundo vertentes analíticas, a atividade de trabalho designa a maneira do ser humano mobilizar suas capacidades para atingir os objetivos da produção (Assunção, 2003). O trabalho também pode ser entendido como elemento de promoção do desenvolvimento pessoal e social, dotado de grande complexidade e particularidades (Lima, 2001). O trabalho apresenta-se como importante determinante para a saúde, abrangendo diversos níveis da realidade humana. Isso pode gerar um parcelamento de sua atenção entre diversas áreas de conhecimento, dificultando a análise de problemas advindos da correlação entre os fatores envolvidos, bem como, de imprevistos, onde pode residir grande parte das explicações para problemas de saúde (Assunção e Lima, 2003).

Transcender barreiras cultural e socialmente impostas sobre a prática da saúde é um desafio perante o reducionismo das abordagens tradicionais em saúde do trabalhador. Mudanças nas estruturas produtivas historicamente se desenrolam, gerando diferenciações nas relações entre os sujeitos envolvidos 
em um processo produtivo e entre o trabalho propriamente dito. Essas alterações, geralmente visam a maximização da produção, tornando-a menos custosa frente a uma maior produtividade, tanto no quesito humano quanto produtivo. O advento de mecanismos mais completos de informação permite maior controle dos processos produtivos, porém, a insuficiência de diversos modelos questionados e propostos por entidades de proteção ao trabalhador contribuem para a redução do trabalho ao instrumento, limitando assim, a compreensão da relação fator de risco-trabalho. Uma lógica da inevitabilidade dos danos decorrentes do trabalho se espalha pelo imaginário de todos os envolvidos no processo de trabalho. Ideias cristalizadas tendem a buscar a compreensão do trabalhador enquanto massa coletiva, desprezando sua individualidade (Assunção, 2003).

Relações diretas entre riscos e doenças são estudadas classicamente, porém, relações indiretas vem se tornando, mais frequentemente, objetos de estudo, analisando tanto o trabalho em si, como as condições dos trabalhadores que o executam e as consequências implícitas. Mais importante que analisar fatores de riscos isolados é entender o funcionamento do trabalho enquanto sistema, considerando as particularidades do ambiente, do trabalho e do trabalhador, de maneira constante e vigilante. A assunção de riscos faz parte da atividade humana e a mensuração total de todos os riscos, é, de maneira geral, utópica. Porém, cabe à estrutura técnico-científica que ampara os trabalhadores estimular e propor aprendizados e ações constantes, com assimilação prática de novos conhecimentos que valorizem a causalidade, 
promovendo saúde ao máximo possível aos trabalhadores (Assunção e Lima, 2003).

Diversos aspectos devem ser considerados como obstáculos no processo de reformulação do trabalho, como, por exemplo, mecanismos de autodefesa coletivo dos trabalhadores para se protegerem contra a conscientização dos perigos de sua atividade. Esses mecanismos anulam a culpa pelos efeitos sociais das medidas de agravamento do trabalho. A primazia do desempenho, enquanto apropriação inconsciente e coletiva, estimulada pela estrutura produtiva vigente, acaba por promover uma dinâmica de expansão infinita do utilitarismo do ser humano (Metzger et al., 2012).

$\mathrm{Na}$ contramão desses processos, profissionais de diversas áreas procuram estruturar meios de compensar riscos presentes, sendo, portanto, inevitável a obtenção de conhecimento, não para acreditar no desprezo completo da vulnerabilidade dos trabalhadores, em virtude da utopia já referida dessa proposta, mas, para conhecer e buscar a minimização e conscientização dos trabalhadores a respeito dos riscos, para que, os processos laborais possam atuar como promotores de saúde, e não como geradores de danos à ela (Costa e Goldbaum, 2017). Assim, conhecer efeitos da exposição a produtos químicos, algo ainda muito recente na literatura científica, associado ao conhecimento já estruturado acerca do ruído, pode auxiliar no oferecimento de subsídio técnico para os normatizadores dos processos produtivos, propiciando maior proteção e qualidade ao trabalho (Mont'Alverne et al., 2016). 


\subsection{Som e Ruído}

A perda auditiva ocupacional é uma das principais doenças relacionadas ao trabalho. Milhões de trabalhadores são expostos a níveis de ruído ocupacional potencialmente prejudiciais (Hutchison e Kirchner, 2014).

Para adequação terminológica, faz-se importante retomar alguns conceitos fundamentais para o estudo do ruído e de seus elementos correlacionados.

Inicialmente, a palavra "Som" tem origem na palavra "Sonu", que, em latim, significa "tudo que impressiona o ouvido". Fisicamente, o som é um fenômeno vibratório que decorre de variações na pressão aérea, propagandose longitudinalmente (Fernandes, 2013).

Historicamente, sabe-se que o estudo dos elementos relativos ao som tem ligação direta com o desenvolvimento da música pelas sociedades, desde, aproximadamente, 4000 a.C. Povos como hindus, egípcios, chineses e japoneses já elaboravam suas percepções sobre o tema. Posteriormente, cerca de 2500 anos atrás, na Grécia, Pitágoras ampliou o conhecimento da humanidade sobre o tema, analisando e elaborando diversos conceitos fundamentais para análise do som enquanto elemento acústico. Cerca de 200 anos depois, Aristóteles deu continuidade aos trabalhos iniciados por seu antecessor, elaborando uma coletânea de artigos conhecida, em inglês, como "Sound and Hearing". A partir desse trabalho, modelos de propagação da onda sonora pelo ar foram propostos. Assim também, Euclides, importante matemático da antiguidade, traçou caminho semelhante para o estudo do som 
e de seus componentes. Os estudos sobre o som desvinculados, necessariamente, da música começaram, efetivamente, no século XVII com Galileu Galilei que procurou estabelecer regras relativas aos processos de reflexão e propagação do som (Nepomuceno, 1994).

O som apresenta propagação através de um meio material, como o ar, gerando pontos de compressão e de rarefação, com deslocamento ao longo da direção de propagação, caracterizando-se como uma onda longitudinal (Ference Junior, 1968).

Por seu padrão ondulatório, definições fundamentais foram elaboradas a respeito de seu deslocamento, como amplitude, período, frequência e fase.

A amplitude da onda apresenta-se como relativa à intensidade de sua propagação. A lei de Weber-Fechner mostra que as sensações percebidas por estímulos diversos são proporcionais ao logaritmo do estímulo produzido. Assim, sugeriu-se a utilização de uma escala logarítmica para aferição da intensidade sonora.

Assim, o nível de intensidade, L, foi proposto segundo a seguinte fórmula:

$$
\mathrm{L}=\log 10 \frac{I}{I 0}
$$

sendo, I a intensidade física recebida por um ouvinte e I0 a intensidade de um padrão arbitrário. 
Foi proposto que a unidade utilizada fosse o bel (B), em homenagem a Alexander Graham Bell, porém, essa unidade mostrou-se muito grande para ser utilizada dessa forma, então, ela foi dividida à sua décima parte, sendo denominada decibel $(\mathrm{dB})$.

Assim, o nível de intensidade sonora em decibels [l(dB)], seria:

$$
\mathrm{I}(\mathrm{dB})=10 \log \frac{I}{I 0}
$$

A intensidade do padrão arbitrário (I0) é adotada como sendo $10^{-12}$ Watt $/ \mathrm{m}^{2}$, na frequência de $1000 \mathrm{~Hz}$, sendo essa intensidade, relativa ao limiar da sensação auditiva. A sensação dolorosa tende a ocorrer em uma intensidade de 12B, ou, 120dB. Assim, essas impressões, somadas à noção de que o valor de tolerância a sons intensos e o limiar de sensação sonora variam com a frequência, deram origem às noções atuais que baseiam a forma de mensuração de audição (Nepomuceno, 1994).

Essas condições fazem com que o bel, e, consequentemente, o decibel não sejam efetivamente caracterizados como unidades de medida, mas, sim, como a relação logarítmica entre duas medidas, sendo uma delas adotada como referência. Dessa forma, é possível a ocorrência de valores negativos para essa escala, o que não ocorreria em diversas outras medidas como metros, kilogramas, entre outras.

O ruído pode ser definido como um fenômeno audível que apresente impossibilidade de discriminação pelo sistema auditivo, pelo fato de suas frequências apresentarem diferenciação em valores inferiores à capacidade de 
detecção desse sistema. Pode haver predomínio de determinadas faixas de frequência, resultando em fenômenos acústicos diversos, porém, ainda assim, não são apresentadas condições de análises efetivas quanto à frequência (Nepomuceno, 1994).

Por se tratar de um risco conhecido há um considerável tempo, diversos decretos foram publicados por diversas instituições, a fim de respaldar e escudar os trabalhadores, no que diz respeito a audição. São exemplos:

- a Norma Regulamentadora (NR) № 15 (Brasil,1978), que estabelece os limites de tolerância para situações ruidosas ocupacionais;

- a NR 17 (Brasil, 1990), que, ao referenciar a norma NBR 10152 da Associação Brasileira de Normas Técnicas (ABNT) (Brasil, 2000), visa garantir ambientes silenciosos para profissionais em atividades de solicitação intelectual e atenção constante;

- a NR 09, que visa a preservação da saúde e a integridade de todos os trabalhadores, por meio da antecipação, reconhecimento, avaliação e controle de riscos ambientais, através do Programa de Prevenção de Riscos Ambientais (PPRA)17, que deve ser articulado ao Programa de Controle Médico de Saúde Ocupacional (PCMSO), previsto na NR 07, onde, por meio da Portaria no 19 de 09 de abril de 1998, são descritas as diretrizes e parâmetros mínimos para a avaliação e acompanhamento da audição em trabalhadores expostos à níveis de pressão sonora elevados, estabelecendo as bases do Programa de Conservação Auditiva (PCA) ou Programa de Prevenção de Perdas Auditivas (PPPA) (Brasil, 1996). 


\subsection{Efeitos do ruído sobre a saúde e medidas de proteção}

Os mais diversos ramos produtivos apresentam íntima ligação com o ruído, e, consequentemente, os trabalhadores envolvidos no processo, podendo acarretar diversas alterações não somente auditivas, como zumbido e redução da acuidade auditiva (Ogido et al., 2009), mas, também, extra auditivas como alterações do sono, complicações vestibulares, mudanças comportamentais, neurológicas e cardiovasculares (Araújo 2002; Marques e Costa, 2006).

Cabe ressaltar que diversas mudanças na organização neuronal podem decorrer da exposição prolongada e danosa ao ruído, promovendo uma série de alterações no processamento sonoro, trazendo os referidos efeitos à tona, como a sensação de zumbido (Muca et al., 2018), ou, promovendo alterações centrais que desfavorecem as habilidades auditivas dos indivíduos expostos (Dewey, 2018).

A referida diminuição na acuidade auditiva, nessa situação específica, conhecida como "Perda Auditiva Induzida por Ruído" (PAIR), ou, "Perda Auditiva Induzida por Níveis de Pressão Sonora Elevados" (PAINPSE), se baseia na lesão de estruturas da orelha interna, ocasionando morte das células ciliadas, em decorrência da agressiva exposição a níveis de pressão sonora potencialmente lesivos em intensidade e/ou duração (Hamernik et al., 1989).

Essa conformação de perda auditiva apresenta-se como uma perda auditiva de caráter neurossensorial, irreversível e, costumeiramente, bilateral. 
Geralmente, não atinge um grau profundo de perda de audição, com tendência ao início nas frequências de 3, 4 ou 6kHz (McBride \& Williams, 2001).

Desde séculos passados, estudiosos da área já apontavam os efeitos dessa exposição inadequada ao ruído, como fez o médico italiano Bernardino Ramazzini nos séculos XVII e XVIII, ao estudar trabalhadores que manipulavam bronze (bronzistas), apontando, pela primeira vez, o que ficou conhecido como "Surdez dos bronzistas" (Ramazzini, 2016).

Em sua obra intitulada "De Morbis Artificum Diatriba", publicada pela primeira vez no ano de 1700 , na cidade italiana de Modena, cita o referido autor: "[...] o contínuo ruído danifica o ouvido, e depois, toda a cabeça; tornamse um pouco surdos e, se envelhecem no mister, ficam completamente surdos" (Ramazzini, 2016).

Hoje, mais de três séculos após a descrição de Ramazzini, ainda notase que a maioria dos funcionários de empresas com importantes riscos para a audição, como indústrias que manipulam ferro e aço, apresenta pouco conhecimento sobre a perda auditiva induzida por ruído, e, consequentemente, sobre as possibilidades e importância de sua prevenção (Nyarubeli et al., 2019).

Também são apontados como fatores importantes de conscientização, além da relação entre a atividade profissional de trabalhadores de ramos profissionais tradicionalmente considerados como potencialmente nocivos à audição, como a construção civil, a limitação à exposição a solventes e à 
fumaça como a do cigarro, sugerindo que a prevenção deve ser o foco principal de atenção para todas estas questões (Dement et al., 2018).

O ideal de proteção não se baseia em uma compensação do fenômeno agressivo, mas sim, na tentativa de evitar sua ocorrência. Dessa forma, buscase a atuação em todos os níveis de proteção aos indivíduos que estejam expostos a níveis de pressão sonora elevados.

Sobre esse assunto, trata a norma ISO 31000 , criada pela ISO (International Organization for Standardization), entidade sediada na Suíça, apresentando que as organizações, responsáveis pelo trabalho, devem identificar os perigos e riscos de saúde e segurança no trabalho associados a mudanças organizacionais, no sistema de gestão ou em suas atividades, antes da introdução dessas mudanças. A organização deve assegurar que os resultados dessas avaliações sejam levados em consideração quando da determinação dos controles. Ao determinar os controles ou considerar mudanças nos controles existentes, deve-se levar em conta a redução dos riscos de acordo com sua hierarquia. Inicialmente, deve-se buscar a eliminação do risco, eliminando, no caso, todo tipo de fonte de ruído potencialmente danosa. Caso não seja possível, busca-se a substituição dessas fontes por outras possibilidades menos danosas aos indivíduos expostos. Caso ainda não seja possível a adoção desse tipo de medida, alterações estruturais e de controle devem ser adotadas a fim de minimizar riscos. Evitar áreas de risco por meio de controles administrativos que recaiam sobre a sinalização e todo o tipo de alerta sobre os riscos envolvidos no local também são etapas a serem adotadas. Em caso de impossibilidade de adoção de todas as etapas 
anteriores, onde, por limitação técnica, o local de trabalho não tenha condições para praticar as medidas apresentadas, preferencialmente, na ordem e hierarquia apresentadas, parte-se então para a aplicação de medidas de proteção individual, como os Equipamentos de Proteção Individual (EPIs) (ISO, 2009).

Continua ainda a norma, sobre o referido tema:

Em algumas circunstâncias, a avaliação de riscos pode levar à decisão de se proceder a uma análise mais aprofundada. A avaliação de riscos também pode levar à decisão de não se tratar o risco de nenhuma outra forma que seja manter os controles existentes. Esta decisão será influenciada pela atitude perante o risco da organização e pelos critérios de risco que foram estabelecidos (ISO 31000, 2009).

Outro guia que embasa essa perspectiva é a OHSAS 18001 (2007) (Occupational Health and Safety Assessment Series), uma série de normas desenvolvidas pelo BSI Group (British Standards Institution) do Reino Unido, visando padronizações e certificações no âmbito de trabalho.

Tanto a OHSAS 18001 (2007) quanto a ISO 31000 (2009) tratam da questão da avaliação de riscos. Essa avaliação tem como finalidade, subsidiar o processo de tomada de decisões e ajustar a adoção de medidas à necessidade identificada. O processo de avaliação deve levar em conta a adequação de qualquer controle existente, a fim de decidir a aceitação ou não do risco, segundo a OHSAS 18001 (2007) e quais riscos necessitam de tratamento e a prioridade para a implementação do tratamento, comparando o nível de risco encontrado durante o processo de análise com os critérios de 
risco estabelecidos quando o contexto foi considerado, conforme complementa a ISO 31000 (2009).

Dessa forma, medidas de proteção devem sempre ser adotadas quando em situações de exposição ao ruído, buscando sua redução, ou, preferencialmente, sua eliminação (EU-OSHA, 2005).

Conforme citado, para os casos de impossibilidade técnica de extinção da fonte sonora, deve-se valer do uso de equipamentos de proteção sonora individuais, sendo evidenciado que seu uso correto também é um fator decisivo para a prevenção de agravos e, para que esta utilização adequada ocorra, é indispensável a realização de treinamento adequado (Neitzel et al., 2008; Samelli e Moreira, 2014).

Ramazzini, em sua obra, refere-se a essa possibilidade ao afirmar:

Não vejo remédio que possa servir para esses males; podem obturar os ouvidos com algodão, de modo que o ruído repercuta menos, nas partes internas, [...] lesionadas pelo contínuo estrépito (Ramazzini, 2016)

Porém, ainda que uma base legal fosse efetivamente estruturada e implantada, ainda seriam necessários estudos contínuos sobre o tema, como propõe o pesquisador Fink (2019), que questiona os valores de segurança estabelecidos por normas internacionais, colocando que $85 \mathrm{~dB}(\mathrm{~A})$ não se trata efetivamente de uma base de medida de segurança para exposição, visto que esse número não está atualizado de acordo com a evolução das características fisiológicas e sociais da população. 
Medidas de proteção ineficiente são apontadas, por diversos autores, como uma das principais causas da perda auditiva induzida por níveis de pressão sonora elevados (Teti et al., 2019).

Recentemente, novas perspectivas foram elencadas para a prevenção das PAINPSEs, incluindo medidas profiláticas, como por exemplo, a exposição prévia a ruídos controlados como agente protetor, o que, até o momento, não apresentou resultados positivos (Strose et al., 2014) ou a análise diferenciada do indivíduo exposto ao ruído, por singularidades como sexo e etnia (Le Prell et al., 2018), já que estudos controlados, realizados em camundongos, apontaram que as fêmeas tendem a apresentar maior proteção fisiológica a danos acústicos decorrentes da exposição a níveis de pressão sonora elevados quando comparadas aos machos. Também apontaram a possibilidade de efeitos diferentes decorrentes de terapêuticas apresentadas a ambas as populações, levantando a hipótese de o estrogênio estar relacionado a algum mecanismo otoprotetor (Milon et al., 2018).

A ingestão de suplementos vitamínicos também tem sido evidenciada na literatura contemporânea. A suplementação oral de Zinco tem sido pesquisada como fator de compensação dos agravos decorrentes da exposição a níveis de pressão sonora elevados. Até o momento, foi possível evidenciar uma redução nos impactos decorrentes do zumbido em atividades de vida diária, medidos por meio do questionário Tinnitus Handicap Inventory, em indivíduos com diagnóstico clínico de perda auditiva induzida por níveis de pressão sonora elevados (Yeh et al., 2019). 
Cabe mencionar, que parte dos danos promovidos às células ciliadas da orelha interna decorrentes da exposição ao ruído pode ser causada por mecanismos de lesão baseados em espécies reativas de oxigênio (Fetoni et al., 2013). Acredita-se também que suas manifestações variem com a forma e a dose de exposição. É apontada a existência de mecanismos internos de compensação da vulnerabilidade auditiva propiciada pelas referidas situações, por meio de antioxidantes inerentes à própria cóclea, que podem se ativar frente às estimulações crônicas propiciadas pelas relatadas espécies reativas de oxigênio (Morioka et al., 2018).

Buscando estratégias de cunho semelhante, porém, de origem externa, terapêuticas medicamentosas de compensação à exposição ao ruído intenso são sugeridas também, com a ressalva de que, devido às barreiras fisiológicas pré-existentes, essas drogas podem encontrar dificuldade para ativação nos objetivados locais de ação (Kayyali et al., 2018).

Assim, vem sendo estudada a utilização de substâncias químicas na atenuação do desenvolvimento da PAINPSE (Liu et al., 2019), como, por exemplo, o Resveratrol, uma espécie de polifenol caracterizado, inicialmente, como uma fitoalexina, especialmente encontrado na uva e em seus derivados, que apresentaria um possível elemento protetivo ao sistema auditivo. Tem-se buscado a interação desse elemento junto ao sistema serotoninérgico em situações de exposição a níveis de pressão sonora elevados. Um estudo com ratos mostrou que a ingestão dessa droga pode apresentar efeitos protetivos no sistema serotoninérgico na referida situação de agravo (Li et al., 2019). 
É importante mencionar também que outros estudos em animais apresentaram a hipótese de que, mesmo em situações onde não há dano aparente nas estruturas cocleares, é possível a ocorrência de alterações permanentes na função auditiva central (Pienkowski e Eggemont, 2012; Shi et al., 2016). Diversas consequências podem ser decorrentes desse tipo de alteração provocada pela exposição prolongada ao ruído, visto que modificações na velocidade, força e topografia das respostas já foram

evidenciadas em pesquisas prévias (Kujala et al., 2004), alterando a discriminação de sons verbais e não-verbais. Ressalta-se que essas alterações podem ocorrer antes mesmo da evidenciação do comprometimento dos limiares auditivos tonais (Santos et al., 2008). Dessa forma, a interferência da exposição ao ruído no processamento auditivo destes indivíduos é algo a ser considerado, tanto como sequela, quanto interferência ambiental no dia-a-dia (Silva et al., 2006).

Ressalta-se que, em curto prazo, situações de ruído contínuo podem propiciar uma inibição cortical e subcortical (Yakunina et al., 2019), e, a longo prazo, a habilidade de compreensão em situações ruidosas pode se tornar deficitária por estar relacionada à alterações anatomo-fisiológicas (Rudner et al., 2019). Cabe destacar que alterações na organização neuronal podem contribuir, também, para a ocorrência do zumbido (Muca et al., 2018).

\subsection{Efeitos da ototoxicidade e medidas de proteção}

A palavra Ototoxicidade deriva da junção da palavra grega "Otos", ou, "Ous", radicais relativos à palavra "orelha" (Rezende, 2004), com a palavra 
"Toxicon", proveniente latina do vocábulo grego "Toxikon Pharmakon", indicando o veneno ("pharmakon") utilizado nas pontas de flechas atiradas em arcos ("toxon") para caçadas ou embates (Oxford Dictionary, 2019).

Do ponto de vista histórico, dois momentos são marcantes no que diz respeito à busca pela compreensão da ototoxicidade. O primeiro se inicia no século XIX, através do estudo dos processos de extração, purificação e síntese de diversos componentes químicos utilizados em diversas drogas. Já, o segundo, acontece no século XX, com a busca por elementos antibióticos cada vez mais potentes, que, como colateralidade, propiciam a potencialidade de danos à audição (Sthepens, 1982).

Novamente, é possível citar Ramazzini, pois, em sua mesma obra ("De Morbis Artificum Diatriba"), o autor, ao citar os bronzistas, faz a ressalva a outras possibilidades de agravo à saúde decorrente da exposição ao bronze e aos produtos químicos envolvidos na sua preparação. Cita o autor: "[...] do bronze batido exalam-se vapores venenosos, os quais elevando-se penetram pela boca e chegam ao estômago e aos pulmões, segundo afirmam, os artífices". (Ramazzini, 2016).

Substâncias ototóxicas podem ser definidas como substâncias químicas com potencial para ocasionar prejuízo funcional ou celular na orelha interna, cujos mecanismos de ação podem variar, envolvendo a orelha interna como um todo, componentes celulares específicos ou vias bioquímicas próprias. Cabe ressaltar o potencial que algumas dessas substâncias apresentam para também afetar vias auditivas centrais, sendo denominadas, nesses casos, 
neurotóxicas, podendo ou não, também serem estritamente ototóxicas (Johnson e Morata, 2010).

São conhecidas mais de 750.000 substâncias químicas, sendo que aproximadamente 85.000 são utilizadas rotineira e comercialmente. Dessas, apenas cerca de 7.000 substâncias têm seus riscos e efeitos descritos e conhecidos, mesmo que, de maneira parcial (Fundação Nacional De Saúde, 2002). O número de substâncias com potencial ototóxico ou neurotóxico, afetando as vias auditivas periféricas e/ou centrais (Johnson e Morata, 2010), conhecido e investigado é pequeno.

Já se tem conhecimento dos principais grupos de substâncias com maior potencial ototóxico e neurotóxico, que são os solventes, asfixiantes, metais pesados e pesticidas organofosforados (Lobato et al., 2014). Porém, sabe-se muito pouco sobre os efeitos desses produtos, bem como os valores de segurança para dose e tempo máximo de exposição. Inúmeras variáveis individuais também são importantes como: idade do indivíduo, estado geral de saúde e exposição ao ruído ou a outros químicos concomitantemente, o que acaba sendo relativamente comum no ambiente ocupacional, entre outras (Morata e Lemasters, 2001; Lobato et al., 2014; Yang et al., 2016).

Assim, o diagnóstico de afecções decorrentes da ototoxicidade deve ser baseado na confirmação da exposição à determinada(s) substâncias e na presença de sinais clínicos e sintomas, considerando o potencial de perda da acuidade auditiva frente ao uso desse tipo de substância (Abreu e Suzuki, 2002). Alguns estudos também preveem a possibilidade da ocorrência de um efeito otoprotetor mediante uma exposição controlada e prévia aos elementos 
ototóxicos, podendo minimizar os efeitos de exposições a essas mesmas substâncias em situações futuras (Oliveira et al., 2002).

Como exemplo de uso de ototóxicos fora do ambiente ocupacional, temse os pacientes em tratamento oncológico por quimioterapia baseada em cisplatina, cuja atuação medicamentosa apresenta colateralidades como a ototoxicidade (Knight et al., 2005), sendo relatado, assim como para diversas outras substâncias químicas, a ocorrência de zumbido, otalgia, alterações vestibulares e alterações de caráter central, que podem afetar, também, as vias auditivas. Nesses casos, essas alterações se tornam mais frequentes em situações de exposições a doses maiores que $60 \mathrm{mg} / \mathrm{m}^{2}$ (Oun et al., 2018).

Como em casos dessa natureza a utilização desses medicamentos não é totalmente opcional, muitos pesquisadores buscaram estratégias para a compensação desses efeitos colaterais, como o uso de forscolina (Guo et al., 2018), que pode reduzir as afecções, principalmente, em frequências altas, que são as mais tradicionalmente afetadas pela ototoxicidade da cisplatina (Oun et al., 2018), que inibe a apoptose e a produção de espécies reativas de oxigênio (Guo et al., 2018). O ácido gálico também se apresentou como possível elemento protetor para essas situações, reduzindo danos na camada de tecido conjuntivo das células endoteliais, e, consequentemente, o comprometimento das células ciliadas externas, minimizando lesões na estria vascular (Kilic et al., 2018).

Situações potencialmente evitáveis também são bastante discutidas no âmbito da ototoxicidade, inerente à prática profissional. Nesses casos, a exposição a agentes ototóxicos pode ocorrer por inalação, ingestão ou contato 
com a pele. Os efeitos danosos podem variar de acordo com a frequência, a intensidade, a duração e o ambiente de trabalho aos quais o indivíduo é exposto. Considerando como ototóxicos, quaisquer substâncias neurotóxicas, cocleotóxicas ou vestibulotóxicas, dentre os ramos profissionais mais descritos como sujeitos à exposição a ototóxicos, podemos destacar as indústrias: de metais, cortumes, têxteis, petrolíferas, de papel, de componentes elétricos e químicas. Já, em relação ao efeito sinérgico (decorrente da exposição a químicos e ruído), vale destacar as seguintes profissões: pintores, construtores, ocupações manufatureiras de diversos setores, bombeiros, profissionais que utilizem armas de fogo, profissionais que tenham contato com pesticidas, entre outros (OSHA, 2018).

Como exemplos de substâncias inerentes a esses grupos, podemos citar: tolueno, xileno, estireno, n-Hexano, dissulfeto de carbono, tricloroetileno (solventes), monóxido de carbono, cianeto de hidrogênio (asfixiantes), chumbo e mercúrio (metais) (Johnson e Morata, 2009). Merece destaque o tolueno, pela ampla utilização cotidiana e pela potencialidade ototóxica, em virtude do seu possível efeito lesivo das células ciliadas externas da região média da cóclea (Silva et al., 2018).

Considerando os efeitos auditivos decorrentes da atividade laboral, é importante ressaltar a possibilidade de ocorrência de efeito sinérgico entre ruído e produtos químicos, que promoveria otoagressões mais importantes que seus componentes separados, como é o caso de solventes orgânicos, que, além do potencial oto e neurotóxicos que já apresentam por si só, na concomitância com o ruído, podem causar danos mais severos à audição. 
Porém, os efeitos específicos dessas substâncias são de difícil avaliação, pois os indivíduos avaliados nas diversas pesquisas, geralmente trabalhadores, comumente estão expostos a uma mistura de substâncias químicas com composições e concentrações que variam substancialmente (Morata e Lemasters, 2001; Lobato et al., 2014; Yang et al., 2016). Sabe-se que a exposição combinada a produtos químicos e ruído já se mostrou como potencialmente lesiva ao sistema auditivo (Schaal et al., 2017).

Semelhanças entre os danos causados por agentes físicos e químicos de otoagressão podem ser observadas, principalmente no que diz respeito ao tipo de perda auditiva (neurossensorial), que, segundo estudos conduzidos com animais, podem decorrer da formação de radicais livres ou espécies reativas de oxigênio (Oichi e Schacht, 2011; Choi e Choi, 2015). A mais importante ressalva, quanto aos referidos agentes, recai na disseminação dos danos. Enquanto o ruído atua principalmente por meio de danos mecânicos e metabólicos localizados na cóclea, os produtos químicos, por atingirem a corrente sanguínea, podem afetar estruturas nervosas superiores, sendo considerados, como já apresentado, neurotóxicos (Campo et al., 2014).

Pesquisas têm buscado a profilaxia de situações inevitavelmente ototóxicas, por meio da aplicação de drogas de recuperação, por diversas vias e sistemas (Kilic et al., 2018, Guo et al., 2018, Sheehan et al., 2018) e a busca de mecanismos de compensação dos agravos já estabelecidos (Zhou et al., 2018). Porém, ainda é muito presente e relevante nesse meio a necessidade de orientação e educação da população, por meio de estratégias, diretrizes e guias bem definidos que possam socializar informações promotoras de saúde e 
preventivas de agravos à saúde (Maru e Malky, 2018), pois muitos trabalhadores não possuem conhecimento sobre inúmeros riscos aos quais estão expostos em suas profissões, bem como, subestimam a importância dos equipamentos e dispositivos de proteção em sua atuação profissional (Dias e Marcolino, 2016).

Um dos grandes desafios enfrentados no tratamento das perdas auditivas é a baixa eficácia das medidas terapêuticas conhecidas. Diversas estratégias baseadas em novas formulações químicas com base protetiva e regenerativa têm sido estudadas, bem como, a mimetização de processos naturais, como a regeneração celular observada em animais como o peixezebra (Ou et al., 2010). Assim, têm-se buscado opções, como a administração de drogas transtimpânicas como a $[\mathrm{R}]-\mathrm{N}$-fenil isopropil adenosina, que pode apresentar efeito protetivo para a cóclea durante a aplicação de tratamento quimioterápico baseado em cisplatina (Sheekan et al., 2018).

O tolueno, como destacado, pode ser considerado um elemento químico ototóxico, pois, apresenta potencial para lesionar células ciliadas externas na região média da cóclea. Também é relatada uma possível interação com ruído. O xileno e etilbenzeno também podem ser considerados como potencialmente ototóxicos. Sobre o benzeno, ainda não é possível concluir se é, de fato, ototóxico, ou não (Silva et al., 2018). Também foram levantadas hipóteses de influência sobre o processamento auditivo para indivíduos expostos a elementos como o próprio tolueno ou o xileno (Fuente e McPherson, 2007; Fuente, 2010). 
Os efeitos da ototóxicidade podem resultar em lesões progressivas, destruindo células sensoriais cocleares e vestibulares, afetando a audição e o equilíbrio (Prasher et al., 2002). 


\section{MÉTODOS}

O projeto recebeu aprovação da Comissão de Ética em Pesquisa da Faculdade de Medicina da Universidade de São Paulo (CEP-FMUSP), sob no CAAE 68181217.0.0000.0065 (Anexo A).

\subsection{Casuística}

Todos os participantes leram, concordaram e assinaram o Termo de Consentimento Livre e Esclarecido (TCLE) (Anexo B).

Participaram da pesquisa, 54 indivíduos, divididos em três grupos:

- Grupo Químicos: 18 trabalhadores expostos a produtos químicos;

- Grupo Ruído: 18 trabalhadores expostos a ruído intenso;

- Grupo Controle: 18 trabalhadores não expostos a produtos químicos ou a ruído.

Esta seleção foi realizada com base no Programa de Prevenção de Riscos Ambientais (PPRA), elaborado pelo Serviço Especializado em Engenharia de Segurança e Medicina do Trabalho (SESMT) da Universidade de São Paulo (USP) que descreve os riscos a que cada trabalhador é exposto em sua jornada de trabalho e nas anamneses realizadas nos exames periódicos realizados no Ambulatório de Audiologia do Hospital Universitário (HU) da USP.

De forma geral, os indivíduos que compõem o Grupo Químicos estão expostos, em sua maioria, aos agentes químicos: ácidos orgânicos e inorgânicos, fenol, cetonas, n-hexano e dimetilformamida. Já os indivíduos do 
Grupo Ruído estão expostos a ruído acima de 85 dBA, durante sua jornada de trabalho.

\subsection{Critérios de inclusão}

Foram incluídos na pesquisa os participantes que se enquadraram nos seguintes critérios:

- Ausência de cerúmen em excesso e de alteração de orelha média;

- Faixa-etária entre 18 e 55 anos;

- Apresentar exposição a produtos químicos há mais de um ano, mas não ter exposição a ruído (Grupo Químicos); apresentar exposição a ruído há mais de um ano, mas não ter exposição a químicos (Grupo Ruído); não apresentar exposição a produtos químicos ou a ruído (Grupo Controle). Deve-se ressaltar que este tempo de exposição foi definido por ser o intervalo de tempo utilizado entre os exames periódicos de funcionários expostos a quaisquer riscos ocupacionais.

\subsection{Procedimentos}

\subsubsection{Dados de exposição a riscos ocupacionais}

Com base no PPRA da USP, foram levantados os produtos químicos e/ou os níveis de ruído aos quais os trabalhadores são expostos. Informações sobre a exposição e dados adicionais sobre o histórico ocupacional e de saúde foram obtidos por meio de anamneses, tanto a específica da pesquisa (Anexo C), quanto a utilizada rotineiramente no serviço do Hospital Universitário. 


\subsubsection{Avaliação audiológica}

Foram realizados os seguintes procedimentos:

a) Meatoscopia: buscou-se verificar as condições do meato acústico externo, garantindo condições adequadas para a realização dos outros procedimentos. Foi utilizado otoscópio Welch Allyn. Os indivíduos foram orientados a permanecer imóveis enquanto o pesquisador investigava as condições citadas, por meio da introdução de um espéculo acoplado ao aparelho emissor de fonte luminosa na porção inicial do meato acústico externo;

b) Imitanciometria: curva timpanométrica e pesquisa dos reflexos acústicos ipsilaterais, a fim de verificar a existência, ou não, de alterações na orelha média. Foi utilizado equipamento $A T 235 h^{\circledR}$ (Interacoustic). Os indivíduos foram orientados a permanecer em repouso, enquanto uma sonda foi posicionada na porção inicial do meato acústico externo, sendo informado que sentiria uma pressão na orelha $(+200 \mathrm{daPa}$ a $-200 \mathrm{daPa})$ e ouviria alguns sons de diversas intensidades, sem a necessidade de responder aos estímulos (de 70 até $110 \mathrm{dBNA}$ );

c) Audiometria tonal por via aérea convencional: pesquisou-se o limiar auditivo (em dBNA) nas frequências de 250, 500, 1.000, 2.000, 3.000, $4.000,6.000$ e $8.000 \mathrm{~Hz}$; e, se necessário, foi realizada audiometria tonal por via óssea nas frequências de 500,1.000, $2.000,3.000$ e $4.000 \mathrm{~Hz}$, em caso de constatação de limiares auditivos com valores maiores ou iguais a 20dBNA na via aérea, nas frequências especificadas. Foram utilizados para 
os exames de audiometria tonal por via aérea e via óssea, os audiômetros AC-40®/Interacoustic e Itera II /Madsen/Otometrics, com fones TDH 39P® Telephonics para via aérea e Radiogear $\mathrm{B} 71 \AA$ para via óssea. Os indivíduos foram posicionados em cabina acústica, solicitando-se que pressionassem o botão de resposta sempre que ouvissem o estímulo sonoro proveniente do fone posicionado em suas orelhas, ou, cabeça, pelo pesquisador. Foi utilizado o critério de classificação de limiares auditivos proposto pela Organização Mundial de Saúde (OMS, 2014).

d) Audiometria tonal de altas frequências: pesquisou-se também os limiares auditivos (em dBNA) nas frequências de 9.000, 10.000, 11.200, 12.500, 14.000 e $16.000 \mathrm{~Hz}$. Foi utilizado o audiômetro Itera $\| \circledast /$ Madsen/Otometrics com fone supra aural Sennheiser HDA $200 \AA$. O procedimento utilizado foi 0 mesmo descrito para a audiometria tonal convencional;

e) Logoaudiometria: buscou-se determinar o "Limiar de Reconhecimento de Fala" (LRF) e "Índice Percentual de Reconhecimento de Fala" (IPRF). Foram utilizados os audiômetros AC- $40 \AA /$ Interacoustic e Itera $\| \circledast /$ Madsen/Otometrics, com fones TDH 39P $\AA$ Telephonics. Os indivíduos, posicionados dentro da cabina acústica, com fone posicionado pelo pesquisador, foram instruídos a repetir as palavras ouvidas, da maneira como entendessem. Para o LRF, foram utilizados trissílabos e polissílabos e, para o IPRF, monossílabos e, se necessário, dissílabos. Todas as palavras foram extraídas da lista de vocábulos propostos por Santos e Russo (1991). 
f) Emissões Otoacústicas Evocadas por estímulo transiente (EOAT): os indivíduos foram posicionados em ambiente silencioso, sendo então realizada a introdução de uma oliva na porção inicial do meato acústico externo, sendo apresentado estímulo tipo clique não linear em intensidade de $80 \mathrm{dBNPS}$. As respostas foram consideradas presentes quando a relação Sinal/Ruído foi maior que 6dBNPS (Dhar e Hall, 2012). Foi utilizado o equipamento DPEchoport ILO292 Otodynamics, acoplado a um notebook Toshiba Satellite modelo 410CDT. Os indivíduos foram orientados que escutariam alguns sons fracos, devendo permanecer em repouso.

g) Emissões Otoacústicas Evocadas por produto de distorção (EOAPD): os indivíduos foram posicionados em ambiente silencioso, sendo então realizada a introdução de uma oliva na porção inicial do meato acústico externo, sendo apresentadas duas frequências diferentes em uma relação que possibilitasse que f1/f2 $=1,2$ e mantida a intensidade de 65 dBNPS para f1 e 55dBNPS para f2. As respostas foram consideradas presentes quando a relação Sinal/Ruído foi maior que 3dBNPS em relação ao segundo desvio padrão de ruído de fundo (Gorga et al., 1997), nas frequências de f2 1001, 1501, 2002, 3003, 4004, 5005, $6006 \mathrm{~Hz}$. Foi utilizado o equipamento DPEchoport ILO292 Otodynamics, acoplado a um notebook Toshiba Satellite modelo 410CDT. Os indivíduos foram orientados que escutariam alguns sons fracos, devendo permanecer em repouso.

h) Efeito inibitório da via auditiva eferente (para EOAT): para os indivíduos que apresentassem EOAT presentes, foi pesquisado o efeito inibitório da via auditiva eferente pelo próprio protocolo do ILO 292. Para isso, foram 
apresentados estímulos do tipo clique lineares a 60 dBNPS, na presença e ausência de ruído White Noise a 60 dBNPS com intervalos de 10 segundos entre cada um deles. Para o cálculo do efeito inibitório, os resultados das EOAT na ausência e presença de ruído foram transformados em microPascal $(\mu \mathrm{Pa})$ e, em seguida, foi obtida a diferença entre as emissões nestas duas situações. Foi considerada como presença do efeito inibitório da via auditiva eferente diferenças que resultaram em valores positivos (Ryan e Kemp, 1996). Além disso, foi calculada a porcentagem deste efeito inibitório. Uma vez que existe uma vantagem da orelha direita sobre a esquerda no que se refere ao efeito inibitório da via eferente, já descrita na literatura (Bidelman e Bhagat, 2015), considerou-se apenas os resultados da orelha direita para esta análise.

i) Teste SSW (Staggered Spondaic Word): avalia as habilidades auditivas de figura-fundo para sons verbais e memória auditiva, entre outras. Para a realização do teste, foi utilizado 0 audiômetro modelo Itera II@/Madsen/Otometrics, com fones TDH-39. Foi conectado ao audiômetro um notebook com o CD do teste. $O$ teste é composto por quarenta sequências de quatro palavras dissílabas, que são apresentadas nas condições de orelha direita não competitiva (DNC), direita competitiva (DC), esquerda competitiva (EC) e esquerda não competitiva (ENC). A intensidade utilizada foi de 50 dBNS acima do LRF para cada orelha. Foi solicitado aos indivíduos que repetissem as palavras na ordem em que ouviram. O resultado do teste é dado em porcentagem de acertos em DC e EC (Pereira e Schochat, 2011). 


\subsection{Análise estatística}

Foram realizadas análises descritivas dos dados, obtendo-se os valores de média, mediana e desvio-padrão, bem como, testes de hipótese.

Para as análises realizadas com variáveis categóricas, os grupos foram comparados por meio da aplicação do teste qui-quadrado de homogeneidade (Bussab e Morettin, 2017).

As médias das variáveis idade e tempo na função foram comparadas entre os grupos por meio da aplicação da técnica de ANOVA com um fator fixo (grupo).

Foram apresentadas medidas descritivas para as variáveis limiar auditivo, intensidade das emissões otoacústicas, intensidade do efeito inibitório da via auditiva eferente e escores do teste SSW. Inicialmente, para cada uma dessas variáveis foi ajustado um modelo misto normal, em que o efeito do indivíduo foi considerado aleatório e os efeitos de grupo e orelha foram considerados fixos (Pinheiros e Bates, 2002). Para cada modelo, foi realizada uma análise de diagnóstico que mostrou que o mesmo não estava bem ajustado (Nobre e Singer, 2007). Como a distribuição dessas variáveis não mostrou seguir uma distribuição normal, suas médias foram comparadas entre os três grupos, por meio da aplicação do teste não paramétrico de KruskalWallis (Conover, 1971).

Adotou-se, para cada teste de hipótese realizado, um nível de significância de $5 \%$. 


\section{RESULTADOS}

\subsection{Caracterização da amostra}

Participaram da pesquisa 54 indivíduos, sendo divididos igualmente entre os grupos Químicos, Ruído e Controle.

A Tabela 1 apresenta a distribuição da amostra em relação ao sexo dos indivíduos participantes. Verificou-se que não há evidência de que a proporção populacional de cada sexo difira entre os três grupos (valor- $\mathrm{p}=0,381$ ).

Tabela 1 - Distribuição da amostra em valores absolutos e percentuais em relação à variável "Sexo" por grupo (porcentagens calculadas por grupo) e valor-p

\begin{tabular}{lllll}
\hline Grupo & \multicolumn{2}{c}{ Feminino } & \multicolumn{2}{c}{ Masculino } \\
& $\mathbf{n}$ & $\%$ & $\mathbf{n}$ & $\%$ \\
\hline Controle & 10 & 55,6 & 8 & 44,4 \\
Químicos & 11 & 61,1 & 7 & 38,9 \\
Ruído & 7 & 38,9 & 11 & 61,1 \\
valor-p $=0,381$ & & & \\
\hline
\end{tabular}

Teste qui-quadrado de homogeneidade.

Legenda: $\mathrm{n}$ = número absoluto; \% = porcentagem

As tabelas 2 e 3 apresentam, respectivamente, as medidas descritivas da idade e do tempo na função dos indivíduos participantes. 
Tabela 2 - Distribuição da amostra em números absolutos, média, desvio padrão, valores mínimos, máximos e mediana em relação à variável "Idade" por grupo e valor-p

\begin{tabular}{cccccccc}
\hline Grupo & n & Média & $\begin{array}{c}\text { Desvio } \\
\text { padrão }\end{array}$ & Mínimo & Mediana & Máximo & valor-p \\
\hline Controle & 18 & 40,7 & 7,1 & 30 & 39,5 & 54 & \\
Químicos & 18 & 40,9 & 6,6 & 30 & 40,0 & 53 & 0,659 \\
Ruído & 18 & 42,4 & 5,2 & 32 & 42,0 & 54 & \\
\hline
\end{tabular}

Teste ANOVA

Legenda: $\mathrm{n}=$ número absoluto

Tabela 3 - Distribuição da amostra em números absolutos, média, desvio padrão, valores mínimo, máximos e mediana em relação à variável "Tempo na função" (em meses) por grupo e valor-p

\begin{tabular}{lccccccc}
\hline \multicolumn{1}{c}{ Grupo } & n & Média & $\begin{array}{c}\text { Desvio } \\
\text { padrão }\end{array}$ & Mínimo & Mediana & Máximo & valor-p \\
\hline Controle & 18 & 114,0 & 91,9 & 2 & 97,0 & 375 & \\
Químicos & 18 & 156,2 & 75,9 & 20 & 146,5 & 290 & 0,157 \\
Ruído & 18 & 163,9 & 77,8 & 61 & 154,0 & 357 & \\
\hline
\end{tabular}

Teste ANOVA

Legenda: $\mathrm{n}=$ número absoluto 
Observando-se as Tabelas 2 e 3, verificou-se que não há evidência de que as médias populacionais difiram entre os três grupos (valores-p iguais a 0,659 e 0,157 , respectivamente), ou seja, não há diferença estatisticamente significante em relação à idade ou ao tempo na função entre os grupos.

A Tabela 4 apresenta a distribuição da amostra em relação à utilização de equipamentos de proteção. Verifica-se que há diferença estatisticamente significante entre a proporção populacional de indivíduos que usam equipamento de proteção nos grupos Químicos e Ruído (valor-p < 0,001), sendo que 100,0\% dos indivíduos do grupo Químicos usam equipamento de proteção, enquanto que, no grupo Ruído, essa porcentagem é de apenas $38,9 \%$.

Tabela 4 - Distribuição da amostra em números absolutos e percentuais em relação à variável "Utilização de Equipamento de Proteção" e valor-p para os grupos Químicos e Ruído

\begin{tabular}{lcccc}
\hline & \multicolumn{3}{c}{ Equipamentos de proteção } \\
Grupo & Não usa & \multicolumn{2}{c}{ Usa } \\
& $\mathbf{n}$ & $\%$ & $\mathbf{n}$ & $\%$ \\
\hline Químicos & 0 & 0,0 & 18 & 100,0 \\
Ruído & 11 & 61,1 & 7 & 38,9 \\
valor-p $<0,001$ & & & \\
\hline
\end{tabular}

Teste qui-quadrado de homogeneidade

Legenda: $n$ = número absoluto; \% = porcentagem

\subsection{Queixas referidas}

A Tabela 5 apresenta a distribuição da amostra em relação à frequência de classe de produtos químicos utilizadas pelos indivíduos do grupo Químicos. 
Nota-se que $100,0 \%$ dos indivíduos usam solventes e mais da metade deles são expostos a mais de um produto químico, simultaneamente.

Tabela 5 - Distribuição da amostra em números absolutos e percentuais em relação à variável "Classe de produtos químicos utilizados"

\begin{tabular}{ccccccc}
\hline \multirow{2}{*}{ Categoria } & \multicolumn{2}{c}{ Metais } & \multicolumn{2}{c}{ Solventes } & \multicolumn{2}{c}{ Asfixiantes } \\
& $\mathbf{n}$ & $\%$ & $\mathbf{n}$ & $\%$ & $\mathbf{n}$ & $\%$ \\
\hline Não usa & 7 & 38,9 & 0 & 0,0 & 16 & 88,9 \\
Usa & 11 & 61,1 & 18 & 100,0 & 2 & 11,1 \\
\hline
\end{tabular}

Legenda: $\mathrm{n}=$ número absoluto; \% = porcentagem

A Tabela 6 apresenta a distribuição da amostra em relação à frequência de ocorrência de zumbido por grupo, e, a Tabela 7, a distribuição em relação ao lado referido de ocorrência do zumbido.

Tabela 6 - Distribuição da amostra em números absolutos e percentuais em relação à variável "Zumbido" por grupo (porcentagens calculadas por grupo) e valor-p.

\begin{tabular}{lllll} 
Grupo & \multicolumn{2}{c}{ Não } & \multicolumn{2}{c}{ Sim } \\
& $\mathbf{n}$ & $\%$ & $\mathbf{n}$ & $\%$ \\
\hline Controle & 15 & 83,3 & 3 & 16,7 \\
Químicos & 13 & 72,2 & 5 & 27,8 \\
Ruído & 15 & 83,3 & 3 & 16,7 \\
valor-p $=0,633$ & & &
\end{tabular}

Teste qui-quadrado de homogeneidade

Legenda: $\mathrm{n}$ = número absoluto; \% = porcentagem 
Tabela 7 - Distribuição da amostra em números absolutos e percentuais em relação à variável "Lado referido do zumbido".

\begin{tabular}{|c|c|c|c|c|c|c|c|c|}
\hline \multirow[t]{2}{*}{ Grupo } & \multicolumn{2}{|c|}{ Ambos } & \multicolumn{2}{|c|}{ Direito } & \multicolumn{2}{|c|}{ Esquerdo } & \multicolumn{2}{|r|}{ Não sabe } \\
\hline & $n$ & $\%$ & $\mathbf{n}$ & $\%$ & $\mathrm{n}$ & $\%$ & & n \% \\
\hline Controle & 1 & 33,3 & 1 & 33,3 & 0 & 0,0 & 1 & 33,3 \\
\hline Químicos & 3 & 60,0 & 1 & 20,0 & 0 & 0,0 & 1 & 20,0 \\
\hline Ruído & 2 & 67,7 & 1 & 33,3 & 0 & 0,0 & 0 & 0,0 \\
\hline
\end{tabular}

Legenda: $\mathrm{n}$ = número absoluto; \% = porcentagem

Pela Tabela 6, nota-se que mais de $70 \%$ dos indivíduos de cada grupo não apresentam zumbido, sendo que a proporção de indivíduos com zumbido não difere entre os três grupos (valor-p $=0,633$ ). Entre os indivíduos que apresentam zumbido, a Tabela 7 mostra que ninguém fez referência ao zumbido do lado esquerdo, estando distribuídos entre o lado direito ou em ambas as orelhas.

Em relação à ocorrência de queixas de tontura por grupo (Tabela 8) e a ocorrência de tonturas em relação ao seu tipo (rotatória e não rotatória) (Tabela 9), nota-se que não há evidência de diferença entre os três grupos (valor-p = $0,122)$ e, para os indivíduos que apresentam tontura, a maioria refere tontura não rotatória. 
Tabela 8 - Distribuição da amostra em números absolutos e percentuais em relação à variável "Ocorrência de tonturas" por grupo (porcentagens calculadas por grupo) e valor-p

\begin{tabular}{llllll}
\hline \multicolumn{1}{c}{ Grupo } & \multicolumn{2}{c}{ Não } & \multicolumn{2}{c}{ Sim } \\
& $\mathbf{n}$ & $\%$ & $\mathbf{n}$ & $\%$ \\
\hline Controle & 11 & 61,1 & 7 & 38,9 \\
Químicos & 8 & 44,4 & 10 & 55,6 \\
Ruído & 14 & 77,8 & 4 & 22,2 \\
valor-p $=0,122$ & & & \\
\hline
\end{tabular}

Teste qui-quadrado de homogeneidade

Legenda: $\mathrm{n}=$ número absoluto; \% = porcentagem

Tabela 9 - Distribuição da amostra em números absolutos e percentuais em relação à variável "Tipo de tontura" por grupo (porcentagens calculadas por grupo)

\section{Grupo Não rotatória Rotatória}

\begin{tabular}{lllll}
\hline & $\mathrm{n}$ & $\%$ & $\mathrm{n}$ & $\%$ \\
Controle & 5 & 71,4 & 2 & 28,6 \\
Químicos & 6 & 60,0 & 4 & 40,0 \\
Ruído & 2 & 50,0 & 2 & 50,0 \\
\hline
\end{tabular}

Legenda: $\mathrm{n}=$ número absoluto; $\%$ = porcentagem

\subsection{Audiometria}

A figura 1, e, as Tabelas 10 e 11, apresentam as medidas descritivas em relação aos valores dos limiares auditivos obtidos na audiometria tonal e a comparação entre os grupos para as frequências de $250-8.000 \mathrm{~Hz}$ (audiometria convencional) e de $9.000-16.000 \mathrm{~Hz}$ (audiometria de altas frequências). 
Figura 1 - Gráfico de distribuição da amostra em relação ao valor das médias dos limiares auditivos (dBNA) para audiometria convencional e audiometria de altas frequências $(250-16.000 \mathrm{~Hz})$.

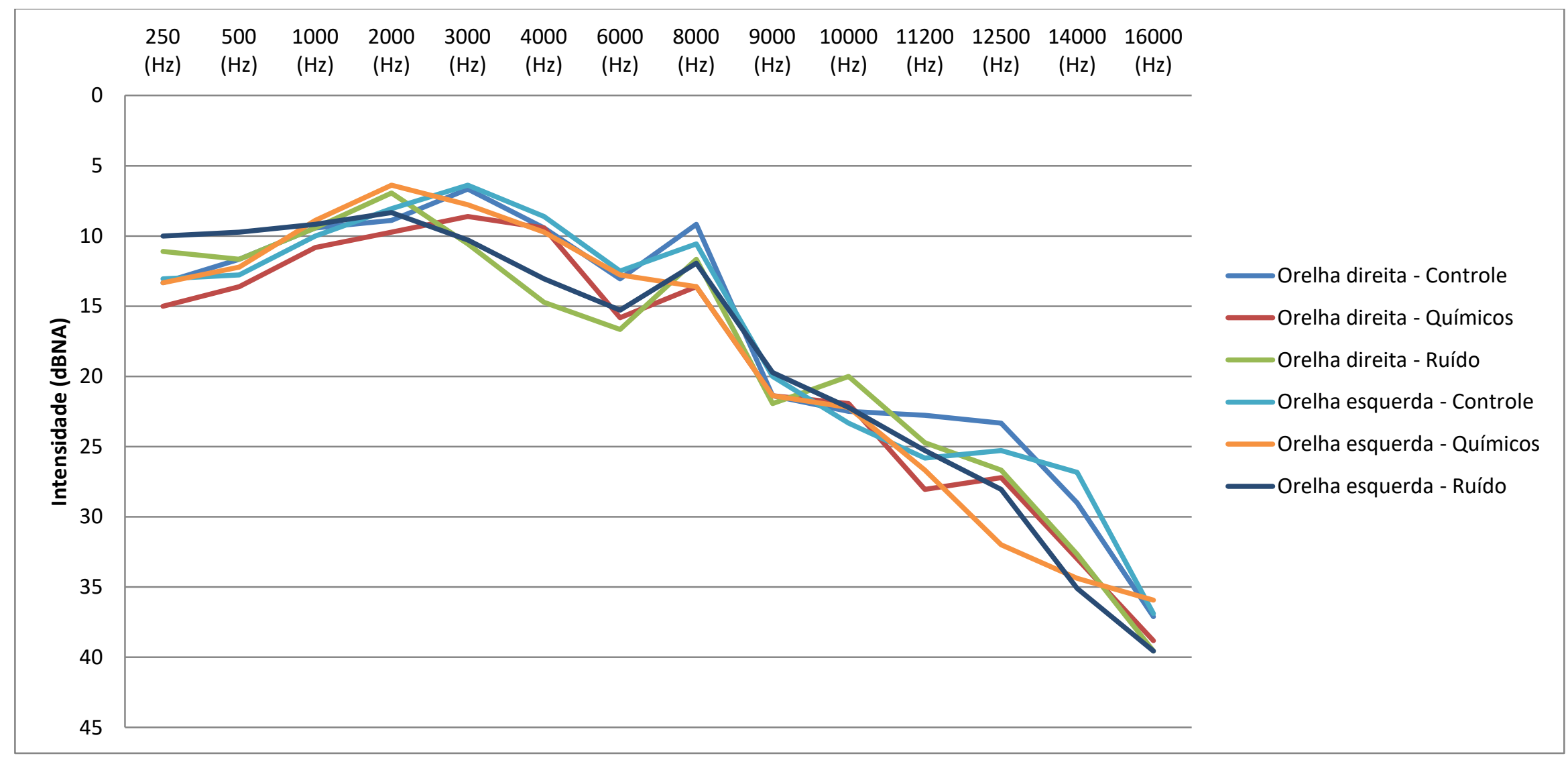


Tabela 10 - Média, desvio padrão, valores mínimos, máximos e medianas em relação à variável "Limiares auditivos (dBNA)" e análise comparativa entre os grupos, valor-p

\begin{tabular}{|c|c|c|c|c|c|c|c|c|c|}
\hline Freq & Orelha & Grupo & $\mathbf{n}$ & Média & DP & Mínimo & Mediana & Máximo & Valor-p \\
\hline \multirow{6}{*}{250} & \multirow{3}{*}{ Direita } & Controle & 18 & 13,33 & 5,14 & 5,00 & 15,00 & 25,00 & \multirow{3}{*}{0,332} \\
\hline & & Químicos & 18 & 15,00 & 8,22 & 5,00 & 15,00 & 40,00 & \\
\hline & & Ruído & 18 & 11,11 & 5,02 & 5,00 & 12,50 & 20,00 & \\
\hline & \multirow{3}{*}{ Esquerda } & Controle & 18 & 13,06 & 5,18 & 5,00 & 15,00 & 20,00 & \multirow{3}{*}{0,171} \\
\hline & & Químicos & 18 & 13,33 & 5,94 & 0,00 & 10,00 & 25,00 & \\
\hline & & Ruído & 18 & 10,00 & 4,85 & 0,00 & 10,00 & 15,00 & \\
\hline \multirow{6}{*}{500} & \multirow{3}{*}{ Direita } & Controle & 18 & 11,67 & 5,42 & 5,00 & 10,00 & 20,00 & \multirow{3}{*}{0,719} \\
\hline & & Químicos & 18 & 13,61 & 6,82 & 5,00 & 12,50 & 35,00 & \\
\hline & & Ruído & 18 & 11,67 & 4,85 & 5,00 & 10,00 & 20,00 & \\
\hline & \multirow{3}{*}{ Esquerda } & Controle & 18 & 12,78 & 5,75 & 5,00 & 15,00 & 25,00 & \multirow{3}{*}{0,247} \\
\hline & & Químicos & 18 & 12,22 & 5,48 & 0,00 & 10,00 & 25,00 & \\
\hline & & Ruído & 18 & 9,72 & 5,28 & 0,00 & 10,00 & 20,00 & \\
\hline \multirow{6}{*}{1000} & \multirow{3}{*}{ Direita } & Controle & 18 & 9,44 & 5,39 & 0,00 & 10,00 & 20,00 & \multirow{3}{*}{0,804} \\
\hline & & Químicos & 18 & 10,83 & 7,12 & 0,00 & 10,00 & 30,00 & \\
\hline & & Ruído & 18 & 9,44 & 6,16 & 0,00 & 10,00 & 25,00 & \\
\hline & \multirow{3}{*}{ Esquerda } & Controle & 18 & 10,00 & 7,07 & 0,00 & 10,00 & 30,00 & \multirow{3}{*}{0,953} \\
\hline & & Químicos & 18 & 8,89 & 5,83 & 0,00 & 10,00 & 20,00 & \\
\hline & & Ruído & 18 & 9,17 & 4,93 & 0,00 & 10,00 & 20,00 & \\
\hline \multirow{6}{*}{2000} & \multirow{3}{*}{ Direita } & Controle & 18 & 8,89 & 7,19 & 0,00 & 10,00 & 25,00 & \multirow{3}{*}{0,253} \\
\hline & & Químicos & 18 & 9,72 & 4,99 & 5,00 & 10,00 & 20,00 & \\
\hline & & Ruído & 18 & 6,94 & 6,22 & 0,00 & 5,00 & 20,00 & \\
\hline & \multirow{3}{*}{ Esquerda } & Controle & 18 & 8,06 & 7,70 & 0,00 & 5,00 & 25,00 & \multirow{3}{*}{0,488} \\
\hline & & Químicos & 18 & 6,39 & 6,37 & 0,00 & 5,00 & 20,00 & \\
\hline & & Ruído & 18 & 8,33 & 5,42 & 0,00 & 7,50 & 20,00 & \\
\hline & & Controle & 18 & 6,67 & 7,28 & 0,00 & 5,00 & 25,00 & \\
\hline & Direita & Químicos & 18 & 8,61 & 6,37 & $-5,00$ & 5,00 & 20,00 & 0,143 \\
\hline & & Ruído & 18 & 10,56 & 6,84 & 5,00 & 7,50 & 25,00 & \\
\hline 3000 & & Controle & 18 & 6,39 & 7,82 & 0,00 & 5,00 & 30,00 & \\
\hline & Esquerda & Químicos & 18 & 7.78 & 6.24 & 0.00 & 7.50 & 20,00 & 0.088 \\
\hline & & Ruído & 18 & 10,28 & 5,81 & 0,00 & 10,00 & 20,00 & \\
\hline & & Controle & 18 & 9,44 & 9,68 & 0,00 & 7,50 & 35,00 & \\
\hline & Direita & Químicos & 18 & 9,44 & 6,16 & 0,00 & 10,00 & 20,00 & 0,159 \\
\hline 1000 & & Ruído & 18 & 14,72 & 9,47 & 5,00 & 15,00 & 35,00 & \\
\hline 4000 & & Controle & 18 & 8,61 & 9,04 & $-5,00$ & 5,00 & 30,00 & \\
\hline & Esquerda & Químicos & 18 & 9.72 & 8.82 & 0.00 & 10.00 & 35,00 & 0.244 \\
\hline & & Ruído & 18 & 13,06 & 9,72 & $-5,00$ & 12,50 & 35,00 & \\
\hline & & Controle & 18 & 13,06 & 5,72 & 5,00 & 10,00 & 25,00 & \\
\hline & Direita & Químicos & 18 & 15,83 & 9,12 & 0,00 & 15,00 & 35,00 & 0,400 \\
\hline cono & & Ruído & 18 & 16,67 & 8,40 & 5,00 & 15,00 & 35,00 & \\
\hline 6000 & & Controle & 18 & 12,50 & 8,95 & 0,00 & 10,00 & 25,00 & \\
\hline & Esquerda & Químicos & 18 & 12,78 & 8,61 & 0,00 & 10,00 & 35,00 & 0,550 \\
\hline & & Ruído & 18 & 15,28 & 9,15 & 0,00 & 15,00 & 30,00 & \\
\hline & & Controle & 18 & 9,17 & 6,00 & 0,00 & 10,00 & 20,00 & \\
\hline & Direita & Químicos & 18 & 13,61 & 10,26 & 0,00 & 10,00 & 45,00 & 0,450 \\
\hline 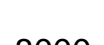 & & Ruído & 18 & 11,67 & 12.95 & $-5,00$ & 10,00 & 45,00 & \\
\hline 8000 & & Controle & 18 & 10,56 & 7,84 & 0,00 & 10,00 & 30,00 & \\
\hline & Esquerda & Químicos & 18 & 13,61 & 7,44 & 0,00 & 15,00 & 30,00 & 0,398 \\
\hline & & Ruído & 18 & 11,94 & 8,60 & $-5,00$ & 15,00 & 25,00 & \\
\hline
\end{tabular}

Teste de Kruskal-Walls

Legenda: Freq = frequência $(\mathrm{em} \mathrm{Hz}) ; \mathrm{n}=$ número absoluto; $\mathrm{DP}=$ desvio padrão 
Tabela 11 - Média, desvio padrão, valores mínimos, máximos e medianas em relação à variável "Limiares auditivos (dBNA) (altas frequências)" e análise comparativa entre os grupos, valor-p

\begin{tabular}{|c|c|c|c|c|c|c|c|c|c|}
\hline Freq & Lado & Grupo & $n$ & Média & DP & Mín & Mediana & Máx & Valor-p \\
\hline \multirow{6}{*}{9000} & \multirow{3}{*}{ D } & Controle & 18 & 21,39 & 10,26 & 5,00 & 20,00 & 40,00 & 0,931 \\
\hline & & Químicos & 18 & 21,39 & 12,70 & 5,00 & 20,00 & 55,00 & \\
\hline & & Ruído & 18 & 21,94 & 16,28 & 5,00 & 15,00 & 70,00 & \\
\hline & \multirow{3}{*}{ E } & Controle & 18 & 20,00 & 13,39 & 5,00 & 15,00 & 45,00 & 0,748 \\
\hline & & Químicos & 18 & 21,39 & 12,70 & 0,00 & 20,00 & 60,00 & \\
\hline & & Ruído & 18 & 19,72 & 13,88 & 5,00 & 17,50 & 50,00 & \\
\hline \multirow{6}{*}{10000} & \multirow{3}{*}{ D } & Controle & 18 & 22,50 & 11,54 & 5,00 & 20,00 & 45,00 & \\
\hline & & Químicos & 18 & 21,94 & 15,82 & 0,00 & 20,00 & 65,00 & 0,592 \\
\hline & & Ruído & 18 & 20,00 & 16,98 & 0,00 & 17,50 & 70,00 & \\
\hline & \multirow{3}{*}{ E } & Controle & 18 & 23,33 & 18,55 & 5,00 & 15,00 & 65,00 & \\
\hline & & Químicos & 18 & 22,22 & 14,06 & 0,00 & 25,00 & 65,00 & 0,877 \\
\hline & & Ruído & 18 & 22,22 & 15,92 & 0,00 & 20,00 & 65,00 & \\
\hline \multirow{6}{*}{11200} & \multirow{3}{*}{ D } & Controle & 18 & 22,78 & 17,92 & 0,00 & 17,50 & 70,00 & \\
\hline & & Químicos & 18 & 28,06 & 18,56 & 0,00 & 25,00 & 75,00 & 0,562 \\
\hline & & Ruído & 18 & 24,72 & 18,27 & 0,00 & 20,00 & 70,00 & \\
\hline & \multirow{3}{*}{ E } & Controle & 18 & 25,83 & 19,19 & 5,00 & 20,00 & 80,00 & \\
\hline & & Químicos & 18 & 26,67 & 16,54 & 0,00 & 25,00 & 70,00 & 0,791 \\
\hline & & Ruído & 18 & 25,28 & 17,36 & 5,00 & 22,50 & 70,00 & \\
\hline \multirow{6}{*}{12500} & \multirow{3}{*}{ D } & Controle & 18 & 23,33 & 19,02 & 0,00 & 17,50 & 75,00 & \\
\hline & & Químicos & 18 & 27,22 & 22,96 & $-10,00$ & 25,00 & 70,00 & 0,866 \\
\hline & & Ruído & 18 & 26,67 & 22,88 & 0,00 & 25,00 & 75,00 & \\
\hline & \multirow{3}{*}{ E } & Controle & 18 & 25,28 & 21,38 & 0,00 & 20,00 & 80,00 & \\
\hline & & Químicos & 18 & 32,00 & 23,01 & 0,00 & 35,00 & 81,00 & 0,593 \\
\hline & & Ruído & 18 & 28,06 & 21,29 & 0,00 & 25,00 & 80,00 & \\
\hline \multirow{6}{*}{14000} & \multirow{3}{*}{$D$} & Controle & 18 & 29,00 & 22,30 & 0,00 & 25,00 & 61,00 & \\
\hline & & Químicos & 18 & 33,00 & 26,77 & $-10,00$ & 50,00 & 61,00 & 0,852 \\
\hline & & Ruído & 18 & 32,67 & 20,48 & 0,00 & 35,00 & 61,00 & \\
\hline & \multirow{3}{*}{$E$} & Controle & 18 & 26,83 & 21,90 & 0,00 & 20,00 & 61,00 & \\
\hline & & Químicos & 18 & 34,39 & 25,41 & $-5,00$ & 37,50 & 61,00 & 0,507 \\
\hline & & Ruído & 18 & 35,11 & 17,91 & 0,00 & 40,00 & 61,00 & \\
\hline \multirow{6}{*}{16000} & \multirow{3}{*}{$D$} & Controle & 18 & 37,11 & 18,26 & 0,00 & 45,00 & 51,00 & \\
\hline & & Químicos & 18 & 38,83 & 16,39 & 0,00 & 48,00 & 51,00 & 0,949 \\
\hline & & Ruído & 18 & 39,56 & 16,66 & 0,00 & 50,00 & 51,00 & \\
\hline & \multirow{3}{*}{$E$} & Controle & 18 & 36,89 & 16,87 & 10,00 & 48,00 & 51,00 & \\
\hline & & Químicos & 18 & 35,94 & 19,48 & $-10,00$ & 45,00 & 51,00 & 0,928 \\
\hline & & Ruído & 18 & 39,56 & 15,37 & 5,00 & 45,00 & 51,00 & \\
\hline
\end{tabular}

Teste de Kruskal-Walls

Legenda: Freq = frequência $(\mathrm{em} \mathrm{Hz}) ; \mathrm{D}=$ direita; $\mathrm{E}=$ esquerda; $\mathrm{n}=$ número absoluto; DP = desvio padrão; Mín = mínimo; Máx = máximo 
A figura 1, e, as Tabelas 10 e 11, mostram que, para as duas orelhas e, para todas as frequências, não há efeito de grupo (valores-p $\geq 0,088$ ) sobre a média do limiar auditivo.

\subsection{Emissões otoacústicas}

A Tabela 12 apresenta os valores referentes à intensidade das emissões otoacústicas evocadas por produto de distorção nas frequências de 1001, 1257, 1587, 2002 e 2515Hz. A Tabela 13 apresenta análise semelhante, porém, para as frequências de 3174, 4004, 5042 e $6348 \mathrm{~Hz}$. 
Tabela 12 - Média, desvio padrão, valores mínimo, máximo e mediana e análise comparativa entre os grupos em relação à variável "Intensidade das emissões otoacústicas evocadas por produto de distorção (dBNPS)", por frequência e orelha para as frequências de 1001, 1257, 1587, 2002 e 2015Hz, Valor-p.

\begin{tabular}{|c|c|c|c|c|c|c|c|c|c|}
\hline Frequência & Orelha & Grupo & $\mathbf{n}$ & Média & $\begin{array}{l}\text { Desvio } \\
\text { Padrão }\end{array}$ & Mínimo & Mediana & Máximo & Valor-p \\
\hline \multirow{6}{*}{1001} & Direita & Controle & 18 & 1,12 & 9,61 & $-22,00$ & 3,95 & 11,40 & \multirow{3}{*}{0,469} \\
\hline & & Químicos & 18 & 3,84 & 10,10 & $-23,60$ & 7,30 & 17,50 & \\
\hline & & Ruído & 18 & 2,02 & 7,86 & $-14,20$ & 4,05 & 14,10 & \\
\hline & \multirow[t]{3}{*}{ Esquerda } & Controle & 18 & 1,96 & 10,66 & $-30,00$ & 4,80 & 13,10 & \multirow{3}{*}{0,339} \\
\hline & & Químicos & 18 & 1,87 & 10,35 & $-21,70$ & 5,10 & 14,80 & \\
\hline & & Ruído & 18 & $-0,22$ & 7,01 & $-14,00$ & 0,30 & 11,50 & \\
\hline \multirow{6}{*}{1257} & \multirow[t]{3}{*}{ Direita } & Controle & 18 & 4,32 & 6,65 & $-8,60$ & 6,00 & 13,00 & \multirow{3}{*}{0,725} \\
\hline & & Químicos & 18 & 4,50 & 10,71 & $-22,30$ & 9,30 & 18,50 & \\
\hline & & Ruído & 18 & 4,42 & 8,65 & $-11,70$ & 8,25 & 17,40 & \\
\hline & \multirow[t]{3}{*}{ Esquerda } & Controle & 18 & 2,64 & 11,84 & $-41,00$ & 5,40 & 15,00 & \multirow{3}{*}{0,825} \\
\hline & & Químicos & 18 & 3,87 & 8,80 & $-9,10$ & 5,25 & 16,80 & \\
\hline & & Ruído & 18 & 2,42 & 9,31 & $-23,50$ & 3,45 & 15,60 & \\
\hline \multirow{6}{*}{1587} & \multirow[t]{3}{*}{ Direita } & Controle & 18 & 5,62 & 6,62 & $-5,60$ & 7,30 & 15,60 & \multirow{3}{*}{0,697} \\
\hline & & Químicos & 18 & 6,01 & 8,60 & $-16,60$ & 7,75 & 16,40 & \\
\hline & & Ruído & 18 & 2,56 & 12,23 & $-30,00$ & 6,05 & 18,20 & \\
\hline & \multirow[t]{3}{*}{ Esquerda } & Controle & 18 & 3,39 & 10,70 & $-30,00$ & 5,15 & 11,80 & \multirow{3}{*}{0,264} \\
\hline & & Químicos & 18 & 6,70 & 6,87 & $-11,10$ & 8,20 & 16,00 & \\
\hline & & Ruído & 18 & 2,33 & 9,91 & $-21,80$ & 2,75 & 19,40 & \\
\hline \multirow{6}{*}{2002} & \multirow[t]{3}{*}{ Direita } & Controle & 18 & 3,83 & 7,85 & $-13,50$ & 5,10 & 15,00 & \multirow{3}{*}{0,694} \\
\hline & & Químicos & 18 & 4,42 & 7,75 & $-13,10$ & 5,05 & 16,00 & \\
\hline & & Ruído & 18 & 1,87 & 9,82 & $-18,50$ & 5,75 & 11,10 & \\
\hline & \multirow[t]{3}{*}{ Esquerda } & Controle & 18 & 1,11 & 12,04 & $-30,00$ & 1,95 & 15,60 & \multirow{3}{*}{0,170} \\
\hline & & Químicos & 18 & 5,41 & 4,96 & $-1,90$ & 4,95 & 14,90 & \\
\hline & & Ruído & 18 & $-1,58$ & 12,58 & $-37,80$ & 2,35 & 19,10 & \\
\hline \multirow{6}{*}{2515} & \multirow[t]{3}{*}{ Direita } & Controle & 18 & $-0,28$ & 11,60 & $-30,00$ & 3,65 & 14,40 & \multirow{3}{*}{0,777} \\
\hline & & Químicos & 18 & 1,79 & 10,55 & $-30,00$ & 5,30 & 11,40 & \\
\hline & & Ruído & 18 & 0,51 & 9,54 & $-23,70$ & 3,60 & 12,90 & \\
\hline & \multirow[t]{3}{*}{ Esquerda } & Controle & 18 & $-2,08$ & 12,08 & $-30,00$ & $-1,35$ & 14,10 & \multirow{3}{*}{0,160} \\
\hline & & Químicos & 18 & 4,46 & 5,42 & $-6,20$ & 3,90 & 14,40 & \\
\hline & & Ruído & 18 & 1,12 & 7,14 & $-9,30$ & 1,95 & 13,30 & \\
\hline
\end{tabular}

Teste de Kruskal-Wallis

Legenda: Freq = frequência $(\mathrm{em} \mathrm{Hz}), \mathrm{n}=$ número absoluto, $\mathrm{DP}=$ desvio padrão 
Tabela 13 - Média, desvio padrão, valores mínimo, máximo e mediana e análise comparativa entre os grupos em relação à variável "Intensidade das emissões otoacústicas evocadas por produto de distorção (dBNPS)", por frequência e orelha para as frequências de $3174,4004,5042,6348$, Valor-P.

\begin{tabular}{|c|c|c|c|c|c|c|c|c|c|}
\hline Frequência & Orelha & Grupo & $\mathbf{n}$ & Média & $\begin{array}{l}\text { Desvio } \\
\text { Padrão }\end{array}$ & Mínimo & Mediana & Máximo & Valor-p \\
\hline \multirow{6}{*}{3174} & Direita & Controle & 18 & 1,11 & 11,39 & $-30,00$ & 3,40 & 16,60 & \multirow{3}{*}{0,674} \\
\hline & & Químicos & 18 & 3,69 & 7,10 & $-11,40$ & 3,00 & 16,20 & \\
\hline & & Ruído & 18 & $-1,34$ & 12,84 & $-36,70$ & 3,05 & 13,10 & \\
\hline & \multirow[t]{3}{*}{ Esquerda } & Controle & 18 & $-0,86$ & 10,88 & $-30,00$ & $-0,10$ & 13,80 & \multirow{3}{*}{0,080} \\
\hline & & Químicos & 18 & 4,39 & 4,99 & $-6,10$ & 5,10 & 14,10 & \\
\hline & & Ruído & 18 & $-1,95$ & 9,29 & $-30,00$ & $-1,00$ & 11,40 & \\
\hline \multirow{6}{*}{4004} & \multirow[t]{3}{*}{ Direita } & Controle & 18 & 3,21 & 11,03 & $-30,00$ & 5,65 & 18,20 & \multirow{3}{*}{$0,036^{*}$} \\
\hline & & Químicos & 18 & 7,36 & 7,11 & $-6,40$ & 8,85 & 18,70 & \\
\hline & & Ruído & 18 & $-2,88$ & 13,90 & $-30,00$ & 0,20 & 14,90 & \\
\hline & \multirow[t]{3}{*}{ Esquerda } & Controle & 18 & 2,92 & 9,05 & $-17,10$ & 5,45 & 18,40 & \multirow{3}{*}{$0,015^{*}$} \\
\hline & & Químicos & 18 & 7,78 & 6,16 & $-6,40$ & 7,60 & 17,20 & \\
\hline & & Ruído & 18 & 1,07 & 6,98 & $-9,50$ & 0,65 & 13,00 & \\
\hline \multirow{6}{*}{5042} & \multirow[t]{3}{*}{ Direita } & Controle & 18 & 5,55 & 5,20 & $-4,50$ & 5,50 & 15,60 & \multirow{3}{*}{$0,005^{*}$} \\
\hline & & Químicos & 18 & 3,33 & 11,05 & $-30,00$ & 7,10 & 18,70 & \\
\hline & & Ruído & 18 & $-4,62$ & 12,25 & $-30,60$ & $-3,60$ & 17,50 & \\
\hline & \multirow[t]{3}{*}{ Esquerda } & Controle & 18 & 3,87 & 7,52 & $-15,80$ & 4,70 & 17,00 & \multirow{3}{*}{$0,001^{*}$} \\
\hline & & Químicos & 18 & 5,99 & 6,99 & $-15,00$ & 8,50 & 13,70 & \\
\hline & & Ruído & 18 & $-6,93$ & 14,44 & $-30,00$ & $-4,50$ & 16,00 & \\
\hline \multirow{6}{*}{6348} & \multirow[t]{3}{*}{ Direita } & Controle & 18 & $-1,52$ & 8,93 & $-21,30$ & 0,05 & 10,40 & \multirow{3}{*}{0,197} \\
\hline & & Químicos & 18 & $-7,29$ & 14,56 & $-30,00$ & $-7,55$ & 13,00 & \\
\hline & & Ruído & 18 & $-10,22$ & 15,03 & $-30,70$ & $-7,40$ & 15,80 & \\
\hline & \multirow[t]{3}{*}{ Esquerda } & Controle & 18 & $-7,67$ & 13,81 & $-31,00$ & $-4,50$ & 12,70 & \multirow{3}{*}{0,828} \\
\hline & & Químicos & 18 & $-6,90$ & 12,18 & $-30,00$ & $-4,60$ & 10,60 & \\
\hline & & Ruído & 18 & $-9,54$ & 13,28 & $-30,00$ & $-7,90$ & 15,00 & \\
\hline
\end{tabular}

Teste de Kruskal-Wallis

Legenda: Freq = frequência $(\mathrm{em} \mathrm{Hz}), \mathrm{n}$ = número absoluto, $\mathrm{DP}=$ desvio padrão 
As Tabelas 12 e 13 mostraram que, para as duas orelhas, apenas nas frequências $4004 \mathrm{~Hz}$ e $5042 \mathrm{~Hz}$, houve efeito de grupo (valores-p $\leq 0,036$ ) sobre a mediana da intensidade das emissões otoacústicas produto de distorção. Para a frequência $4004 \mathrm{~Hz}$, a única diferença na comparação entre os grupos (Tabela 14) ocorreu entre os grupos Químicos e Ruído, em que a mediana no grupo Químicos é maior do que no grupo Ruído. Já, para a frequência $5042 \mathrm{~Hz}$, não houve evidência de diferença entre as medianas nos grupos Químicos e Controle, sendo maiores do que no grupo Ruído (Tabela 14).

Tabela 14 - Valores-p associados aos testes de diferenças de medianas da Intensidade das emissões otoacústicas evocadas por produto de distorção (dBNPS), entre dois grupos, para as frequências 4004 e $5042 \mathrm{~Hz}$, por orelha

\begin{tabular}{|c|c|c|c|}
\hline Frequência & Orelha & $\begin{array}{c}\text { Diferença } \\
\text { de medianas }\end{array}$ & $\begin{array}{c}\text { Valor- } \\
\text { p }\end{array}$ \\
\hline \multirow{6}{*}{4004} & \multirow{3}{*}{ Direita } & Químicos - Controle & 0,638 \\
\hline & & Ruído - Controle & 0,463 \\
\hline & & Ruído - Químicos & $0,028^{*}$ \\
\hline & \multirow{3}{*}{ Esquerda } & Químicos - Controle & 0,170 \\
\hline & & Ruído - Controle & 0,808 \\
\hline & & Ruído - Químicos & $0,010^{*}$ \\
\hline \multirow{6}{*}{5042} & \multirow{3}{*}{ Direita } & Químicos - Controle & $>0,999$ \\
\hline & & Ruído - Controle & $0,008^{*}$ \\
\hline & & Ruído - Químicos & $0,012^{*}$ \\
\hline & \multirow{3}{*}{ Esquerda } & Químicos - Controle & 0,920 \\
\hline & & Ruído - Controle & $0,015^{\star}$ \\
\hline & & Ruído - Químicos & $0,001^{*}$ \\
\hline
\end{tabular}

As Tabelas 15 a 23 apresentam a distribuição da amostra em relação à variável presença/ausência das emissões otoacústicas evocadas por produto de distorção por frequência. 
Tabela 15 - Distribuição de frequências da Classificação das emissões otoacústicas evocadas por produto de distorção, para a frequência $1001 \mathrm{~Hz}$, por orelha e grupo (as porcentagens foram calculadas por grupo) e valores-p do teste quiquadrado de homogeneidade.

\begin{tabular}{|c|c|c|c|c|c|}
\hline Orelha & Grupo & & sência & & Presença \\
\hline & & $\mathbf{n}$ & & & \\
\hline & Controle & 2 & 11,1 & 16 & 88,9 \\
\hline Direita & Químicos & 2 & 11,1 & 16 & 88,9 \\
\hline & $\begin{array}{l}\text { Ruído } \\
\text { valor-p = 0,802 }\end{array}$ & 1 & 5,6 & 17 & 94,4 \\
\hline & Controle & 1 & 5,6 & 17 & 94,4 \\
\hline & Químicos & 2 & 11,1 & 16 & 88,9 \\
\hline Esquerda & Ruído & 1 & 5,6 & 17 & 94,4 \\
\hline & valor-p $=0,763$ & & & & \\
\hline
\end{tabular}

Tabela 16 - Distribuição de frequências da Classificação das emissões otoacústicas evocadas por produto de distorção, para a frequência $1257 \mathrm{~Hz}$, por orelha e grupo (as porcentagens foram calculadas por grupo) e valores-p do teste quiquadrado de homogeneidade.

\begin{tabular}{|c|c|c|c|c|c|}
\hline \multirow[t]{2}{*}{ Orelha } & \multirow[t]{2}{*}{ Grupo } & \multicolumn{2}{|c|}{ Ausência } & \multicolumn{2}{|c|}{ Presença } \\
\hline & & & $\%$ & & $\%$ \\
\hline \multirow{4}{*}{ Direita } & Controle & 0 & 0,0 & 18 & 100,0 \\
\hline & Químicos & 1 & 5,6 & 17 & 94,4 \\
\hline & Ruído & 0 & 0,0 & 18 & 100,0 \\
\hline & valor- $p>0$ & (999 & & & \\
\hline \multirow{4}{*}{ Esquerda } & Controle & 1 & 5,6 & 17 & 94,4 \\
\hline & Químicos & 0 & 0,0 & 18 & 100,0 \\
\hline & Ruído & 1 & 5,6 & 17 & 94,4 \\
\hline & valor- $p>0$ & -999 & & & \\
\hline
\end{tabular}

Legenda: $\mathrm{n}=$ número absoluto; $\%$ = porcentagem 
Tabela 17 - Distribuição de frequências da Classificação das emissões otoacústicas evocadas por produto de distorção, para a frequência $1587 \mathrm{~Hz}$, por orelha e grupo (as porcentagens foram calculadas por grupo) e valores-p do teste quiquadrado de homogeneidade.

\begin{tabular}{llllll}
\hline Orelha & Grupo & \multicolumn{2}{c}{ Ausência } & \multicolumn{2}{c}{ Presença } \\
& & $\mathbf{n} \%$ & $\mathbf{n}$ & $\%$ \\
\hline \multirow{5}{*}{ Direita } & Controle & 0 & 0,0 & 18 & 100,0 \\
& Químicos & 0 & 0,0 & 18 & 100,0 \\
& Ruído & 1 & 5,6 & 17 & 94,4 \\
& valor-p $>0,999$ \\
\cline { 2 - 6 } Esquerda & Controle & 2 & 11,1 & 16 & 88,9 \\
& Químicos & 0 & 0,0 & 18 & 100,0 \\
& Ruído & 0 & 0,0 & 18 & 100,0 \\
& valor-p=0,321 & & \\
\hline
\end{tabular}

Legenda: $\mathrm{n}=$ número absoluto; \% = porcentagem

Tabela 18 - Distribuição de frequências da Classificação das emissões otoacústicas evocadas por produto de distorção, para a frequência $2002 \mathrm{~Hz}$, por orelha e grupo (as porcentagens foram calculadas por grupo) e valores-p do teste quiquadrado de homogeneidade.

\begin{tabular}{llllll}
\hline Orelha & Grupo & \multicolumn{2}{c}{$\begin{array}{c}\text { Ausência } \\
\text { n }\end{array}$} & \multicolumn{2}{c}{$\begin{array}{c}\text { Presença } \\
\text { n }\end{array}$} \\
\hline \multirow{5}{*}{ Direita } \\
& Controle & 0 & 0,0 & 18 & 100,0 \\
& Químicos & 0 & 0,0 & 18 & 100,0 \\
& Ruído & 1 & 5,6 & 17 & 94,4 \\
& valor-p > 0,999 & & \\
\cline { 2 - 6 } Esquerda & Controle & 1 & 5,6 & 17 & 94,4 \\
& Químicos & 0 & 0,0 & 18 & 100,0 \\
& Ruído & 1 & 5,6 & 17 & 94,4 \\
& valor-p > 0,999 \\
\hline
\end{tabular}

Legenda: $\mathrm{n}=$ número absoluto; \% = porcentagem 
Tabela 19 - Distribuição de frequências da Classificação das emissões otoacústicas evocadas por produto de distorção, para a frequência $2515 \mathrm{~Hz}$, por orelha e grupo (as porcentagens foram calculadas por grupo) e valores-p do teste quiquadrado de homogeneidade.

\begin{tabular}{llllll}
\hline Orelha & Grupo & \multicolumn{2}{c}{ Ausência } & \multicolumn{2}{c}{ Presença } \\
& & $\mathbf{n}$ & $\%$ & $\mathbf{n}$ & \multicolumn{1}{c}{$\%$} \\
\hline \multirow{4}{*}{ Direita } & Controle & 1 & 5,6 & 17 & 94,4 \\
& Químicos & 1 & 5,6 & 17 & 94,4 \\
& Ruído & 0 & 0,0 & 18 & 100,0 \\
& valor-p $>0,999$ & & & \\
\cline { 2 - 6 } Esquerda & Controle & 1 & 5,6 & 17 & 94,4 \\
& Químicos & 0 & 0,0 & 18 & 100,0 \\
& Ruído & 0 & 0,0 & 18 & 100,0 \\
& valor-p > 0,999 & & \\
\hline
\end{tabular}

Legenda: $\mathrm{n}=$ número absoluto; \% = porcentagem

Tabela 20 - Distribuição de frequências da Classificação das emissões otoacústicas evocadas por produto de distorção, para a frequência $3174 \mathrm{~Hz}$, por orelha e grupo (as porcentagens foram calculadas por grupo) e valores-p do teste quiquadrado de homogeneidade.

\begin{tabular}{llllll}
\hline Orelha & Grupo & \multicolumn{2}{c}{ Ausência } & \multicolumn{2}{c}{ Presença } \\
& & n & \% & n & \% \\
\hline \multirow{5}{*}{ Direita } & Controle & 1 & 5,6 & 17 & 94,4 \\
& Químicos & 0 & 0,0 & 18 & 100,0 \\
& Ruído & 1 & 5,6 & 17 & 94,4 \\
& valor-p $>0,999$ & & \\
\cline { 2 - 7 } Esquerda & Controle & 1 & 5,6 & 17 & 94,4 \\
& Químicos & 0 & 0,0 & 18 & 100,0 \\
& Ruído & 1 & 5,6 & 17 & 94,4 \\
& valor-p $>0,999$ & & \\
\hline
\end{tabular}

Legenda: $\mathrm{n}=$ número absoluto; \% = porcentagem 
Tabela 21 - Distribuição de frequências da Classificação das emissões otoacústicas evocadas por produto de distorção, para a frequência $4004 \mathrm{~Hz}$, por orelha e grupo (as porcentagens foram calculadas por grupo) e valores-p do teste quiquadrado de homogeneidade.

\begin{tabular}{llllll}
\hline Orelha & Grupo & \multicolumn{2}{c}{ Ausência } & \multicolumn{2}{c}{ Presença } \\
& & $\mathbf{n} \%$ & $\mathbf{n}$ & $\%$ \\
\hline \multirow{5}{*}{ Direita } & Controle & 0 & 0,0 & 18 & 100,0 \\
& Químicos & 0 & 0,0 & 18 & 100,0 \\
& Ruído & 2 & 11,1 & 16 & 88,9 \\
& valor-p=0,321 & & \\
\hline \multirow{5}{*}{ Esquerda } & Controle & 0 & 0,0 & 18 & 100,0 \\
& Químicos & 0 & 0,0 & 18 & 100,0 \\
& Ruído & 0 & 0,0 & 18 & 100,0 \\
& valor-p $>0,999$ & & \\
\hline
\end{tabular}

Legenda: $\mathrm{n}=$ número absoluto; \% = porcentagem

Tabela 22 - Distribuição de frequências da Classificação das emissões otoacústicas evocadas por produto de distorção, para a frequência $5042 \mathrm{~Hz}$, por orelha e grupo (as porcentagens foram calculadas por grupo) e valores-p do teste quiquadrado de homogeneidade.

\begin{tabular}{llllll}
\hline Orelha & Grupo & \multicolumn{2}{c}{ Ausência } & \multicolumn{2}{c}{ Presença } \\
& & $\mathbf{n} \%$ & $\mathbf{n}$ & $\%$ \\
\hline \multirow{4}{*}{ Direita } & Controle & 0 & 0,0 & 18 & 100,0 \\
& Químicos & 0 & 0,0 & 18 & 100,0 \\
& Ruído & 2 & 11,1 & 16 & 88,9 \\
& valor- $p=0,321$ & & \\
\hline \multirow{4}{*}{ Esquerda } & Controle & 0 & 0,0 & 18 & 100,0 \\
& Químicos & 0 & 0,0 & 18 & 100,0 \\
& Ruído & 4 & 22,2 & 14 & 77,8 \\
& valor-p $p=0,029^{*}$ \\
\hline
\end{tabular}

Legenda: $\mathrm{n}=$ número absoluto; $\%$ = porcentagem 
Tabela 23 - Distribuição de frequências da Classificação das emissões otoacústicas evocadas por produto de distorção, para a frequência $6348 \mathrm{~Hz}$, por orelha e grupo (as porcentagens foram calculadas por grupo) e valores-p do teste quiquadrado de homogeneidade.

\begin{tabular}{|c|c|c|c|c|c|}
\hline \multirow[t]{2}{*}{ Orelha } & \multirow[t]{2}{*}{ Grupo } & \multicolumn{2}{|c|}{ Ausência } & \multicolumn{2}{|c|}{ Presença } \\
\hline & & $\mathbf{n}$ & $\%$ & $\mathbf{n}$ & $\%$ \\
\hline \multirow{3}{*}{ Direita } & Controle & 0 & 0,0 & 18 & 100,0 \\
\hline & Químicos & 3 & 16,7 & 15 & 83,3 \\
\hline & $\begin{array}{l}\text { Ruído } \\
\text { valor-p }=0,185\end{array}$ & 3 & 16,7 & 15 & 83,3 \\
\hline \multirow{3}{*}{ Esquerda } & Controle & 0 & 0,0 & 18 & 100,0 \\
\hline & Químicos & 2 & 11,1 & 16 & 88,9 \\
\hline & $\begin{array}{l}\text { Ruído } \\
\text { valor-p }=0.214\end{array}$ & 3 & 16,7 & 15 & 83,3 \\
\hline
\end{tabular}

Pelas Tabelas 15 a 21 e 23, nota-se que, nas duas orelhas e em todas as frequências, mais de $83 \%$ dos indivíduos de cada grupo foram classificados como tendo presença de emissões otoacústicas produto de distorção. Essas tabelas mostram, também, ao nível de $5 \%$ de significância, que não há evidência de que a proporção populacional de indivíduos classificados como tendo presença difira entre os três grupos (valores- $p \geq 0,185$ ). A Tabela 22 mostra que esses resultados também se verificaram para a frequência $5042 \mathrm{~Hz}$ na orelha direita. No entanto, na orelha esquerda, ao nível de $5 \%$ de significância, há evidência de que a proporção populacional de indivíduos classificados como tendo presença difira entre os três grupos $($ valor-p $=0,029)$. Nessa orelha, a porcentagem de indivíduos classificados como tendo presença de emissões otoacústicas produto de distorção é $77,8 \%$, no grupo Ruído, enquanto que nos demais grupos essa porcentagem é igual a 100\%.

A Tabela 24 apresenta medidas descritivas para a variável intensidade global das emissões otoacústicas evocadas por estímulo transiente. Já a 
Tabela 25, apresenta os valores de comparação dois a dois entre as diferenças de mediana da intensidade global das emissões otoacústicas evocadas por estímulo transiente, por orelha.

Tabela 24 - Média, desvio padrão, valores mínimo, máximo e mediana e análise comparativa entre os grupos em relação à variável "Intensidade global das emissões otoacústicas evocadas por transiente (dBNPS)", por orelha e grupo.

\begin{tabular}{lcccccccc}
\hline \multirow{2}{*}{ Orelha } & Grupo & $\mathbf{n}$ & Média & $\begin{array}{c}\text { Desvio } \\
\text { Padrão }\end{array}$ & Mínimo & Mediana & Máximo & Valor-p \\
\hline \multirow{3}{*}{ Direita } & Controle & 18 & 8,78 & 3,842 & $-2,500$ & 9,500 & 14,40 & \\
& Químicos & 18 & 8,71 & 5,15 & $-1,50$ & 10,20 & 14,90 & 0,245 \\
& Ruído & 18 & 6,39 & 5,90 & $-9,90$ & 7,20 & 15,30 & \\
\cline { 2 - 9 } Esquerda & Controle & 18 & 8,36 & 4,81 & $-3,30$ & 9,20 & 16,20 & \\
& Químicos & 18 & 10,66 & 4,07 & $-0,30$ & 10,90 & 17,50 & $0,040^{*}$ \\
& Ruído & 18 & 6,57 & 6,48 & $-7,50$ & 7,05 & 19,20 & \\
\hline
\end{tabular}

Legenda: $\mathrm{n}=$ número absoluto; Teste de Kruskal-Wallis

Tabela 25 - Valores-p associados aos testes de diferenças de medianas da Intensidade global das emissões otoacústicas evocadas por transiente (dBNPS) entre dois grupos, por orelha

\begin{tabular}{ccc}
\hline Orelha & $\begin{array}{c}\text { Diferença } \\
\text { de medianas }\end{array}$ & $\begin{array}{c}\text { Valor- } \\
\mathbf{p}\end{array}$ \\
\hline \multirow{3}{*}{ Esquerda } & Químicos - Controle & 0,304 \\
& Ruído - Controle & $>0,999$ \\
& Ruído - Químicos & $0,034^{*}$ \\
\hline
\end{tabular}

A Tabela 24 mostra que, para a orelha direita, não há efeito de grupo (valor$p=0,245)$ sobre a mediana da intensidade global das emissões otoacústicas transientes. Já, para a orelha esquerda, há efeito de grupo (valor-p $=0,040)$, sendo que a única diferença (Tabela 25) ocorreu entre os grupos Químicos e Ruído, em que a mediana no grupo Químicos é maior do que no grupo Ruído. 
A Tabela 26 apresenta a distribuição de frequências da classificação das emissões otoacústicas evocadas por estímulo transiente, por grupo e orelha. Nota-se que, para as duas orelhas, que os grupos Ruído e Químicos apresentam uma maior proporção de ausência de emissões otoacústicas transientes, com diferença estatisticamente significante para a orelha esquerda e tendência a significância estatística para a orelha direita.

Tabela 26 - Distribuição da amostra em números absolutos e percentuais em relação à variável "Presença/ausência das emissões otoacústicas evocadas por transiente" e análise comparativa entre os grupos, valor-p.

\begin{tabular}{llccccc}
\hline \multirow{2}{*}{ Orelha } & \multicolumn{1}{c}{ Grupo } & \multicolumn{2}{c}{ Ausência } & \multicolumn{2}{c}{ Presença } \\
& & n & $\%$ & n & \% \\
\hline \multirow{3}{*}{ Direita } & Controle & 3 & 16,7 & 15 & 83,3 \\
& Químicos & 7 & 38,9 & 11 & 61,1 \\
& Ruído & 10 & 55,5 & 8 & 44,5 \\
& valor-p $=0,052$ & & & & \\
\hline \multirow{5}{*}{ Esquerda } & Controle & 2 & 11,1 & 16 & 88,9 \\
& Químicos & 4 & 22,2 & 14 & 77,7 \\
& Ruído & 10 & 55,5 & 8 & 44,5 \\
& valor-p $=0,009^{*}$ & & & & \\
\hline
\end{tabular}

Teste qui-quadrado de homogeneidade

Legenda: $\mathrm{n}$ = número absoluto; \% = porcentagem

As Tabelas 27 e 28 apresentam, respectivamente, a estatística descritiva para a intensidade das emissões otoacústicas evocadas por estímulo transiente por frequência, nas frequências de 1000, 1400, 2000, 2800 e $4000 \mathrm{~Hz}$ por grupo e a comparação entre os valores de mediana da referida variável para a frequência de $2800 \mathrm{~Hz}$. 
Tabela 27 - Média, desvio padrão, valores mínimo, máximo e mediana e análise comparativa entre os grupos em relação à variável Intensidade das emissões otoacústicas evocadas por transiente (dBNPS), por frequência $(1000,1400,2000,2800$, 4000, em Hz), orelha e grupo.

\begin{tabular}{|c|c|c|c|c|c|c|c|c|c|}
\hline Frequência & Orelha & Grupo & $\mathbf{n}$ & Média & $\begin{array}{l}\text { Desvio } \\
\text { Padrão } \\
\end{array}$ & Mínimo & Mediana & Máximo & Valor-p \\
\hline \multirow[t]{6}{*}{1000} & Direita & Controle & 18 & $-0,31$ & 5,13 & $-9,80$ & $-0,45$ & 8,20 & \\
\hline & & Químicos & 18 & 1,46 & 7,25 & $-17,10$ & 2,40 & 10,70 & 0,442 \\
\hline & & Ruído & 18 & 0,21 & 5,57 & $-11,00$ & $-0,20$ & 8,10 & \\
\hline & Esquerda & Controle & 18 & 0,22 & 6,10 & $-14,40$ & 0,50 & 10,50 & \\
\hline & & Químicos & 18 & 2,38 & 7,59 & $-11,30$ & 3,40 & 14,60 & 0,459 \\
\hline & & Ruído & 18 & 0,11 & 8,11 & $-20,50$ & 1,40 & 12,50 & \\
\hline \multirow[t]{6}{*}{1400} & Direita & Controle & 18 & 3,11 & 5,84 & $-10,00$ & 3,40 & 11,00 & \\
\hline & & Químicos & 18 & 2,42 & 7,96 & $-23,00$ & 5,50 & 11,60 & 0,375 \\
\hline & & Ruído & 18 & 1,37 & 6,27 & $-10,40$ & 1,90 & 13,20 & \\
\hline & Esquerda & Controle & 18 & 3,28 & 6,42 & $-15,90$ & 3,80 & 11,80 & \\
\hline & & Químicos & 18 & 4,67 & 5,64 & $-6,70$ & 6,10 & 12,60 & 0,142 \\
\hline & & Ruído & 18 & 0,26 & 8,65 & $-18,90$ & 1,10 & 17,20 & \\
\hline \multirow[t]{6}{*}{2000} & Direita & Controle & 18 & 0,09 & 5,46 & $-9,90$ & 0,35 & 10,20 & \\
\hline & & Químicos & 18 & 2,31 & 5,48 & $-6,90$ & 4,00 & 10,10 & 0,349 \\
\hline & & Ruído & 18 & 0,24 & 5,18 & $-13,40$ & 0,85 & 8,60 & \\
\hline & Esquerda & Controle & 18 & 0,49 & 6,33 & $-8,60$ & 1,55 & 9,70 & \\
\hline & & Químicos & 18 & 3,21 & 3,92 & $-3,20$ & 2,35 & 9,80 & 0,356 \\
\hline & & Ruído & 18 & $-0,01$ & 6,66 & $-12,90$ & 1,55 & 10,20 & \\
\hline \multirow[t]{6}{*}{2800} & Direita & Controle & 18 & $-1,58$ & 5,97 & $-11,10$ & $-2,70$ & 6,70 & \\
\hline & & Químicos & 18 & 0,52 & 4,80 & $-5,30$ & 0,20 & 8,80 & $0,043^{*}$ \\
\hline & & Ruído & 18 & $-4,54$ & 4,85 & $-11,30$ & $-4,05$ & 5,00 & \\
\hline & Esquerda & Controle & 18 & $-2,58$ & 6,47 & $-13,40$ & $-2,85$ & 6,10 & \\
\hline & & Químicos & 18 & 0,52 & 4,31 & $-9,00$ & 0,65 & 5,90 & $0,025^{*}$ \\
\hline & & Ruído & 18 & $-4,51$ & 4,97 & $-14,30$ & $-4,00$ & 4,10 & \\
\hline \multirow[t]{6}{*}{4000} & Direita & Controle & 18 & $-5,55$ & 5,35 & $-15,50$ & $-6,25$ & 4,70 & \\
\hline & & Químicos & 18 & $-5,87$ & 5,28 & $-19,90$ & $-6,45$ & 6,00 & 0,127 \\
\hline & & Ruído & 18 & $-8,09$ & 4,69 & $-16,50$ & $-9,10$ & 0,80 & \\
\hline & Esquerda & Controle & 18 & $-5,99$ & 7,44 & $-18,20$ & $-7,65$ & 9,00 & \\
\hline & & Químicos & 18 & $-3,25$ & 5,77 & $-14,60$ & $-3,10$ & 9,40 & 0,085 \\
\hline & & Ruído & 18 & $-7,49$ & 5,19 & $-16,10$ & $-6,70$ & 2,30 & \\
\hline
\end{tabular}

Legenda: $\mathrm{n}=$ número absoluto; Teste de Kruskal-Wallis 
Tabela 28 - Valores-p associados aos testes de diferenças de medianas da a Intensidade das emissões otoacústicas evocadas por transiente (dBNPS) entre dois grupos, para a frequência 2800 $\mathrm{Hz}$, por orelha

\begin{tabular}{cccc}
\hline \multirow{2}{*}{ Frequência } & Orelha & $\begin{array}{c}\text { Diferença } \\
\text { de medianas }\end{array}$ & $\begin{array}{c}\text { Valor- } \\
\text { p }\end{array}$ \\
\hline \multirow{4}{*}{2800} & \multirow{2}{*}{ Direita } & $\begin{array}{c}\text { Químicos - Controle } \\
\text { Ruído - Controle }\end{array}$ & 0,979 \\
& & 0,344 \\
& Ruído - Químicos & $0,037^{*}$ \\
\cline { 2 - 4 } & \multirow{3}{*}{ Esquerda } & Químicos - Controle & 0,324 \\
& Ruído - Controle & 0,670 \\
& Ruído - Químicos & $0,018^{*}$ \\
\hline
\end{tabular}

A Tabela 27 mostra que, para as duas orelhas, apenas na frequência $2800 \mathrm{~Hz}$ há efeito de grupo (valores-p $\leq 0,043$ ) sobre a mediana da intensidade das emissões otoacústicas transientes. Pela Tabela 28, observa-se que a única diferença ocorreu entre os grupos Químicos e Ruído, em que a mediana no grupo Químicos é maior do que no grupo Ruído.

\subsection{Efeito inibitório da via auditiva eferente}

As Tabelas 29 e 30 apresentam, respectivamente, a estatística descritiva para a intensidade do efeito inibitório da via auditiva eferente (em $\mu \mathrm{Pa})$ e sua comparação percentual em relação à intensidade da emissão (sem ruído contralateral) do próprio indivíduo. 
Tabela 29 - Média, desvio padrão, valores mínimo, máximo, mediana e análise comparativa entre os grupos em relação à variável Intensidade do efeito inibitório da via auditiva eferente $(\mu \mathrm{Pa})$ na orelha direita, por grupo.

\begin{tabular}{lccccccc}
\hline Grupo & $\mathbf{n}$ & Média & $\begin{array}{c}\text { Desvio } \\
\text { Padrão }\end{array}$ & Mínimo & Mediana & Máximo & Valor-p \\
\hline Controle & 15 & 3,82 & 3,04 & 0,26 & 2,95 & 12,78 & \\
Químicos & 15 & 4,0 & 3,80 & 0,93 & 2,44 & 15,03 & 0,945 \\
Ruído & 13 & 3,12 & 2,73 & 0,64 & 2,93 & 10,63 & \\
\hline Legenda: $n$ & $=$ número absoluto (a intensidade do efeito inibitório somente foi \\
mensurada quando houve presença de EOAT com estímulo linear na situação sem \\
ruído); Teste de Kruskal-Wallis.
\end{tabular}

Tabela 30 - Média, desvio padrão, valores mínimo, máximo, mediana e análise comparativa entre os grupos em relação à variável Intensidade do efeito inibitório da via auditiva eferente (\%) na orelha direita, por grupo.

\begin{tabular}{cccccccc}
\hline Grupo & $\mathbf{n}$ & Média & $\begin{array}{c}\text { Desvio } \\
\text { Padrão }\end{array}$ & Mínimo & Mediana & Máximo & Valor-p \\
\hline Controle & 15 & 9,80 & 5,81 & 1,12 & 8,79 & 20,57 & \\
Químicos & 15 & 8,52 & 5,05 & 2,29 & 7,74 & 19,66 & 0,775 \\
Ruído & 13 & 7,72 & 6,17 & 4,50 & 6,66 & 14,87 & \\
\hline
\end{tabular}

Legenda: $\mathrm{n}=$ número absoluto (a intensidade do efeito inibitório somente foi mensurada quando houve presença de EOAT com estímulo linear na situação sem ruído); Teste de Kruskal-Wallis.

As Tabelas 29 e 30 mostram que não há efeito de grupo (valores-p $\geq$ $0,337)$ sobre a mediana da intensidade do efeito inibitório da via auditiva eferente.

A Tabela 31 apresenta a distribuição de frequências e comparação entre os grupos em relação à classificação do efeito inibitório da via auditiva eferente. Não houve diferença estatisticamente significante entre os grupos. 
Tabela 31 - Distribuição de frequências da Classificação da supressão das emissões otoacústicas evocadas por transiente, por orelha e grupo (as porcentagens foram calculadas por grupo) e valores-p do teste qui-quadrado de homogeneidade.

\begin{tabular}{lllll}
\hline Grupo & Ausência & \multicolumn{3}{c}{ Presença } \\
& $\mathbf{n}$ & $\%$ & $\mathbf{n}$ & $\%$ \\
\hline Controle & 0 & 0,0 & 15 & 100,0 \\
Químicos & 3 & 20,0 & 12 & 80,0 \\
Ruído & 2 & 15,4 & 11 & 84,6 \\
valor-p $=0,204$ & & & & \\
\hline
\end{tabular}

Legenda: $\mathrm{n}=$ número absoluto; \% = porcentagem

5.6 Habilidade auditiva de figura-fundo para sons verbais - SSW

A Tabela 32 apresenta a estatística descritiva para o escore obtido no teste SSW, em porcentagem (\%) por orelha (em situação competitiva) e grupo.

Tabela 32 - Estatísticas descritivas para o Escore SSW (\%), por orelha competitiva e grupo.

\begin{tabular}{lcccccccc}
\hline Orelha & Grupo & N & Média & $\begin{array}{c}\text { Desvio } \\
\text { Padrão }\end{array}$ & Mínimo & Mediana & Máximo & $\begin{array}{c}\text { Valor- } \\
\text { p }\end{array}$ \\
\hline \multirow{3}{*}{ Direita } & Controle & 18 & 94,17 & 5,69 & 82,50 & 95,00 & 100,00 & \\
& Químicos & 18 & 93,75 & 9,40 & 67,50 & 97,50 & 100,00 & 0,706 \\
& Ruído & 18 & 95,41 & 3,663 & 87,50 & 95,00 & 100,00 & \\
\hline \multirow{3}{*}{ Esquerda } & Controle & 18 & 91,81 & 8,26 & 75,00 & 93,75 & 100,00 & \\
& Químicos & 18 & 90,00 & 7,72 & 70,00 & 92,50 & 100,00 & 0,394 \\
& Ruído & 18 & 93,88 & 2,60 & 87,50 & 95,00 & 97,50 & \\
\hline
\end{tabular}

Legenda: $\mathrm{n}=$ número absoluto; \% = porcentagem

Verifica-se, pela a Tabela 32 que, para as duas orelhas, não há efeito de grupo (valores-p $\geq 0,082$ ) sobre o escore do SSW. 


\section{DISCUSSÃO}

O objetivo principal do presente estudo foi avaliar os efeitos da exposição ao ruído ou a químicos sobre a audição periférica, habilidade do processamento auditivo e efeito inibitório da via auditiva eferente de trabalhadores expostos a produtos químicos ou a ruído intenso, comparando os grupos entre si e com trabalhadores que não possuem exposição a nenhum destes agentes.

No que se refere à caracterização da amostra, o presente estudo avaliou ambos os sexos, numa proporção similar em cada um dos grupos, uma vez que possíveis diferenças entre os sexos, para os testes realizados, podem existir (Lonsbury-Martin et al., 1990; Baraldi et al., 2007). Desta forma, buscouse balancear homens e mulheres nos três grupos para que possíveis diferenças relacionadas ao sexo não interferissem na comparação entre os grupos.

Quanto à idade, foi utilizado o mesmo critério, já que assim como possíveis diferenças entre os sexos, as possíveis diferenças entre indivíduos de faixas-etárias diversas também podem influenciar nos resultados audiológicos (Baraldi et al., 2007). A faixa-etária avaliada é similar à observada em outros estudos, como o de Vallejo et al. (2001), que analisou a correlação entre emissões otoacústicas e ototoxicidade.

$\mathrm{Na}$ análise realizada no presente estudo, as variáveis sexo e idade não mostraram diferenças estatisticamente significantes entre os grupos, sugerindo que estas características são semelhantes entre eles. Deve-se ressaltar que 
um pareamento exato entre os grupos não foi possível, pois existem certas características inerentes a cada um dos grupos; os participantes são trabalhadores da universidade e aqueles que trabalham com ruído são geralmente mais velhos e do sexo masculino, enquanto o grupo de químicos possui mais mulheres e que são, em geral, mais novas.

O tempo na função, que indica o tempo de exposição ao ruído ou aos químicos, também foi outra variável analisada na presente amostra. Faz-se importante essa avaliação, conforme citado pela NR09, condicionando os agentes agressores em função do tempo de exposição (Brasil, 1978). Apesar de observarmos grandes variações entre os valores máximos e mínimos, bem como, para a mediana, entre os grupos, não houve diferença estatisticamente significante entre eles, em relação ao tempo na função, sugerindo que os indivíduos do grupo Ruído e Químico têm tempos de exposição a estes agentes similares.

Conforme previsto pela NR 06, todo equipamento, dispositivo ou produto, destinado à proteção de riscos suscetíveis de ameaçar a segurança e saúde no trabalho, ao trabalhador, pode ser considerado como um equipamento de proteção, podendo abranger o indivíduo (proteção individual), ou, a coletividade (proteção coletiva), sendo a empresa, obrigada a fornecê-los (Brasil, 1978).

No presente estudo, para os indivíduos do grupo Químicos, estes são expostos constantemente a diversas substâncias potencialmente nocivas. Esta exposição ocorre em ambientes, geralmente, laboratoriais e pode ser considerada como uma imersão em um ambiente complexo, dada a grande 
gama de materiais, substâncias e equipamentos envolvidos (Sangioni, 2012). Observou-se que todos os indivíduos do grupo Químicos fazem uso ao menos de um tipo de equipamento de proteção. Esse fato pode decorrer de uma possível maior facilidade de acesso aos equipamentos de proteção neste ambiente, dada a inserção destes trabalhadores em um local previamente preparado para tal, visto que a ergonomia nos laboratórios é algo bastante discutido em sua manutenção, bem como, nas condições de trabalho dos indivíduos lá sitiados (Gomes et al., 2018). Deve-se mencionar que diversos laboratórios, em questão, contam com equipamentos de proteção coletiva, como por exemplo "capelas", sendo que as atividades desenvolvidas nestes locais, necessariamente, são realizadas com o uso destes equipamentos.

No que se refere à proteção contra o ruído, é importante mencionar que medidas de controle dos riscos devem ser realizadas de forma hierárquica, buscando-se inicialmente a eliminação ou substituição do risco, seguidas por medidas de controle de engenharia ou administrativas e, em último caso, o uso da proteção individual (Morata e Meinkle, 2016). No entanto, em virtude de aspectos relacionados principalmente aos custos, os protetores auriculares vêm sendo utilizados como primeira estratégia para controle do risco (Arezes e Miguel, 2013).

Além disso, para os indivíduos expostos ao ruído, é descrito na literatura que diversos fatores podem influenciar na utilização dos equipamentos de proteção individual como, por exemplo, os níveis de pressão sonora aos quais os indivíduos estão expostos (Lusk et al., 1999; Sbihi et al., 2010), etnias (Hong et al., 2005; Raymond et al., 2006) e idade (Sbihi et al., 2010). 
Foi observado no presente estudo que, apenas uma parte da população exposta ao ruído faz uso dos equipamentos de proteção individual, o que também foi verificado por outros autores (Cerqueira et al., 2013; Pommerehn et al., 2016). A falta de informação dos trabalhadores e empregadores, bem como uma organização do trabalho, muitas vezes deficitária podem contribuir para uma redução na utilização do equipamento de proteção auditiva, embora muitos estudos já tenham mostrado a importância do uso deste tipo de proteção (Ferreira e Oliveira, 2019).

Sendo assim, ressalta-se a importância do uso dos equipamentos de proteção, quando necessário, tanto para trabalhadores expostos a níveis de pressão sonora elevados quanto a produtos químicos potencialmente ototóxicos (Hammil et al., 2019).

Quanto aos tipos de elementos químicos aos quais os indivíduos do grupo Químicos estão expostos, nota-se que todos têm exposição ao menos a um tipo de solvente. Tais elementos apresentam potencial para alterações retrococleares (Zucki et al., 2017). Metais e asfixiantes também podem ser incluídos na lista de produtos potencialmente lesivos à audição (Morata e Johnson, 2012; NIOSH, 2018). No presente estudo, apesar da baixa ocorrência de relatos de exposição a produtos asfixiantes, os metais apresentam importante representação $(61,1 \%)$. Tais produtos podem atuar diretamente no sistema nervoso, bem como, no auditivo, podendo ocasionar danos à audição e ao sistema vestibular, tal como os demais produtos (Steyger et al., 2018).

A literatura científica apresenta estudos com resultados indicativos de relação entre o zumbido e a exposição ao ruído (Boger et al., 2016; Bramhall et 
al., 2018); e a produtos químicos (Vasconcelos et al., 2017). No entanto, foi observada similaridade entre os grupos (controle, ruído e químicos) no que se refere à prevalência da queixa de zumbido, concordando com o estudo de Staudt et al. (2019), que analisaram a correlação entre a exposição a solventes e a ocorrência de zumbido, mas discordando de outros autores, que verificaram uma prevalência maior deste sintoma em indivíduos expostos a ruído (Dias et al., 2006).

Deve-se enfatizar, contudo, que todos os indivíduos participantes do presente estudo apresentam audição dentro dos limites de normalidade e este aspecto deve ser levado em consideração na comparação com a literatura da área, que, na maioria das vezes, avalia indivíduos que já apresentam perda auditiva. Uma revisão da literatura sobre o assunto elaborada pelo Health and Safety Laboratory (Poole, 2010) verificou que a prevalência de zumbido em trabalhadores expostos a ruído é significantemente maior do que em trabalhadores não expostos. Além disso, a maioria dos estudos incluídos encontrou associação entre zumbido e perda auditiva induzida por ruído, sendo que, quanto maior a perda auditiva, maior a prevalência de zumbido. Além disso, Poole (2010) descreveu um estudo longitudinal de 15 anos que mostrou que o zumbido é um indicador "precoce" de risco de desenvolvimento de perda auditiva.

Em relação à lateralidade do zumbido, no presente estudo, também não foram observadas diferenças entre os grupos, sendo que o zumbido bilateral foi o mais comumente referido. Predominância semelhante foi observada em estudos pregressos, como por exemplo o de Ibraheem e Hassaan (2017). 
No que se refere à ocorrência de tontura na população estudada, notouse que, apesar de não haver diferença estatisticamente significante entre os grupos, o grupo Químicos apresentou maior ocorrência, com 10 casos $(55,6 \%)$, frente aos $7(38,9 \%)$ e $4(22,2 \%)$, respectivamente, dos grupos Controle e Ruído.

Relatos como o de Almeida et al. (1980) já apresentaram uma possível relação entre a exposição a produtos químicos e a ocorrência de tonturas, numa população exposta a pesticidas, assim como Rostami et al. (2018). Rocha et al. (2004) também fizeram semelhante observação, porém, em relação a profissionais expostos a medicamentos quimioterápicos. Fox et al. (2018) também encontraram indícios de correlação entre a exposição a substâncias potencialmente ototóxicas e ocorrência de tonturas em veteranos da Guerra do Golfo.

O estudo de Queiroz et al. (2017), envolvendo trabalhadores expostos a ruído, encontrou prevalência de ocorrência de tontura semelhante ao presente estudo (30\%). Outro estudo (Cerqueira et al., 2013) encontrou relatos de tontura em apenas $8,8 \%$ de trabalhadores de postos de gasolina, expostos, concomitantemente, a níveis de pressão sonora elevados e substâncias químicas potencialmente ototóxicas.

Cabe ressaltar que a tontura é um sintoma comum em diversas faixas etárias (Lewis, 1996; Chawla e Olshaker, 2006), podendo afetar cerca de 8\% da população (Neuhauser et al., 2005), atingindo, potencialmente, porcentagens maiores em populações com idades mais avançadas (Jonsson et al., 2004). 
A tontura do tipo rotatória pode estar relacionada à sensação de que os elementos ao redor giram, ou que o indivíduo está girando, podendo ser ocasionada por acometimentos vestibulares unilaterais periféricos ou centrais, enquanto a não rotatória pode se relacionar à sensação de balanço e perda de equilíbrio, com origem em distúrbios vestibulares ou não (Velasco et al., 2003; Ganança et al., 2004).

A grande variedade de causas e o significativo aumento de ocorrência com o envelhecimento (Hueb \& Feliciano, 2012) são fatores que dificultam a análise dos dados relativos à tontura na população estudada, bem como, dos tipos de tontura verificados. Apesar de não haver diferença estatisticamente significante entre as tonturas rotatórias e não rotatórias verificadas no estudo, a literatura tende a apresentar resultados variáveis, com maiores prevalências de tonturas do tipo rotatória (Moraes et al., 2011) ou do tipo não-rotatória (Gazzola et al., 2006), assim como observado no presente estudo, com 71,4\%, $60 \%$ e 50\% entre os grupos Controle, Químico e Ruído, respectivamente, de presença de tonturas do tipo não rotatória.

Em relação aos limiares auditivos, não foram observadas diferenças estatisticamente significantes entre os grupos para os limiares auditivos por via aérea tanto para a audiometria convencional quanto para a audiometria de altas frequências.

Em um estudo longitudinal, realizado com dois indivíduos expostos a ruído intenso e produtos químicos (pesticidas), concomitantemente, um dos casos não apresentou alterações em seus limiares auditivos mesmo após dois anos de exposição, enquanto o outro apresentou alterações apenas nas 
frequências de $11 \mathrm{kHz}$ (Sena et al., 2018). Outro estudo, realizado com trabalhadores expostos ao ruído e a produtos químicos (solventes industriais) mostrou que estes tendem a apresentar maior prevalência de perdas auditivas (Morata et al., 1993; Metwally et al., 2011).

Em nossa amostra, cabe ressaltar que a paridade entre os grupos, em relação aos limiares auditivos por via aérea para audiometria tonal convencional $(250 \mathrm{a} 8.000 \mathrm{~Hz})$ era esperada em virtude dos critérios de inclusão (obrigatoriedade de laudo indicando limiares auditivos dentro dos padrões da normalidade em ambas as orelhas, de acordo com o critério da Organização Mundial da Saúde - OMS, 2014).

Quanto à audiometria tonal por via aérea de altas frequências (9.000 a $16.000 \mathrm{~Hz}$ ), embora também não se tenha observado diferenças estatisticamente significantes para essas frequências, nossa hipótese inicial era de que os grupos Ruído e Químico apresentariam limiares auditivos mais elevados, quando comparados ao controle (Crundwell et al., 2015). De fato, para as frequências mais altas (a partir de $11.200 \mathrm{~Hz}$ ), os limiares auditivos dos grupos Químico e Ruído tenderam a se apresentar mais rebaixados, porém sem diferenças significativas.

Estudos prévios sobre esta temática referem que a audiometria de altas frequências pode ser utilizada como um indicador mais precoce de danos cocleares causados pelo ruído (Somma et al., 2008; Mehrparvar et al., 2011) ou pelos químicos (Johnson e Morata, 2010), quando comparada à audiometria convencional. Somma et al. (2008), ressaltaram que o efeito da idade é mais 
evidente sobre os limiares de altas frequências e, assim, deve ser considerado no acompanhamento dos indivíduos expostos aos agentes otoagressores.

É importante ressaltar que além da exposição ao ruído ou aos químicos, outros inúmeros fatores podem interferir nos limiares auditivos, principalmente, nas frequências mais altas, podendo explicar os resultados obtidos no presente estudo. No que se refere ao grupo Químicos, estes indivíduos são expostos a uma grande variedade de produtos químicos potencialmente ototóxicos; no entanto, $100 \%$ dos indivíduos realizam suas atividades profissionais na presença de equipamentos de proteção, o que pode mitigar o contato destes indivíduos com tais produtos e, portanto, trazer menores consequências para o sistema auditivo. Já o grupo Ruído está mais exposto ao agente otoagressor, uma vez que a maioria dos indivíduos referiram o não uso dos protetores auditivos.

Outras variáveis descritas como podendo interferir nos limiares auditivos são aquelas relativas ao perfil econômico e social, como por exemplo, a predominância de homens em funções com exposição ao ruído, as condições de inserção no trabalho (idade de início, entre outras) (Lewkoski et al., 2019), assim como diversas outras causas inerentes aos processos naturais de degeneração auditiva (Keithley, 2019), envolvendo diversos mecanismos, como a degeneração neuronal (Parthasarathy \& Kujawa, 2018) ou a influência da dieta, no tocante aos elementos antioxidantes ingeridos (Le \& Keithley, 2007; Curhan et al., 2018).

Assim, podemos notar que uma grande diversidade de fatores pode ter contribuído para a não obtenção de diferenças estatisticamente significantes 
entre os grupos no que diz respeito à audiometria tonal de altas frequências. Além disso, a amostra não tão numerosa de indivíduos por grupo e o não pareamento por idade e sexo entre os grupos podem ter influenciado nestes resultados.

A mesma reflexão acerca dos limiares auditivos por via aérea de altas frequências pode ser feita para as emissões otoacústicas evocadas. Para as emissões otoacústicas evocadas por produto de distorção, não foram observadas diferenças entre os três grupos em nenhuma das frequências testadas $(1001,1257,1587,2002,2515,3174,4004,5042$ e $6348 \mathrm{~Hz})$ no que diz respeito à amplitude das emissões otoacústicas. Apenas para as medianas da intensidade das emissões otoacústicas por produto de distorção nas frequências de 4004 e $5042 \mathrm{~Hz}$ foi observado efeito de grupo com significância estatística, sendo que o grupo Ruído apresentou amplitudes menores quando comparado aos outros dois grupos.

Em relação à presença e ausência das emissões otoacústicas evocadas por produto de distorção, também não foram observadas diferenças estatisticamente significantes, com exceção da frequência de $5042 \mathrm{~Hz}$ (orelha esquerda), com o grupo Ruído mostrando maiores porcentagens de ausência das emissões, quando comparado aos outros dois grupos.

Para a análise comparativa entre os grupos em relação à variável amplitude global das emissões otoacústicas transientes, para ambas as orelhas, o grupo Ruído apresentou amplitudes mais baixas, quando comparado aos outros dois grupos, com diferença estatisticamente significante para a orelha esquerda. 
Para a análise de presença e ausência das emissões otoacústicas evocadas por estímulo transiente, verificou-se que o grupo Ruído apresentou um número mais elevado de emissões ausentes, seguido pelo grupo Químicos, com diferença estatisticamente significante para a orelha esquerda e tendência à significância estatística para a orelha direita.

Quando realizada a análise das amplitudes das emissões otoacústicas evocadas por estímulo transiente por frequência, nota-se que não houve diferença estatisticamente significante entre os grupos para as frequências 1000, 1400, 2000 e $4000 \mathrm{~Hz}$. Houve diferença estatisticamente significante entre os grupos apenas para a frequência de $2800 \mathrm{~Hz}$, sendo que o grupo Ruído apresentou amplitudes menores para ambas as orelhas.

Estudos que analisaram as emissões otoacústicas evocadas de trabalhadores também encontraram semelhanças nos resultados entre grupos expostos a diferentes níveis de ruído; porém, quando comparados a um grupo Controle, diferenças foram observadas, no que se refere à relação sinal-ruído das emissões (Nassiri et al., 2016; Boger et al., 2012).

Henning e Bobholz (2016) compararam músicos e não músicos com audição normal, sem encontrar diferenças significantes para os limiares auditivos da audiometria convencional. Os dois grupos também não diferiram no que se refere às amplitudes das emissões otoacústicas por produto de distorção. No entanto, houve um número significantemente maior de ausência de emissões otoacústicas para o grupo de músicos, sugerindo que estágios iniciais de dano coclear podem estar ocorrendo na população de músicos. 
Sobre este assunto, uma revisão da literatura realizada por Alcarás et al. (2012) concluiu que o teste de emissões otoacústicas evocadas em trabalhadores expostos a ruído é uma ferramenta importante no diagnóstico precoce de alterações auditivas cocleares induzidas por ruído.

Estudos realizados em adultos com audição normal, mas expostos a ruído, mostraram ausência de emissões otoacústicas ou redução da amplitude das emissões nas altas freqüências para os dois tipos de emissões evocadas (Vinck et al., 1999; Sliwinska-Kowalska et al., 1999). Desta forma, a ausência ou diminuição da amplitude das emissões otoacústicas fornecem os primeiros indícios de dano coclear (Lalaki, 2003). Comparando os dois tipos de emissões otoacústicas no que se refere a sua sensibilidade na detecção de alterações cocleares subclínicas, alguns autores relatam maior sensibilidade das emissões otoacústicas por estímulo transiente (Attias et al., 1998), enquanto outros defendem que as emissões por produto de distorção podem ser tão sensíveis quanto as transientes (Attias et al., 2001).

Helleman et al. (2018), ao realizarem uma revisão sistemática da literatura a respeito do acompanhamento longitudinal da perda auditiva induzida por ruído pelas emissões otoacústicas e audiometria, enfatizaram que a idade dos indivíduos, o estado inicial da audição, o uso adequado dos dispositivos de proteção auditiva e os níveis de exposição ao ruído podem afetar a magnitude das alterações observadas na audição.

Em relação aos químicos, a maioria dos estudos realizados, utilizando emissões otoacústicas, avaliaram indivíduos expostos concomitantemente a químicos e ruído. 
Prasher et al. (2005) investigaram trabalhadores de manutenção de aeronaves expostos à misturas de solventes e ruído intermitente. O grupo foi comparado a trabalhadores expostos somente a ruído sozinho, a outro pequeno grupo exposto apenas a mistura de solventes e a controles não expostos. Além da audiometria tonal liminar, foram avaliadas as emissões otoacústicas transitórias e por produto de distorção, bem como os potenciais evocados auditivos de tronco encefálico e a função vestibular. O grupo Ruído apresentou maior prevalência de perda auditiva e diminuição das emissões otoacústicas. $\mathrm{O}$ grupo exposto a solventes e ruído mostrou efeitos significativos nos potenciais evocados auditivos de tronco encefálico e 32\% dos indivíduos apresentaram resultados anormais nos testes de equilíbrio.

Johnson et al. (2006) avaliaram trabalhadores expostos a ruído (>85 dBA), a ruído mais estireno, a estireno isoladamente (exposição a ruído $<85$ dBA) e controles (sem exposição a nenhum destes agentes). O grupo Ruído mais estireno, assim como o grupo estireno, apresentaram limiares auditivos significantemente mais elevados nas frequências de 3 a $8 \mathrm{kHz}$ quando comparados aos controles e aos trabalhadores expostos apenas a ruído. Embora tenham sido observadas anormalidades nas emissões otoacústicas por produto de distorção e nos potenciais evocados corticais, os testes de fala interrompida e reconhecimento de fala no ruído foram os mais sensíveis para avaliar os efeitos do estireno.

Triebig et al. (2009) avaliaram trabalhadores de uma fábrica de barcos, expostos a estireno e ruído abaixo de 85 dBA. A audição foi avaliada por meio de audiometria tonal e emissões otoacústicas evocadas transiente. Os níveis 
de exposição de estireno foram avaliados por meio de exames de urina e sangue. Um total de 248 trabalhadores foi dividido em três grupos: baixa, média ou alta exposição atual ao estireno. Não foram encontradas diferenças estatisticamente significantes entre os três grupos no que se refere aos limiares auditivos (250 Hz a $16 \mathrm{kHz}$ ) ou aos resultados das emissões otoacústicas. No entanto, limiares auditivos elevados em algumas frequências ( $>25 \mathrm{~dB}, 3-6 \mathrm{kHz}$ ) e um risco aumentado de perda auditiva foram encontrados para o subgrupo exposto a altos níveis de estireno por 10 a 26 anos, quando comparado ao grupo expostos a níveis mais baixos de estireno por um tempo mais curto (2 a 16 anos).

Roggia et al. (2019) avaliaram indivíduos expostos a solventes (trabalhadores de postos de gasolina) com e sem perda auditiva e indivíduos sem exposição. Os autores verificaram diferença estatisticamente significante entre os grupos sem perda auditiva para a relação sinal/ruído das emissões otoacústicas evocadas por produto de distorção para as frequências de 3500 a $4500 \mathrm{~Hz}$. Desta forma, sugeriram que tanto os frentistas sem perda auditiva, como os frentistas com perda auditiva apresentaram disfunções auditivas periféricas que podem estar relacionadas com a exposição à gasolina.

Nota-se, que tanto para os estudos envolvendo trabalhadores expostos a químicos quanto a ruído, os resultados são variados, no que se refere às emissões otoacústicas. Contudo, a maioria dos estudos destaca a importância das emissões otoacústicas como ferramenta importante na detecção precoce de alterações cocleares (Rosati et al., 2017; Nadon et al., 2017). Ressalta-se, no entanto, que assim como para os limiares auditivos, as variáveis como idade 
e sexo podem influenciar nos resultados (Rosati et al., 2017) e dificultar a identificação de diferenças entre grupos expostos a diferentes agentes otoagressores, como no caso do presente estudo. Embora tenhamos buscado realizar um pareamento "perfeito" quanto ao sexo, o grupo Ruído contou com mais indivíduos do sexo masculino e o grupo Químicos com mais indivíduos do sexo feminino, assim como o controle.

Retomando-se o conceito da possível proteção auditiva fornecida pelo arcabouço hormonal feminino relativo ao estrogênio (Meltser et al., 2008, Charitidi et al., 2010), possíveis interferências nos resultados da avaliação audiológica também podem ter sido decorrentes dessas pequenas variações entre os grupos, apesar de não existirem diferenças significantes, do ponto de vista estatístico, para as variáveis sexo e idade. Diferenças também entre os diferentes hábitos dos indivíduos, como tabagismo (Habybabady et al., 2019) e consumo de álcool (Hwang et al., 2003), entre outros, podem influenciar nos resultados, mas estas variáveis não foram estudadas no presente estudo.

O efeito inibitório da via auditiva eferente, também denominado de supressão das emissões otoacústicas, é caracterizado por uma diminuição na amplitude das emissões otoacústicas na presença de ruído contra ou ipsilateral. A comparação teste-reteste mostra que os efeitos supressores são consistentes e que efeito inibitório da via auditiva eferente é clinicamente útil na avaliação e no gerenciamento das perdas auditivas periféricas e centrais. As fibras eferentes mediais podem inibir o componente contrátil ativo das células ciliadas externas, diminuindo assim a amplitude das emissões, quando estas são afetadas por estimulação sonora (no caso, o ruído) (Andrade et al., 2017). 
Estudos vêm mostrando que o efeito inibitório do sistema auditivo eferente é mais forte na orelha direita em comparação com a orelha esquerda (Khalfa e Collet, 1996; Khalfa et al., 1998; Bidelman e Bhagat, 2015). Por este motivo, no presente estudo, avaliamos este efeito apenas sobre a orelha direita.

Foi verificado que não houve diferença estatisticamente significante em relação à intensidade $(\mathrm{em} \mu \mathrm{Pa})$ do efeito inibitório do sistema eferente entre os grupos ou em relação à porcentagem deste efeito. No entanto, observa-se que este efeito foi menor para o grupo Ruído, seguido pelo grupo Químicos e pelo grupo Controle. Nota-se, ainda, que $100 \%$ dos indivíduos do grupo Controle apresentaram presença deste efeito, enquanto aproximadamente 80 a $84 \%$ dos outros grupos apresentaram este efeito, sugerindo que a análise qualitativa pode trazer mais informações que a análise quantitativa, já que a análise qualitativa, embora sem significância estatística, indica que alguns dos indivíduos dos grupos Ruído e Controle podem apresentar disfunções no sistema auditivo eferente.

Alguns estudos sobre o assunto mostraram diferentes achados. Bernardi (2000) avaliou 140 trabalhadores (18 a 48 anos) com limiares auditivos para tom puro normais, subdivididos em grupos controle, expostos a ruído isoladamente ou a ruído combinado ao tolueno. O autor verificou ausência de respostas das EOAT maior no grupo exposto ao tolueno e ruído (64\%) em comparação com o grupo expostos somente ao ruído (62\%) e ao grupo não exposto (27\%). A ausência do efeito inibitório do sistema auditivo eferente foi muito mais prevalente entre os trabalhadores expostos a ambos os agentes 
(49\%) do que apenas ao ruído (17\%) ou o grupo não exposto (7\%). Estes resultados sugeriram um efeito retrococlear do tolueno.

Sliwinska-Kowalska e Kotylo (2002) verificaram que trabalhadores expostos a ruído ocupacional apresentaram uma redução significativa do efeito inibitório do sistema auditivo eferente em relação a indivíduos não expostos a ruído ocupacional. Da mesma forma, Peng et al. (2010), observaram que adultos jovens usuários de dispositivos pessoais de música apresentaram efeito inibitório do sistema eferente menor, mas sem diferença estatisticamente significante, quando comparados a não usuários.

Alcarás et al. (2013) analisaram as emissões otoacústicas evocadas e o efeito de supressão das emissões de trabalhadores normo-ouvintes expostos a agrotóxicos e ruído e de um grupo controle. Os achados revelaram diferenças entre os achados das EOAT e EOAPD entre os grupos, sendo que o grupo exposto apresentou piores resultados. Da mesma forma, foi observado menor efeito de supressão para o grupo exposto a ruído e agrotóxico.

Micarelli et al. (2016) avaliaram 18 pacientes com sensibilidade química múltipla (SQM), que é um distúrbio crônico caracterizado por uma variedade de sintomas associados à exposição a produtos químicos em uma concentração abaixo do nível tóxico. Eles foram submetidos à avaliação das emissões otoacústicas transientes com e sem ruído contralateral para avaliar o efeito inibitório do complexo olivococlear medial (COM). Os resultados foram comparados com um grupo controle pareado por idade e sexo. Não houve diferenças estatisticamente significantes entre os grupos tanto para os limiares auditivos quanto para as emissões otoacústicas. Contudo, os indivíduos 
afetados por SQM apresentaram comprometimento estatisticamente significante do efeito inibitório do COM. Os autores sugeriram que estas alterações poderiam fazer parte das características complexas desta doença, embora sejam necessários mais estudos para explorar melhor a percepção auditiva destes indivíduos.

Esta diversidade de achados referentes ao efeito inibitório do sistema auditivo eferente pode ser explicada, em parte, pela grande variedade de metodologias e protocolos empregados (Alcaras et al., 2013), bem como pelas diferentes populações avaliadas, tanto no que se refere a idade e sexo, quanto no que se refere aos produtos otoagressores a que os indivíduos foram expostos (tipos, quantidades, doses cumulativas e combinação entre eles).

Fatores envolvendo o próprio envelhecimento também podem contribuir para a modificação do efeito inibitório da via auditiva eferente (Boboshko et al., 2019), assim como a exposição prévia a situações sonoras diversificadas como treinamentos musicais e atividades que envolvam exposição continuada a doses baixas de estímulos sonoros, que podem favorecer a ocorrência do efeito inibitório da via auditiva eferente (Kumar et al., 2016; Joseph et al., 2019).

Tradicionalmente, os limiares auditivos para tom puro são utilizados para determinar a extensão da PAIR, resultando em uma subestimação da prevalência e impacto funcional da PAIR. A PAIR pode estar associada a uma diminuição nos escores de reconhecimento de fala tanto no silêncio quanto no ruído de fundo, mesmo na presença de um audiograma com limiares normais (Lieberman et al., 2017). Isso pode estar relacionado com alterações nos 
mecanismos sinápticos e à redução das habilidades de processamento temporal, que podem ser afetados pelo estresse oxidativo (Choi e Choi, 2015; Le et al., 2017). Mecanismos semelhantes podem estar envolvidos nas perdas auditivas relacionadas à ototóxicos e à idade (Wong et al., 2015).

Por fim este motivo foi incluído neste estudo um teste para avaliar a habilidade auditiva de figura-fundo para sons verbais. No entanto, não foi verificada diferença estatisticamente significante entre os grupos, para ambas as orelhas, no que se refere a esta habilidade auditiva, o que concorda com estudos prévios.

Moreira e Ferreira Jr. (2004) avaliaram o reconhecimento de fala em indivíduos com perda auditiva induzida por ruído, comparando-os a um grupo controle normo-ouvintes, utilizando os testes SSW e Teste de Fala no Ruído. Os autores não verificaram diferenças para o SSW entre os grupos e concluíram que o teste de fala no ruído pode ser sensível para a identificação das alterações auditivas apresentadas pelos indivíduos com PAIR.

Com o objetivo de avaliar o processamento auditivo de militares expostos a ruído ocupacional, Santos et al. (2008) avaliaram militares, com exposição a ruído superior a 10 anos, subdivididos em dois grupos, com e sem perda auditiva. Os autores realizaram avaliação audiológica básica e testes para avaliação do processamento auditivo (testes de Fala Filtrada, SSW, Padrão de Freqüência). Observaram muitas avaliações alteradas, em ambos os grupos, principalmente no grupo com perda auditiva, para os testes de fala filtrada e padrão de frequência. No entanto, o teste SSW não se mostrou eficiente para diferenciar os grupos. 
Desta forma, sugere-se que futuros estudos utilizem outros protocolos para avaliar as habilidades auditivas envolvidas no reconhecimento de fala no ruído na investigação dos efeitos do ruído e de químicos sobre as habilidades auditivas centrais.

Em suma, apesar dos limiares auditivos normais para a audiometria convencional, podemos sugerir que, de forma geral, houve alguns indícios de disfunção coclear principalmente para o grupo Ruído, seguido pelo grupo Químicos: a audiometria de altas frequências (a partir da frequência de 11200 $\mathrm{Hz}$ ) mostrou limiares auditivos mais elevados, sobretudo para o grupo Ruído; as emissões otoacústicas evocadas por produto de distorção e por estímulo transiente mostraram amplitudes mais baixas para o grupo Ruído (em algumas frequências); na análise da presença e ausência das emissões por produto de distorção, o grupo Ruído apresentou maior porcentagem de ausência de respostas $(5024 \mathrm{~Hz})$; na análise de presença e ausência das emissões otoacústicas evocadas por estímulo transiente, verificou-se que o grupo Ruído apresentou um número mais elevado de emissões ausentes, seguido pelo grupo Químicos; e, finalmente, para a comparação do efeito inibitório do sistema eferente entre os grupos, embora sem diferença significante em relação ao aspecto quantitativo, a análise qualitativa mostrou maior quantidade de ausência deste efeito para o grupo Ruído, seguido pelo grupo Químicos, sugerindo disfunção no sistema auditivo eferente. O teste SSW não foi sensível para detectar diferenças entre os grupos. 


\section{CONCLUSÃO}

Com base nos resultados obtidos no presente estudo, pode-se sugerir que a exposição ao ruído ou a químicos produziu efeitos deletérios sobre a audição periférica, bem como para a via auditiva eferente de trabalhadores expostos a produtos químicos ou a ruído intenso, apesar dos limiares auditivos dentro da normalidade para a audiometria convencional.

- A audiometria de altas frequências não mostrou diferenças estatisticamente significantes entre os grupos, embora nas frequências a partir de $11.200 \mathrm{~Hz}$, os limiares auditivos para os grupos Ruído e Químicos se apresentassem, em geral, mais elevados do que o grupo Controle;

- As emissões otoacústicas por produto de distorção e por estímulo transiente mostraram amplitudes mais baixas para o grupo Ruído (em algumas frequências);

- Na análise da presença e ausência das emissões por produto de distorção, o grupo Ruído apresentou maior porcentagem de ausência de respostas $(5024 \mathrm{~Hz})$ e para as emissões otoacústicas evocadas por estímulo transiente, verificou-se que o grupo Ruído apresentou um número mais elevado de emissões ausentes, seguido pelo grupo Químicos;

- Na comparação do efeito inibitório do sistema eferente entre os grupos, a análise qualitativa mostrou maior quantidade de ausência deste efeito para o grupo Ruído, seguido pelo grupo Químicos. 
- Na comparação da habilidade de figura-fundo para sons verbais entre os grupos, não houve diferenças significantes entre eles. 


\section{ANEXOS}

8.1 Anexo A - "Parecer - CEP"

\section{FACULDADE DE MEDICINA DA UNIVERSIDADE DE SÃO PAULO - FMUSP}

\section{PARECER CONSUBSTANCIADO DO CEP}

\section{DADOS DO PROJETO DE PESQUISA}

Título da Pesquisa: Efeitos da exposição a produtos químicos e ao ruído sobre a audição

Pesquisador: Alessandra Giannella Samelli

Área Temática:

Versão: 2

CAAE: 68181217.0 .0000 .0065

Instituição Proponente: Faculdade de Medicina da Universidade de São Paulo

Patrocinador Principal: Financiamento Próprio

\section{DADOS DO PARECER}

Número do Parecer: 2.435.006

\section{Apresentação do Projeto:}

Trata-se de um projeto de Mestrado do Departamento FOFITO, estudando tanto a porção periférica quanto a central da via auditiva, em indivíduos expostos a agentes otoagressores como o ruído e os químicos.

A hipótese é de que os grupos expostos a químicos ou ruído apresentem respostas piores tanto para as avaliações periféricas quanto para as avaliações centrais, quando comparados ao grupo sem exposição, ou seja, limiares auditivos mais rebaixados, menores amplitudes de emissões otoacústicas, supressão das emissões com amplitudes menores e potenciais evocados corticais com latências maiores e amplitudes menores. Além disso, quanto ao 
mapeamento cortical, espera-se verificar diferenças entre os grupos. Esperamos ainda que o grupo exposto a químicos apresente respostas piores do que o grupo exposto a ruído.

\section{Objetivo da Pesquisa:}

Avaliar a via auditiva periférica e central de trabalhadores expostos a químicos ou a ruído, comparando-os com trabalhadores que não possuem exposição a nenhum destes agentes.

\section{Avaliação dos Riscos e Benefícios:}

Os procedimentos referidos acima não oferecem risco ou desconforto.

Não há benefício direto para o participante, além de receber o exame indicando como está a sua audição.

\section{Comentários e Considerações sobre a Pesquisa:}

Espera-se encontrar distinções entre os grupos expostos a ruído e a produtos químicos em comparação ao grupo controle nos quesitos: limiares auditivos rebaixados, amplitude das EOAPD menores, amplitude da supressão das EOAPD rebaixada e potenciais evocados corticais com maiores latências e menores amplitudes. Espera-se também que o grupo exposto a produtos químicos apresente resultados ainda mais comprometidos quando comparados aos expostos ao ruído. Porém não está mencionada a conduta perante a identificação de eventuais alterações auditivas.

\section{Considerações sobre os Termos de apresentação obrigatória:}

Todos os termos, anuências e autorizações dos departamentos envolvidos foram devidamente apresentados

\section{Recomendações:}

Sugiro incluir a conduta perante a identificação de perda auditiva ou alteração na via auditiva central no Projeto e no TCLE.

Conclusões ou Pendências e Lista de Inadequações: 
Trata-se da revisão e resposta ao parecer anterior deste CEP solicitando os documentos de anuência dos Departamentos envolvidos.

Todas as solicitações foram atendidas.

Considerações Finais a critério do CEP: 


\subsection{Anexo B - "Termo de consentimento livre e esclarecido"}

\section{HOSPITAL UNIVERSITÁRIO DA UNIVERSIDADE DE SÃO PAULO}

\section{TERMO DE CONSENTIMENTO LIVRE E ESCLARECIDO}

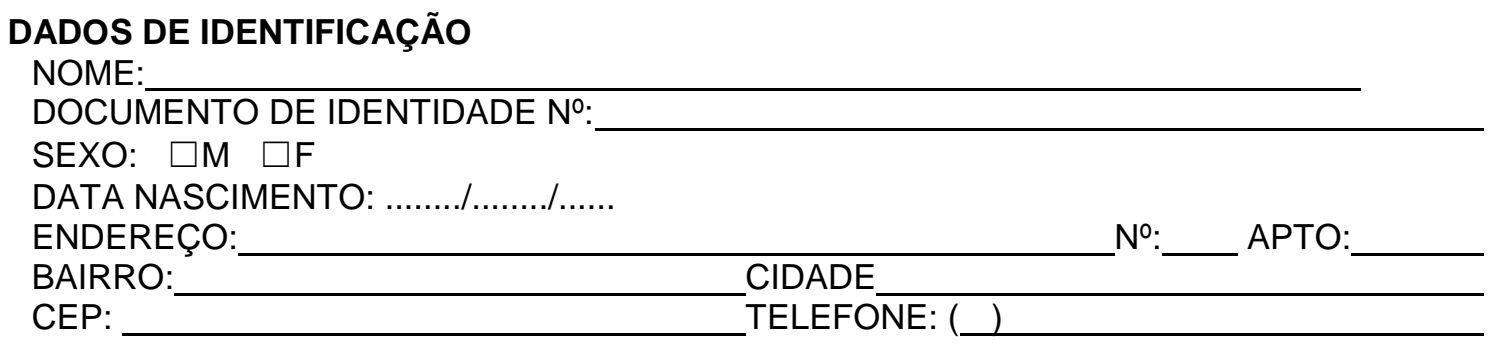

\section{DADOS SOBRE A PESQUISA}

TÍTULO DO PROTOCOLO DE PESQUISA: Efeitos da exposição a produtos químicos e ao ruído sobre a audição

PESQUISADORES: / RESPONSÁVEL: Prof ${ }^{a}$ Dra Alessandra Giannella Samelli

CRFa2 - 7614

CARGO/FUNÇÃO: DOCENTE FMUSP

UNIDADE DO HCFMUSP: Departamento de Fisioterapia, Fonoaudiologia e Terapia Ocupacional da FMUSP

1. AVALIAÇÃO DO RISCO DA PESQUISA: Risco mínimo $\otimes$ Risco baixo $\square$

Risco médio $\square$ Risco Maior $\square$

2. DURAÇÃO DA PESQUISA: 2 anos

Essas informações estão sendo fornecidas para sua participação voluntária neste estudo, que visa realizar uma avaliação audiológica por meio de um audiômetro, um imitanciômetro e um equipamento de emissões otoacústicas. Este estudo tem o objetivo de avaliar a audição de pessoas expostas e não expostas a produtos químicos ou ruído, buscando verificar se estes agentes podem causar perda auditiva.

Primeiramente será realizada uma inspeção da orelha com otoscópio para verificar a ausência de obstrução por cera, que pode interferir no resultado dos outros testes. Depois serão realizadas: a imitanciometria, a audiometria tonal (convencional e de altas frequências) e vocal e, por último a realização das emissões otoacústicas. Para audiometria a orientação será: quando você escutar qualquer som (apito), por menor que seja, por meio dos fones, deverá responder. Em seguida será realizada a imitanciometria, com a colocação de uma sonda (de silicone) em sua orelha, que emitirá alguns apitos mais altos, mas não necessita de nenhuma resposta; você só deve permanecer em silêncio e sem se movimentar por alguns segundos. Logo após, será realizado o exame de emissões otoacústicas, no qual será colocada uma sonda (de silicone) em sua orelha e você ouvirá alguns sons, deverá permanecer em silêncio, sem se movimentar e não precisará responder.

Os procedimentos referidos acima não oferecem risco ou desconforto.

Não há benefício direto para o participante, além de receber o exame indicando como está sua audição. 
Em qualquer etapa do estudo, você terá acesso aos profissionais responsáveis pela pesquisa para esclarecimento de eventuais dúvidas. Os investigadores são: Renata Rodrigues Moreira e a Profa. Dra. Alessandra G. Samelli, que podem ser encontrados no endereço Rua Cipotânea, 51 - Cidade Universitária, tel.: 3091-8442. Se você tiver alguma consideração ou dúvida sobre a ética da pesquisa, entre em contato com o Comitê de Ética em Pesquisa da Faculdade de Medicina da Universidade de São Paulo (CEPFMUSP): Av. Dr. Arnaldo, 251 - Cerqueira César - São Paulo - SP -210 andar - sala 36- CEP: 01246-000 Tel: 3893-4401/4407 E-mail: cep.fm@usp.br

É garantida a liberdade da retirada de consentimento a qualquer momento e deixar de participar do estudo, sem qualquer prejuízo à continuidade de seu tratamento na Instituição.

As informações obtidas serão analisadas em conjunto com outros pacientes, não sendo divulgada a identificação de nenhum paciente.

Asseguramos o seu direito em ser mantido atualizado sobre os resultados parciais da pesquisa ou de resultados que sejam do conhecimento dos pesquisadores.

Não haverá despesas pessoais para o participante em qualquer fase do estudo, incluindo exames e consultas. Também não haverá compensação financeira relacionada à sua participação, não havendo ressarcimento quanto a despesas de transporte. Se existir qualquer despesa adicional, ela será absorvida pelo orçamento da pesquisa. Garantimos, ainda, indenização diante de eventuais danos decorrentes da pesquisa.

Asseguramos que os resultados de seus exames serão utilizados somente para esta pesquisa.

Acredito ter sido suficientemente informado a respeito das informações que li ou que foram lidas para mim, descrevendo o estudo "Efeitos da exposição a produtos químicos e ao ruído sobre a audição". Eu discuti com os pesquisadores sobre a minha decisão de participar deste estudo. Ficaram claros para mim quais são os propósitos do estudo, os procedimentos a serem realizados, seus desconfortos e riscos, as garantias de confidencialidade e de esclarecimentos permanentes. Ficou claro também que minha participação é isenta de despesas e que tenho garantia do acesso a tratamento hospitalar quando necessário. Concordo voluntariamente em participar deste estudo e poderei retirar 0 meu consentimento a qualquer momento, antes ou durante o mesmo, sem penalidades ou prejuízo ou perda de qualquer benefício que eu possa ter adquirido, ou no meu atendimento neste Serviço.

Este termo será elaborado em duas vias, sendo uma para o pesquisador e a outra para o para o participante.

Assinatura do paciente/representante legal

Data:

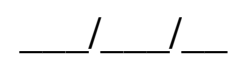

Assinatura da testemunha*

Data: 
*para casos de pacientes menores de 18 anos, analfabetos, semi-analfabetos ou portadores de deficiência auditiva ou visual.

\section{(Somente para o responsável do projeto)}

Declaro que, após convenientemente esclarecido pelo pesquisador e ter entendido o que me foi explicado, consinto em participar do presente Projeto de Pesquisa

Sujeito da pesquisa

Giannella Samelli
Alessandra

Pesquisadora responsável

São Paulo, 
8.3 Anexo C - "Anamnese"

PROTOCOLO DE PESQUISA - ANAMNESE

$\square$ GRUPO QUÍMICO

口GGRUPO RUÍDO

$\square$ GRUPO CONTROLE

PARTICIPANTE №:

DATA DA ENTREVISTA:

\section{A. DADOS PESSOAIS / PROFISSIONAIS}

1) Nome:

3) Matrícula HU:

6) Categoria:

$\square$ Básico

$\square$ Médio

$\square$ Superior

7) Tempo na função atual:
4) Unidade USP:

2) DN:

5) Função:

\section{B. RUÍDO}

9) Exposição ao ruído elevado (acima de $85 \mathrm{~dB}$ ) na atual função? $\square$ Não $\square \operatorname{Sim}$, $\mathrm{h} / \mathrm{sem}$

10) Utiliza Protetor auditivo? $\square$ Não $\square$ Sim

11) Se sim, qual de qual tipo? $\square$ Silicone $\quad \square$ Espuma $\quad \square$ Concha $\quad \square$ Dupla proteção

12) Histórico de exposição ao ruído ocupacional (empregos anteriores)?

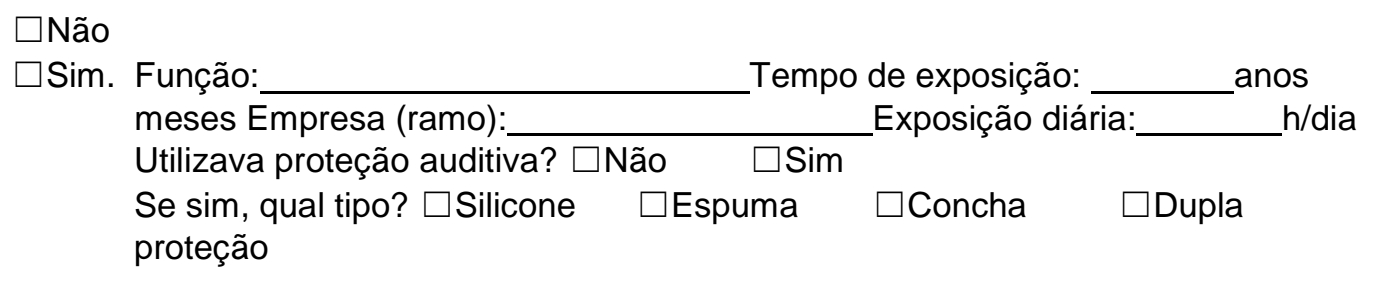

\section{QUÍMICOS}

13) Exposição a produtos químicos na atual função?

$\square$ Não

$\begin{array}{llll}\square \text { Sim. Metais: } & \square \text { Mercúrio } \square \text { Chumbo } & \square \text { Estanho } & \square \text { Manganês } \\ \text { Solventes: } & \square \text { Dissulfeto de Carbono } & \square \text { Estireno } \quad \square \text { N-Hexano } \\ & \square \text { Tricloroetileno } & \square \text { Tolueno } \square \text { Xilol } \\ \text { Asfixiantes: } & \square \text { Monóxido de Carbono } & \square \text { Cianeto de Hidrogênio } \\ \text { Outros: } & & \text { Categoria: } \\ \text { Outros: } & & \text { Categoria: } \\ \text { Outros: } & & \text { Categoria: }\end{array}$

14) Utiliza proteção contra químicos? $\square$ Luva

$\square$ Máscara $\quad \square$ Óculos

$\square$ Avental

$\square$ Sapatos

$\square$ Não utiliza $\quad \square$ Outros: 
15) Histórico de exposição a químicos (empregos anteriores)?

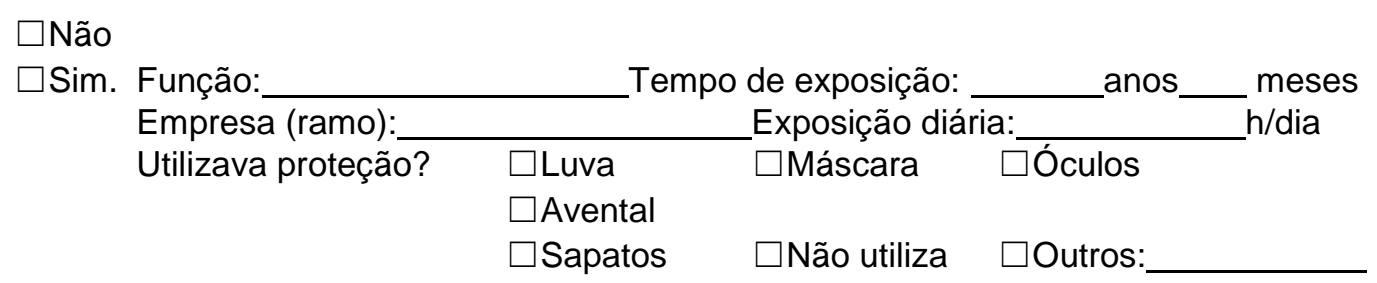

\section{SAÚDE AUDITIVA}

16) Nos últimos 12 meses, sentiu algum tipo de zumbido por mais de 10min? $\square$ Não $\square \operatorname{Sim}$

17) Se sim, de que tipo? $\square$ Apito $\quad \square$ Chiado $\quad \square$ Outro:

18) Escutou o zumbido de qual lado? $\square$ Direito $\square$ Esquerdo $\square$ Ambos $\quad \square$ Não sabe localizar

19) Sente tontura? $\square$ Não $\quad \square \operatorname{Sim}$

20) Se sim, de que tipo? $\square$ Rotatória $\square$ Não rotatória

\section{E. SAÚDE GERAL}

21) Apresenta alguma das doenças à seguir?

$\square$ Hipertensão

$\square$ Diabetes

$\square$ Doença renal crônica

$\square$ AVE

$\square$ Depressão / Ansiedade / Problemas emocionais

$\square$ Câncer. Especificar:

$\square$ Doença cardíaca. Especificar:

$\square$ Outra doença crônica. Especificar:

22) Hábitos nocivos:

Tabagismo.

Cigarros/dia:

$\square<5$

$\square 5-10$

$\square 11-20$

$\square>20$

Etilismo

Doses/semana (copos/taças/latas):

$\square<1$

$\square 1-2$

$\square 2-4$

$\square 5-7$

$\square 7-9$

$\square 10$ ou mais

Outras drogas. Especificar:

Dose: 


\section{REFERÊNCIAS}

Abreu MT, Suzuki FA. Avaliação audiométrica de trabalhadores ocupacionalmente expostos a ruído e cádmio. Rev Bras Otorrinolaringol. 2002;68(3):488-94.

Alcaras PAS, Lacerda ABM, Marques JM. Estudo das Emissões Otoacústicas Evocadas e efeito de supressão em trabalhadores expostos a agrotóxicos e ruído. CoDAS 2013; 25(6):527-33.

Alcarás PAS, Lüders D, França DMVR, Klas RM, Lacerda ABM, Gonçalves CGOEvoked otoacoustic emissions in workers exposed to noise: A review. Int. Arch. Otorhinolaryngol. 2012; 16(4):515-22.

Almeida WF, Mello D, Puga FR, Gaeta R. Intoxicações profissionais por pesticidas. In: Mendes, R. Medicina do trabalho-doenças profissionais. São Paulo: Sarvier, 1980. P. 511-69.

Araújo SA. Perda auditiva induzida pelo ruído em trabalhadores de metalúrgica. Rev. Bras. Otorrinolaringol. 2002; 68(1):47-52.

Andrade KCL, Peixoto GO, Carnaúba ATL, Costa KVT, Menezes PL. Suppression of Otoacoustic Emissions Evoked by WhiteNoise and Speech Stimuli. In: Hatzsopoulos S. Advances in Clinical Audiology.2017. Zagreb Croatia.

Arezes PM, Miguel AS. Assessing the use of hearing protection in industrial settings: A comparison between methods. Int. J. Ind. Ergon. 2013;43:518-25.

Associação brasileira de normas técnicas - ABNT. NBR 10152 - Nível de ruído para conforto acústico; 2000.

Assunção AA, Lima, FPA. A contribuição da ergonomia para a identificação, redução e eliminação da nocividade do trabalho In $\mathrm{R}$ Mendes (org.). Patologia do trabalho. $2^{\mathrm{a}}$ ed. Editora Atheneu, São Paulo; 2003. p.1767-89. 
Assunção AA. Uma contribuição ao debate sobre as relações saúde e trabalho Ciênc. Saúde coletiva. 2003; 8(4):1005-18.

Attias J, Bresloff I, Reshef I, Horowitz G, Furman V. Evaluating noise-induced hearing loss with distorion product otoacoustic emissions. Br J Audiol. 1998; 32:39-46.

Attias J, Horowitz G, El-Hatib N, Nageris B. Detection and clinical diagnosis of noise-induced hearing loss by otoacoustic emissions. Noise Health. 2001; 3:1931.

Baraldi GS, Almeida LC, Borges ACC. Evolução da perda auditiva no decorrer do envelhecimento. Rev Bras Otorrinolaringol. 2007; 73(1):64-70.

Bernardi APA. Workers exposed to noise and toluene: study of otoacoustic emissions and contralateral suppression [dissertação de mestrado]. São Paulo, Brazil: Faculdade de Saúde Pública. Universidade de São Paulo, 2000.

Bidelman G, Bhagat S. Right-ear advantage drives the link between olivocochlear efferent 'antimasking' and speech-in-noise listening benefits. Neuroreport. 2015; 26(8):483-87.

Boboshko M, Garbaruk ES, Timofeeva MV. Age-related changes of otoacoustic emission. Bulletin of Otorhinolaryngology. 2019; 84(1):18-24.

Boger ME, Sampaio ALL, De Oliveira CAC. Analysis of Hearing and Tinnitus in Workers Exposed to Occupational Noise. Int Tinnitus J. 2016; 20(2):88-92.

Bramhall NF, Konrad-Martin D, McMillan GP. Tinnitus and Auditory Perception After a History of Noise Exposure. Ear and Hearing. 2018; 39(5), 881-94.

Brattico E, Kujala T, Tervaniemi M, Alku P, Ambrosi L, Monitillo V. Long-term exposure to occupational noise alters the cortical organization of sound processing. Clin Neurophysiol. 2005;116(1):190-203.

Brasil. Ministério do Trabalho e Emprego. NR - 15. Atividades e Operações. Brasilia (DF): Ministério do Trabalho e Emprego; 1978. 
Brasil. Ministério do Trabalho e Emprego. NR 07 - Programa de Controle Médico de Saúde Ocupacional - PCMSO. Brasília (DF): Ministério do Trabalho e Emprego; 1996.

Brasil. Ministério do Trabalho e Emprego. NR 09 - Programa de Prevenção de Riscos Ambientais - PPRA. Ministério do Trabalho e Emprego; 1978.

Brasil. Ministério do Trabalho e Emprego. NR 17 - Ergonomia. Brasília (DF): Ministério do Trabalho e Emprego; 1990.

Broyles G, Butler CR, Kardous CA. Noise exposure among federal wildland fire fighters. J Acoust Soc Am. 2017; 141(2):177-83.

Bussab WO. Morettin, P.A. Estatística Básica. 9ª . Edição. Editora Saraiva. 2017.

Campo P, Venet T, Thomas A, Cour C, Brochard C, Cosnier F. Neuropharmacological and cochleotoxic effects of styrene. Consequences on noise exposures. Neurotoxicology and teratology, 2014; 44:113-20.

Cerqueira GS, Félix AS, Barbosa RS, França MGL, Silva RC, Assis JJC, Martins CS, Freitas RM. Exposição Ocupacional a Gasolina: Um Estudo Transversal. Revinter. 2015; 6(1).

Charitidi K, Canlon B. Estrogen receptors in the central auditory system of male and female mice. Neuroscience. 2010;165(3):923-933.

Chawla N; Olshaker, JS. Diagnosis and management of dizziness and vertigo. The Medical clinics of North America. 2006; 90(2):291-304.

Choi SH, Choi CH. Noise-Induced Neural Degeneration and Therapeutic Effect of Antioxidant Drugs. J Audiol Otol. 2015; 19(3):111-119.

Conover, WJ. Practical Nonparametric Statistics. John Wiley and Sons. 1971.

Costa DF, Goldbaum M. Contaminação química, precarização, adoecimento e morte no trabalho: benzeno no Brasil. Cienc. Saúde colet. 2017; 22(8):2681-92. 
Crundwell G, Gomersall P, Baguley DM. Ototoxicity (cochleotoxicity) classifications: A review. International Journal of Audiology. 2015; 55(2):65-74.

Curhan, SG, Wang M Eavey RD, Stampfer, MJ, Curhan GC. Adherence to Healthful Dietary Patterns Is Associated with Lower Risk of Hearing Loss in Women. The Journal of Nutrition. 2018; 148(6):944-51.

Dement J,Weich LS, Ringen K, Quinn P. Hearing loss among older construction workers: Updated analyses. Am J ind Med. 2018; 61(4):326-35.

Dewey RS, Hall DA, Guest H, Prendergast G, Plack CJ, Francis S. The Physiological Bases of Hidden Noise-Induced Hearing Loss: Protocol for a Functional Neuroimaging Study. JMIR Res Protoc.2018;7(3):e79.

Dhar S, Hall JW. Otoacoustic Emissions. Principles, procedures and protocols. Plural Publishing. 2012.

Dias A, Cordeiro R, Corrente JE, Gonçalves CGO. Associação entre perda auditiva induzida pelo ruído e zumbidos. Cad. Saúde Pública. 2006; 22(1):63-8.

Dias LE, Marcolino JS. Conhecimento sobre riscos ocupacionais pela exposição a inseticidas em agentes comunitários de endemias de municípios do noroeste do Paraná, Brasil. Rev Uningá. 2016; 47(2):31-6.

Dutra MDS, Monteiro MC, Câmara VM. Avaliação do processamento auditivo central em adolescentes expostos ao mercúrio metálico. Pró-Fono R. Atual. Cient. 2010; 22(3):339-44.

EU-OSHA (Agência Européia para a Segurança e Saúde no Trabalho). Redução e controlo do ruído. Ficha n 58. 2005.

Ference Junior, Michael. Curso de Física: ondas (som e luz). Coautoria de Harvey B Lemon, Reginald J Stephenson. São Paulo, SP: Edgard Blucher, 1968. 
Fernandes APS. Ruído Ocupacional. Avaliação de Ruído - Estaleiro Central da SETH, AS [dissertação de mestrado]. Setúbal: Instituto Politécnico de Setúbal. 2013.

Ferreira WFS, Oliveira EM. Biossegurança em relação a adesão de equipamentos de proteção individual. Rev Univ Vale do Rio Verde. 2019; 17(1).

Fetoni AR, Bartolo P, Eramo SLM, Rolesi R, Paciello F, Bergamini C, Fato R, Paludetti G, Petrosini G, Troiani. Noise-Induced Hearing Loss (NIHL) as a Target of Oxidative Stress-Mediated Damage: Cochlear and Cortical Responses after an Increase in Antioxidant Defense. J Neurosci. 2013; 33(9):4011-23.

Fink D. $85 \mathrm{~dB}$ is Not a Safe Noise Level to Prevent Hearing Loss. The Hearing Journal. 2019, Jan: 26-7.

Fox A, Riska K, Tseng CL, McCarron K, Satcher S, Osinubi O, Helmer D. Dizziness, Vertigo, and Mental Health Comorbidity in Gulf War Veterans. J am Acad Audiol. 2018.

Frota, S; lório, MCM. Emissões otoacústicas por produto de distorção e audiometria tonal liminar: estudo da mudança temporária do limiar. Rev. Bras. Otorrinolaringol. , 2002; 68(1):15-20.

Fuente A, Mcpherson B, Muñoz V, Pablo Espina J. Assessment of central auditory processing in a group of workers exposed to solvents. Acta Otolaryngol. 2006; 126(11):1188-94.

Fuente A, McPherson B. Central Auditory Damage Induced by Solvent Exposure. International Journal of Occupational Safety and Ergonomics 2007;13(4) 391-397.

Ganança FF, Castro ASO, Branco FC, Natur J. Interferência da tontura na qualidade de vida de pacientes com síndrome vestibular periférica. Rev Bras Otorrinolaringol. 2004; 70(1):94-101. 
Gazzola JM, Ganança FF, Aratani MC, Perracini MRP, Ganança MM. Caracterização clínica de idosos com disfunção vestibular crônica. Rev Bras Otorrinol. 2006; 72(4):515-22.

Gomes, MZCG, John KAL, Sousa DL, Oliveira DB, Bernardino ACSS. Ergonomia e segurança no trabalho em laboratórios. Mostra científica de biomedicina. 2018; 3(2).

Gorga MP, Neely ST, Ohlrich B, Hoover B, Redner J, Peters J. From laboratory to clinic: a large scale study of distortion product otoacoustic emissions in ears with normal hearing and ears with hearing loss. Ear Hear. 1997;18(6):440-55

Guo X, Bai X, Li L, Li J, Wang H. Forskolin protects against cisplatin-induced ototoxicity by inhibiting apoptosis and ROS production. Biomedicine \& Pharmacotherapy. 2018; 99:530-36.

Guthrie OW, Wong BA, Mcinturf SM, Reboulet JE, Ortiz PA, Mattie DR, Background Noise Contributes to Organic Solvent Induced Brain Dysfunction, Neural Plasticity. 2016: 2016.

Habybabady RH, Mohammadi M, Mortazavi SB, Khavanin A, Mirzaei R, Malvajerdi MS. The effect of simultaneous exposure to cigarette smoke and noise on distortion product otoacoustic emissions in rats. Toxicol Ind Health. 2019; 35(5):349-57.

Hamernik RP, Patterson JH, Turrentine GA, Ahroon WA. The quantitative relation between sensory cell loss and hearing thresholds. Hear Res 1989; 38:199-211.

Hammill TL, McKenna E, Hecht Q, Buchanan K, Pryor N. I'm Wearing My Hearing Protection - Am I Still At Risk for Hearing Loss? Lurking Ototoxins in the Military Environment. Military medicine. 2019; 184:615-20.

Helleman HW, Eising H, Limpens J, Dreschler WA. Otoacoustic emissions versus audiometry in monitoring hearing loss after long-term noise exposure - a systematic review. Scand J Work Environ Health. 2018; 44(6):585-600. 
Henning RL, Bobholz K. Distortion product otoacoustic emissions in college music majors and nonmusic majors. Noise Health 2016;18:10-20.

Hong O, Lusk SL, Ronis DL. Ethnic differences in predictors of hearing protection behavior between Black and White worke. Res Theory Nurs Pract. 2005; 19(11):63-76.

Hueb MM, Feliciano CP. Avaliação diagnóstica das síndromes vertiginosas. Revista Hospital Universitário Pedro Ernesto. 2012; 11(3):23-35.

Hutchison T, Kirchner B. Occupational Hearing Conservation Team: Mission, Training and Role. In: Hutchison, T; Schulz, T.Y. (eds) Hearing Conservation Manual. Milwaukee: CAOHC; 2014. Chapter 1.

Hwang JH, Tan CT, Chiang CW, Liu TC. Acute Effects of Alcohol on Auditory Thresholds and Distortion Product Otoacoustic Emissions in Humans. Acta Otolaryngol. 2003; 123:936-40.

Ibraheen OA, Hassan MR. Psychoacoustic Characteristics of Tinnitus versus Temporal Resolution in Subjects with Normal Hearing Sensitivity. Int Arch Otorhinolaryngol 2017;21:144-150.

Irgens-Hansen K, Baste V, Bratveit M, Lind O, Koefoed VF, Moen BE. Hearing loss in the Royal Norwegian Navy: A longitudinal study. Noise Health. 2016; 18(82):157-65.

ISO. Gestão de riscos - Princípios e diretrizes. Norma brasileira. ABNT NBR ISO 31000. 2009.

Johnson AC, Morata TC, Lindblad AC, Nylén PR, Svensson EB, Krieg E, Aksentijevic A, Prasher D. Audiological findings in workers exposed to styrene alone or in concert with noise. Noise Health. 2006; 8:45-57.

Johnson AC, Morata TC, Occupational Exposures to Chemical and Hearing Impairment. In Torén Kjell. Arbete och Hälsa. Occupational and Environmental Medicine at Sahlgrenska Academy, Gothenburg: Univ. of Gothenburg. 2010. 
Johnson AC, Morata TC. Occupational exposure to chemicals and hearing impairment. The Nordic Expert Group for Criteria Documentation of Health Risks from Chemicals. Sweden. NR10.2009; 44(4).

Jonsson R, Sixt E, Landahi S, Rosenhall U. Prevalence of dizziness and vertigo in an urban elderly population. Journal of vestibular research. 2004; 14(1):47-52.

Joseph J, Suman A, Jayasree GK, Prabhu P. Evaluation of Contralateral Suppression of Otoacoustic Emissions in Bharatanatyam Dancers and NonDancers. J Int Adv Otol. 2019; 15(1):118-120.

Juárez-Pérez CA, Valenzuela AT, Haro-Garcia L, Borja-Arbuto V, Madrid GA. Ototoxicity effects of low exposure to solvent mixture among paint manufacturing workers. Int J Aud. 2014; 53(6):1-7.

Kayyali MN, Wooltorton JRA, Ramsey AJ, Lin M, Chao TN, Tsourkas A, O'Malley BW Jr, Li D. A novel nanoparticle delivery system for targeted therapy of noise induced hearing loss. J Control Release. 2018; 279:243-50.

Keithley EM. Pathology and mechanisms of cochlear aging. J Neurosci Res. 2019; 00:1-11.

Khalfa S, Collet L. Functional asymmetry of medial olivocochlear system in humans. Towards a peripheral auditory lateralization. Neuroreport. 1996; 7:9936.

Khalfa S, Micheyl C, Veuillet E, Collet L. Peripheral auditory lateralization assessment using TEOAEs. Hear Res. 1998; 121(1-2):29-34.

Kilic K Sakat MS, Akdemir FNE, Yidirim S, Saglam YS, Askin S. Protective effect of gallic acid against cisplatin-induced ototoxicity in rats. Braz J Otorhinolaryngol. 2019; 85(3):267-74.

Knight KRG, Kraemer DF, Neuwelt EA. Ototoxicity in Children Receiving Platinum Chemotherapy: Underestimating a Commonly Occurring Toxicity That 
May Influence Academic and Social Development. Journal of Clinical Oncology. 2005; 23(34): 8588-96.

Kovalova, M; Mrazkova, E; Sachova, P; Vojkovska, K; Tomaskova, H; Janoutova, J; Janout, V. Hearing Loss in Persons Exposed and not Exposed to Occupational Noise. J Int Adv Otol. 2016; 12(1):49-54.

Kujala T, Shtyrov Y, Winkler I, Saher M, Tervaniemi M, Sallinen M, TederSälejärvi W, Alho K, Reinikainen K, Näätänen R. Long-term exposure to noise impairs cortical sound processing and attention control. Psychophysiology. 2004; 41(6):875-81.

Kumar P, Sanju HK, Nikhil J. Temporal resolution and active auditory discrimination skill in vocal musicians. Int Arch Otorhinolaryngol. 2016; 20:3104.

Lalaki G. 6th EFAS meeting. 2003. Noise Induced Hearing Loss (NIHL) and OAEs. Crete; 2003.

Le prell CG, Siburt HW, Lobarinas E, Spankovich C. No Reliable Association Between Recreational Noise Exposure and Threshold Sensitivity, Distortion Product Otoacoustic Emission Amplitude, or Word-in-Noise Performance in a College Student Population. Ear Hear. 2018; 39(6):1057-74.

Le T, Keithley EM. Effects of antioxidants on the aging inner ear. Hearing Research. 2007; 226(1-2):194- 202.

Le TN, Straatman LV, Lea J, Westerberg B. Current insights in noise-induced hearing loss: a literature review of the underlying mechanism, pathophysiology, asymmetry, and management options. J Otolaryngol Head Neck Surg. 2017; 46(1):41.

Lewis, R.F. Vertigo: some uncommon causes of a common problem. Seminars in neurology. 1996; 16(1):55-62.

Lewkowski K, Heyworth JS, Li IW, Williams W, McCausland K, Gray C, Ytterstad C, Glass DC, Fuente A, Si S, Florath I, Fritschi L. Exposure to noise 
and ototoxic chemicals in the Australian workforce. Occupational and Environmental Medicine 2019; 76:341-8.

Li IH Shin JH, Jhao YT, Chen HC, Chiu CH, Chen CF, Huang YS, Shiue CY, $\mathrm{Ma} \mathrm{KH}$. Regulation of Noise-Induced Loss of serotonin transporters with resveratrol in a rat model using 4-[18F]-ADAM/Small-Animal Positron Emission Tomography. Molecules. 2019; 24(7):e1344.

Liu Y, Ao L, Li Y, Zhao Y, Wen Y, Ding H. The SIRT2 inhibitor AK-7 decreases cochlear cell apoptosis and attenuates noise-induced hearing loss. Biochem Biophys Res Commun. 2019; 509(3):641-46.

Liberman MC, Epstein MJ, Cleveland SS, Wang H, Maison SF. Toward a Differential Diagnosis of Hidden Hearing Loss in Humans. PLoS One. 2016;11:e0162726.

Lima, F. P. A. A formação em ergonomia. In: KIEFER, C.; FAGÁ, I.; SAMPAIO, M. R. (Org.). Trabalho, educação e saúde: um mosaico em múltiplos tons. São Paulo: Fundacentro, 2001. p. 133-148.

Lobato DCB, Lacerda ABMD, Gonçalves CGDO, Coifman H. Auditory Effects of Exposure to Noise and Solvents: A Comparative Study. International Archives of Otorhinolaryngology. 2014; 18(2):136-141.

Lonsbury-Martin, BL, Harris FP, Stagner BB, Hawkins MD, Martin GK. Distortion product emissions in humans. Basic properties in normaly hearing subjects. Ann Otol. Rhinol. Laryngol. 1990; 147:3-14, 1990.

Lopes AC, Otubo KA, Basso TC, Marinelli EJC, Lauris JRP. Perda Auditiva Ocupacional: Audiometria Tonal X Audiometria de Altas Frequencias. Arq. Int. Otorrinolaringol. 2009; 13(3):293-99.

Lusk SL, hong O, Ronis DL, Eakin BL. Effectiveness of an Intervention to Increase Construction Workers' Use of Hearing Protection. Hum Factors; 1999; 41(3): 487-94. 
Marques FP, Costa EA. Exposição ao ruído ocupacional: alterações no exame de emissões otoacústicas. Rev. Bras. Otorrinolaringol. 2006; 72(3):362-366.

Maru D, Malky GA. Current practice of ototoxicity management across the United Kingdom. Int. J Audiol. 2018; 20:1-13.

Massa CGP, Rabelo CM, Moreira RR, Matas CG, Schochat E, Samelli AG. P300 em trabalhadores expostos a ruído ocupacional. Braz J Otorhinolaryngol. 2012;78(6):107-12.

McBride D, Williams S. Audiometric notch as a sign of noise induced hearing loss. Occup Environ Med. 2001; 58:46-51.

Mehrparvar AH, Mirmohammadi SJ, Ghoreyshi A, Mollasadeghi A, Loukzadeh Z. High-frequency audiometry: A means for early diagnosis of noise-induced hearing loss. Noise Health 2011; 13:402-6.

Meltser I, Tahera Y, Simpson E, Hultcrantz M, Charitidi K, Gustafsson JA, Canlon B. Estrogen receptor beta protects against acoustic trauma in mice. $\mathrm{J}$ Clin Invest. 2008; 118(4):1563-70.

Metzger, JL; Maugeri, S, Benedetto-Meyer M. Predomínio da gestão e violência simbólica. Rev. bras. Saúde ocup. 2012; 37(126):225-242.

Metwally FM, Aziz HM, Mahdy-Abdallah H, ElGelil KS, El-Tahlawy. Effect of combined occupational exposure to noise and organic solvents on hearing. Toxicol Ind Health. 2012; 28(10):901-7.

Micarelli A, Viziano A, Genovesi G, Bruno E, Ottaviani F, Alessandrini M. Lack of contralateral suppression in transient-evoked otoacoustic emissions in multiple chemical sensitivity: a clinical correlation study. Noise Health. 2016; 18(82):143-9.

Milon B, Mitra S, Song Y, Marguilies Z, Casserly R, Drake V, Mong JA, Depireux DA, Hertzano R. The impact of biological sex on the response to noise and otoprotective therapies against acoustic injury in mice. Biol Sex Differ. 2018; 9:12. 
Mont'Alverne LR, Coronoa AP, Rêgo MAV. Perda auditiva associada à exposição ocupacional a solventes orgânicos: uma revisão sistemática. Rev Bras Saúde Ocup.2016. 41:e10.

Moraes SA, Soares WJS, Rodrigues RAS, Fett WCR, Ferriolli E, Perracini, MR. Tontura em idosos da comunidade: estudo de base populacional. Brazilian Journal of Otorhinolaryngology. 2011; 77(6):691-9.

Morata TC, Dunn DE, Kretschmer LW, Lemasters GK, Keith RW. Effects of occupational exposure to organic solvents and noise on hearing. Scand J Wirk Environ Health. 1993; 19(4):245-54.

Morata TC, Lemasters, G. Considerações epidemiológicas para o estudo de perdas auditivas ocupacionais. In Ver Nudelmann, E. da Costa, J. Seligman, \& R. Ibañez, Perda auditiva induzida pelo ruído p. 1:16. Rio de Janeiro: Revinter; 2001.

Morata TC, Meinke D. Uncovering effective strategies for hearing loss prevention. Acoustic Aust. 2016; 44(1):67-75.

Morata TC, Johnson AC. Effects of Exposure to Chemicals on Noise-Induced Hearing Loss in Le Prell CG, Henderson G, Fay R, Popper AN. Noise-Induced Hearing Loss: Scientific Advances. 2012. Springer.

Moreira RR, Ferreira Junior M. Speech tests: application in individuals with noise induced hearing loss . Pro Fono. 2004;16(3):293-300.

Morioka S, Sakaguchi H, Yamaguchi T, Ninoyu Y, Mohri H, Nakamura T, HIsa Y, Ogita K, Saito N, Ueyama T. Hearing vulnerability after noise exposure in a mouse model of reactive oxygen species overproduction. J Neurochem. 2018; 146(4):459-73.

Muca A, Standafer E, Apawu AK, Ahmad F, Ghoddoussi F, Hali M, Warila J, Berkowitz BA, Holt AG. Tinnitus and temporary hearing loss result in differential noiseinduced spatial reorganization of brain activity. Brain Struct Function. 2018; 223(5):2343-60. 
Nadon V, Bockstael AB, Botteldooren D, Voix J. Field Monitoring of Otoacoustic Emissions During Noise Exposure: Pilot Study in Controlled Environment. American Journ of Audiol. 2017; 26(3S) 352-68.

Nassiri P, Zare S, Monazzam MR, Pourcakht A, Azam K, Golmohammadi T. Modeling Signal-to-Noise Ratio of Otoacoustic Emissions in Workers Exposed to Different Industrial Noise Levels. Noise Health. 2016; 18(85):391-8.

National Institute for Occupational Safety and Health (NIOSH). Preventing hearing loss caused by chemical (ototoxicity) and noise exposure. Publication No. 2018-124. 2018.

Neitzel R, Meischke H, Daniell WE, Trabeau M, Somers S, Seixas NS. Development and pilot test of hearing conservation training for construction workers. Am J Ind Med. 2008; 51(2):120-9.

Nepomuceno, L. A. Elementos de acústica física e psicoacústica. São Paulo: Editora Edgar Blücher, 1994.

Neuhauser HK, von Brevern M, Radtke A, Lezius F, Feldmann M, Ziese T, Lempert T. Epidemiology of vestibular vertigo: a neurotologic survey of the general population. Neurology. 2005; 65(6):898-904.

Nobre JS, Singer JM. Residual analysis for linear mixed models. Biometrical Journal. 2007; 49:863 - 875 .

Nyarubeli IP, Tungu AM, Bratveit M, Moen BE. Occupational noise exposure and hearing loss: A study of knowledge, attitude and practice amon Tanzanian iron and steel workers. Archives of Environmental \& Occupational Health. 2019; 29:1-10.

Occupational Safety and Health Admnistration (OSHA). Preventing Hearing Loss Caused by Chemical (Ototoxicity) and Noise Exposure. DHHS NIOSH Publication, 2018.

Oishi N, Schacht J. Emerging treatment for noise-induced hearing loss. Expert Opin Emerg Drugs. 2011; 16(2):235-45. 
Ogido R, Costa EA, Machado HC. Prevalência de sintomas auditivos e vestibulares em trabalhadores expostos a ruído ocupacional. Rev. Saúde Pública. 2009; 43(2):377-80.

OHSAS. Sistemas de gestão da segurança e da saúde do trabalho Requisitos. OHSAS 18001:2007. 2007.

Oliveira JAA, Canedo DMC, Rossato M. Otoproteção das células ciliadas auditivas contra a ototoxicidade da amicacina. Rev Bras Otorrinolaringol. 2002; 68(1):7-13.

Organização Mundial da Saúde. Grades of hearing impairment: OMS; 2014 [citado jun 2019]. Disponível em: https://www.who.int/pbd/deafness/hearing_impairment_grades/en/.

OSHA. Preventing Hearing Loss Caused by Chemical (Ototoxicity) and Noise Exposure. DHHS (NIOSH) Publication number 2018-124. 2018.

Ou HC, Santos F, Raible DW, Simon JÁ, Rubel E. Drug screening for hearing loss: using the zebrafish lateral line to screen for drugs that prevent and cause hearing loss. Drug Discov Today. 2010; 15(7-8):265-71.

Oun R, Moussa YE, Wheate NJ. The side effects of platinum-based chemotherapy drugs: a review for chemists. Dalton Transactions. 2018; 47(19): 6654-53.

Oxford Dictionary. Toxic. Oxford University Press; 2019 [citado junho 2019]. Disponível em: https://www.lexico.com/en/definition/toxic.

Parthasarathy A, Kujawa, SG. Synaptopathy in the aging cochlea: Characterizing early-neural deficits in auditory temporal envelope processing. Journal of Neuroscience. 2018; 38(32):7108-19.

Peng JH, Wang JB, Chen JH. Recreational noise exposure decreases olivocochlear efferentre flex strength in young adults. J.Otolaryngol. HeadNeckSurg. 2010; 39:426-432. 
Pereira LD, Schochat E. Testes Auditivos Comportamentais Para Avaliação do Processamento Auditivo Central. 1a ed. São Paulo: Pro Fono; 2011.

Pinheiro JC, Bates DM. Mixed-Effects Models in S and S-PLUS. Springer. 2002.

Pienkowski M, Eggermont JJ. Reversible long-term changes in auditory processing in mature auditory cortex in the absence of hearing loss induced by passive, moderate-level sound exposure. Ear Hear. 2012; 33(3):305-14.

Poole K. A review of the current state of knowledge on tinnitus in relation to noise exposure and hearing loss. Health and Safety Laboratory. Health and Safety Executive. 2010.

Pommerehn J, Filha VAVS, Miolo SB, Fedosse E. O ruído e a qualidade de vida na perspectiva de trabalhadores de postos de combustíveis. Rev Cefac. 2016; 18(2):377-384.

Prasher D, Al-Hajjaj H, Aylott S, Aksentijevic A. Effect of exposure to a mixture of solvents and noise on hearing and balance in aircraft maintenance workers. Noise Health. 2005; 7:3139.

Prasher D, Morata T, Campo P, Fechter L, Johnson AC, Lund SP, Pawlas K, Starck J, Sliwinska-Kowalska M, Sulkowski W. NoiseChem : An European Commission research project on the effects of exposure to noise and industrial chemicals on hearing and balance. Noise Health2002; 4(14):41-8.

Queiroz MAT, Brant LOC, Queiroz CA, Batista NRT, Queiroz FA. Avaliação do ruído ambiental em uma mineradora. Rev Gest Industr. 2017; 13(2). 198:214.

Ramazzini, B. Doença dos bronzistas. In: Raimundo, E (tradutor). As doenças dos trabalhadores. Brasil: FUNDACENTRO; 2016:261-63.

Raymond DMIII, Hong O, Lusk SL, Ronis DL. Predictors of hearing protection use for Hispanic and non-Hispanic White factory workers, Res Theory Nurs Pract. 2006; 20(2):127-40. 
Rezende, JM. Orelha e Ouvido in: Linguagem Médica 3ํ․ í. Goiânia, AB Editora e Distribuidora de Livros Ltda, 2004.

Rocha FL, Marziale MHP, Robazzi MLCC. Perigos potenciais a que estão expostos os trabalhadores de enfermagem na manipulação de quimioterápicos antineoplásicos: conhecê-los para preveni-los. Rev Latino-am Enfermagem. 2004; 12(3):511-7.

Roggia SM, França AG, Morata TC, Krieg E, Earl B. Auditory system dysfunction in Brazilian gasoline station workers. Inter Jour of Audiol. 2019; 24:1-13.

Rosati MV, Tomei F, Loreti B, Casale T, Cianfrone G, Altissimi G, Sancini, A. Distortion-product otoacoustic emissions in workers exposed to urban stressors. Archives of Environmental \& Occupational Health. 2017; 73(3):176-185.

Rostami F, Afshari M, Rostami-Moez M, Assari MJ, Soltanian AR. Knowledge, Attitude, and Practice of Pesticides Use Among Agricultural Workers. Indian J Occup Environ Med. 2019; 23(1):42-47.

Rudner M, Seeto M, Keidser G, Johnson B, Ronnberg J. Poorer speech reception threshold in noise is associated with lower brain volume in auditory and cognitive processing regions. JSLHR.2019; 62:1117-30.

Ryan S, Kemp DT. The influence of evoking stimulus level on the neural suppression of transient evoked otoacoustic emissions. Hear Res. 1996; 94(12):140-7.

Samelli, SG; Moreira RR. Saúde auditiva do trabalhador: uma intervenção necessária. In: Marchesan IQ; Silva, HJ; Tomé, MC (Org). Tratado das especialidades em fonoaudiologia. São Paulo: Guanabara Koogan, p.10461052, 2014.

Sangioni LV, Pereira DIB, Vogel FSF, Botton S. Princípios de biossegurança aplicados aos laboratórios de ensino universitário de microbiologia e parasitologia. Ciência Rural, 2012; 43(1):91-99. 
Santos CS, Juchem LS, Rossi AG. Processamento auditivo de militares expostos a ruído ocupacional. Rev Cefac. 2008; 10(1):92-103.

Santos TMM, Russo ICP. A prática da audiologia clínica. 3ª̣ed. São Paulo: Cortez; 1991.

Sbihi H, Teschke K, MacNab YC, Davies HW. Determinants of use of hearing protection devices in Canadian lumber mill workers. Ann Occup Hyg. 2010; 54(3):319-28.

Schaal N, Slagley J, Zreiqat M, Paschold $\mathrm{H}$. Effects of combined exposure to metals, solvents, and noise on permanent threshold shifts. American Journal of Industrial Medicine. 2017; 60(3):227-38.

Sena TR, Dourado SS, Lima LV, Antoniolli AR. The hearing of rural workers exposed to noise and pesticides. Noise Health. 2018; 20(92):23-6.

Sheehan K, Shets S, Rybak LP, Ramkumar V.. Trans-Tympanic Drug Delivery for the Treatment of Ototoxicity. J Vis Exp. 2018; (133).

Shi L, Chang Y, Li X, Aiken S, Liu L, Wang J, Cochlear Synaptopathy and Noise-Induced Hidden Hearing Loss, Neural Plasticity.2016; 2016.

Silva MCBS, Cunha MB, Souza CCLS, Mitre El. Avaliação do processamento auditivo em operadores de telemarketing. Rev Cefac. 2006; 8(4):536-42.

Silva TF, Rodrigues DRF, Coutinho GBF, Soares M, Almeida MS, Sarcinelli PN, Mattos RCO, LArentis AL, Matos GGO . Ototoxicidade dos hidrocarbonetos presentes na gasolina: uma revisão de literatura. Rev. Cefac. São Paulo. 2018;20(1):110-122.

Sliwinska-Kowalska M, Kotylo P, Hendler B.. Comparing changes in transientevoked otoacoustic emission and pure-tone audiometry following short exposure to industrial noise. Noise Health. 1999; 2:50-57.

Sliwinska-Kowalska M,Kotylo, P. Occupational exposure to noise decreases optoacoustic. Emission efferent suppression. Int. J. Audiol.2000; 41, 113-119. 
Sliwinska-Kowalska, M; Davis, A. Noise-induced hearing loss. Noise and Health. 2012; 14(61):274-280.

Somma G, Pietroiusti A, Magrini A, Coppeta L, Ancona C, Gardi S, Messina M, Bergamaschi A.. Extended High-Frequency Audiometry and Noise Induced Hearing Loss in Cement Workers. Am. J. Ind. Med. 2008; 51:452-462.

Staudt AM, Whitworth KW, Chien LC, Whitehead LW, Porras GRD. Association of organic solvents and occupational noise on hearing loss and tinnitus among adults in the U.S., 1999-2004. Int Arch Occup Environ Health. 2019 Apr;92(3):403-413.

Stephens SD. Some historical aspectos of ototoxicity. $\mathrm{Br} J$ Audiol. 1982; 16(2):76-80.

Steyger P, Cunningham LL, Esquivel CR, Watts KL, Zuo J. Editorial: Cellular Mechanisms of Ototoxicity. Front Cell Neurosci. 2018;12:75.

Strose A, Hyppolito MÂ, Colombari GC, Rossato M, de Oliveira SJA. Lack of protection against gentamicin ototoxicity by auditory conditioning with noise. Braz J Otorhinolaryngol. 2014;80:390-6.

Teti BS, Cruz FM, Lago EMG, Zlatar T, Júnior BB. Perdas auditivas induzidas pelo ruído no ambiente ocupacional da construção civil. Revista de Engenharia e Pesquisa Aplicada. 2019; 4(1):146-53.

Triebig G, Bruckner T, Seeber A. Occupational styrene exposure and hearing loss: a cohort study with repeated measurements. Int Arch Occup Environ Health. 2009; 82:463-480.

Unlu I, Kesici GG, Basturk A, Kos M, Yilmaz Oh. A comparison of the effects of solvent and noise exposure on hearing, together and separately. Noise Health. $2014 ; 16(73): 410-5$.

Valejo JC, Silva MN, Oliveira JAA, Carneiro JJ, Rocha LSO, Figueiredo JFC, Chiosi MFV. Detecção precoce de ototoxicidade usando emissões otoacústicas produtivas de distorção. Rev Bras Otorrinolaringol. 2001; 67(6):845-51. 
Vasconcelos KA, Frota SMMC, Ruffino-netto A, Kritski AL. The importance of audiometric monitoring in patients with multidrug-resistant tuberculosis. Rev Soc Bras Med Trop. 2017; 50(5):646-51.

Velasco IT, Scalabrini A Neto, Karan JA, Cruz LM Neto, Caramez MPR, Gattaz MD. Propedêutica na emergência. São Paulo; Atheneu, 2003.

Vinck BM, van Cauwenberge PB, Leroy L, Corthals P. Sensitivity of transient evoked and distortion product otacoustic emissions to the direct effects of noise on the human cochlea. Audiology. 1999; 38:44-52.

Wong AC, Ryan AF. Mechanisms of sensorineural cell damage, death and survival in the cochlea. Front Aging Neurosci. 2015;7:58.

Yakunina N, Tae WS, Kim SS, Nam EC. Functional MRI evidence of the cortico-olivary efferent pathway during active auditory target processing in humans. Hearing Research. 2019; 379:1-11.

Yang $\mathrm{H}$, Shie R, Chen P. Hearing loss in workers exposed to epoxy adhesives and noise: a cross-sectional study. BMJ Open. 2016; 18(6):e010533.

Yeh CW, Tseng LH, Yang CH, Hwang CF. Effects of oral zinc supplementation on patients with noise-induced hearing loss associated tinnitus: A clinical trial. Biomed J. 2019; 42(1):46-52.

Zhou S, Sun Y, Kuang X, Hou S, Wang Z, Qiang Z, Liu H. Mitochondria-homing peptide functionalized nanoparticles performing dual extracellular/intracellular roles to inhibit aminoglycosides induced ototoxicity. J Art Cells, Nanomed \& Biotec. 2018; 46: 314-23.

Zucki F, Corteletti LCBJ, Tsunemi MH, Munhoz GS, Quadros IA, Alvarenga KF. Caracterização do perfil auditivo de frentistas de postos de combustível. Audiol., Commun.2017, 22:e1759. 